\title{
FORGOTTEN INTERIORS
}

by

ALEXANDER LOVE

A 120-point thesis submitted to

Victoria University of Wellington in partial

fulfilment of the requirements for the degree of

Master of Interior Architecture.

Victoria University of Wellington

School of Architecture

2018 


\section{ABSTRACT}

Historic buildings play an important role in helping shape and characterise a city's' urban fabric. They extend beyond purely the aesthetic by enhancing our urban experience through providing a notion of continuity, and, by forming an enduring connection to our past, present, and future. In many instances, extending a historic building's life that has fallen into a state of dilapidation, and, saving the rich history in which resides within its walls requires a rehabilitative or adaptive approach. Undertaking this process however, can become challenging when there lies an absence of interior documentation for the site. A clear understanding of the current, forsaken state in which the building's interior has sunken into cannot therefore be established.

The aim of this research is to therefore explore how a rehabilitative approach can be applied to the dilapidated, heritage listed, former Tramway Hotel to rejuvenate its forgotten interiors. By breathing another life into the building's old bones, it seeks to make it fit for modern purposes once again whilst tangentially retaining the rich history that is housed within its weathered walls. Through the cyclical, reflective, and iterative nature of action research, this research investigates a range of techniques in response to the site's forgotten interiors. By initially exploring the issue from various avenues, through the cycles of identifying, planning, acting and then critically self-reflecting, the design iterations produced refined in scope to eventuate in the act of strategically inserting, and then shifting newly built elements within the existing structure of the former Tramway Hotel. What was essential throughout the research and was therefore translated into a criterion for the evaluation of each iteration, was the need to add another life to the building, to allow it to persist, to live on without disrupting its historic integrity and character. Through the implementation and direct visual contrast of the newly built elements from historic ones, the developed design response seeks to establish a clear dialogue between the two so that each complements and enhances the other. 


\section{ACKNOWLEDGEMENTS}

I would like to acknowledge every person that I have crossed throughout my education. From my peers to my tutors, to the technical staff and everyone in between, you have all helped shape my journey and I will be forever grateful. Specifically, I would like to thank my partner Savannah and my family for their undying support and guidance especially when times got tough. Lastly, I would like to thank my supervisor Antony Pelosi for your all your time, advice and friendship that you given me throughout this project.

Thank you all. 
1.0 INTRODUCTION

1.1 OVERVIEW

1.2 THE PROBLEM

1.3 RESEARCH QUESTION

1.4 RESEARCH AIMS AND OBJECTIVES

1.5 THE SCOPE

1.6 RESEARCH METHODOLOGY

2.0 CONTEXT ANALYSIS

9.

2.1 OVERVIEW

10.

2.2 SITE SELECTION

11.

2.2.1 SITE ANALYSIS

14.

2.2.2 SITE IN CONTEXT

15.

2.3 PROGRAMMATIC ANALYSIS

17.

2.3.1 PROGRAMMATIC FINDINGS

19.

3.0 LITERATURE REVIEW

21.

3.1 OVERVIEW

22.

3.2 HISTORIC CONSERVATION - TREATMENT METHODS

23.

3.3 REHABILITATION THEORY

24.

3.4 WHY REHABILITATE?

26.

3.4.1 ECONOMIC VALUE

26.

3.4.2 ENVIRONMENTAL / SUSTAINABLE VALUE

28.

3.4.3 SOCIAL / CULTURAL VALUE

28. 
3.5 REHABILITATIVE METHODS

3.6 SEISMIC OVERVIEW

3.6.1 SEISMIC MITIGATION STRATEGIES

4.0 PRECEDENT ANALYSIS

4.1 OVERVIEW

4.2 CARLO SCARPA: THE CASTELVECCHIO MUSEUM IN VERONA, ITALY

4.2.1 CASTELVECCHIO SUMMARY

4.3 DAVID CLOSES: CONVENT DE SANT FRANCESC IN SANTPEDOR, SPAIN

4.3.1 CONVENT DE SANT FRANCESC SUMMARY

5.1 OVERVIEW

54.

5.2 ITERATIVE CRITERIA

56.

5.3 DESIGN ITERATIONS

57.

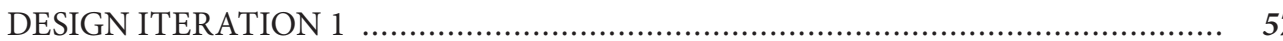

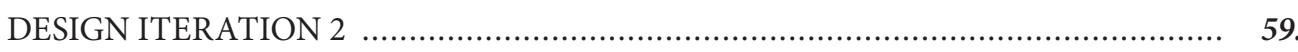

DESIGN ITERATION 3 ........................................................................... 61.

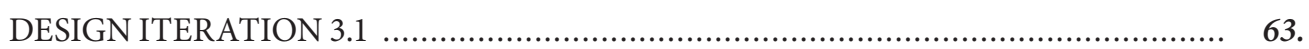

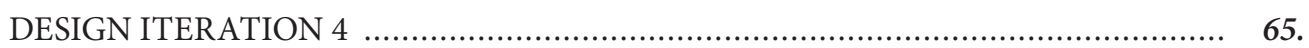

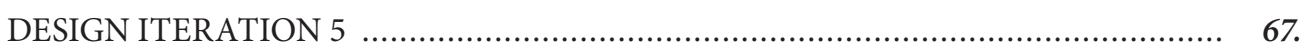

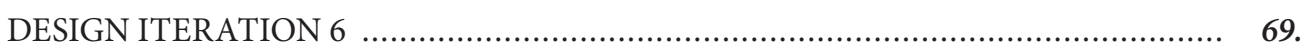

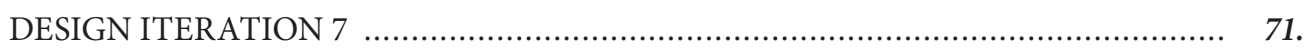

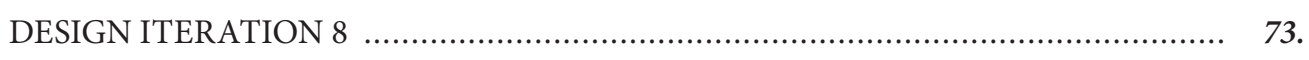

DESIGN ITERATION 9 ...................................................................... 75. 
DESIGN ITERATION 10

6.0 DEVELOPED DESIGN RESPONSE

6.1 OVERVIEW

6.2 DIAGRAMMATIC THOUGHT PROGRESSION

6.3 PLANS

6.4 FROM THE STREET

6.5 DRUMMOND STREET FUNCTION ROOM

6.6 ADELAIDE ROAD FUNCTION ROOM

6.7 GROUND FLOOR RESTAURANT AND BAR

102.

6.8 GROUND FLOOR DINING SPACES

8.0 REFERENCES

107.

8.1 BIBLIOGRAPHY

108.

8.2 LIST OF FIGURES

111.

8.3 APPENDIX A

114. 


\subsection{INTRODUCTION}




\section{1 - OVERVIEW}

This research project seeks to create a case for the rehabilitation and retention of one of Wellington's iconic, yet dilapidated historic buildings, the former Tramway Hotel on Adelaide Road. The site however, does not have any remaining interior documentation which was surprising due to its heritage status, and because of such, it informed the development of the research question. In response, this thesis investigates a range of techniques, many beginning with, or only exploring the façade as that is one of the only known remaining features of the building, to both the site's dilapidated state and more specifically, it's forgotten interiors. Wellington is one city that has prospered due to its amalgamation of historic buildings. Whilst in many instances its historic buildings are juxtaposed with varying architectural styles, amidst it all, a dynamic tension has formed that enriches the character and adds a lively atmosphere to the city's built environment. Like many cities however, this is under threat due to numerous historic buildings suffering seismic damage or becoming seismically prone, leading to subsequent disuse and dilapidation. And the result, many face the risk of demolition. 


\section{2 - THE PROBLEM}

Historic buildings play an important role in helping shape and characterise a city's urban fabric. They extend beyond purely the aesthetic by enhancing our urban experience through embodying our history, providing a notion of continuity, and, by forming an enduring connection and glimpse into our past, present, and future (Baum, 2012; Brand, 1994; Bullen \& Love, 2010; Coles \& House, 2007; Dedek, 2014). Our cities are constantly changing and evolving however, and with it, our use of our building stock has become more temporary as a result of today's transient and technologically advanced lifestyle (Johnson, 1996; Langston, 2008). This however has led to large numbers of buildings, whether they are historic or not, becoming obsolete or redundant for their original purpose (Johnson, 1996; Langston, 2008). There are two sides to this depending on how you want to look at it. On the one hand, we are driving many of our predominantly older buildings into redundancy as we seek newer, more "comfortable environments for work and leisure" (Johnson, 1996, p. 209), and on the other hand, this shift has "provided an abundance of buildings suitable for rehabilitation and reuse" (Johnson, 1996, p. 209).

When a historic building becomes obsolete and redundant, or, it falls into a state of dilapidation and subsequent disuse, such as that of the former Tramway Hotel in Wellington, without projects that seek to preserve, and in some cases rehabilitate these buildings, irreversible loss of cultural heritage will ensue through the demolition and rebuild process (Bullen \& Love, 2010; Brooker \& Stone, 2004). Furthermore, if a historic building or any building for that matter is demolished prematurely, whether dilapidated or otherwise, we are not utilising the building's full life span and potential and therefore we are forming an unsustainable use of our building stock (Bullen \& Love, 2010).

\section{3 - RESEARCH QUESTION}

How can the interior of a derelict, historic building be rehabilitated when no interior documentation of the building remains? 


\section{4 - RESEARCH AIMS AND OBJECTIVES}

With a focus on the site's interior, the aim is to explore how a rehabilitative approach can be applied to the dilapidated, heritage listed, former Tramway Hotel to breathe another life into the building, to make it fit for modern purposes once again whilst tangentially retaining the rich history that is housed within its weathered walls. Due to the ongoing iterative and reflective nature of the research, the research objectives are also used as the self-reflective criteria for each design iteration. By establishing a self-reflective criteria, as the research progressed it enabled the identification of both the strengths and weaknesses of each design iteration to occur. The criteria are as follows:

- $\quad$ Are new spatial insertions enhancing the existing building? (Brooker \& Stone, 2004)

- Does the design balance the building's historic integrity with modern function as per the goal of rehabilitation? (Dedek, 2014)

- With the insertion of new built elements, are clear dialogues established between the new and the existing? (Brooker \& Stone, 2004)

- Are the seismic mitigation strategies inserted sensitively to address the building's seismic vulnerability whilst retaining its historic integrity? (Aguilar, 2016)

- $\quad$ Are the circulation paths appropriate for the site's programme? (Hamer, 2016)

- $\quad$ Are the architectural elements within the design such as materiality, light, and the space plan helping to facilitate a positive user experience? (Gander, 2016)

By critically reflecting on design work produced throughout the progression of the research using this selfreflective criteria, the aim is to develop a design proposal that by implementing thoughtfully considered additions to the building, not only will they help to develop a new use for the redundant space, the juxtaposition between new and old elements will seek to complement and enhance each other to form a building of new and greater worth (Brooker \& Stone, 2004). In short, the eventual design will seek to facilitate valuable resources that benefit the Mount Cook and neighbouring Newtown communities, in the form of a two-storey restaurant and bar using a currently unproductive, dilapidated property (Bullen, 2007). 


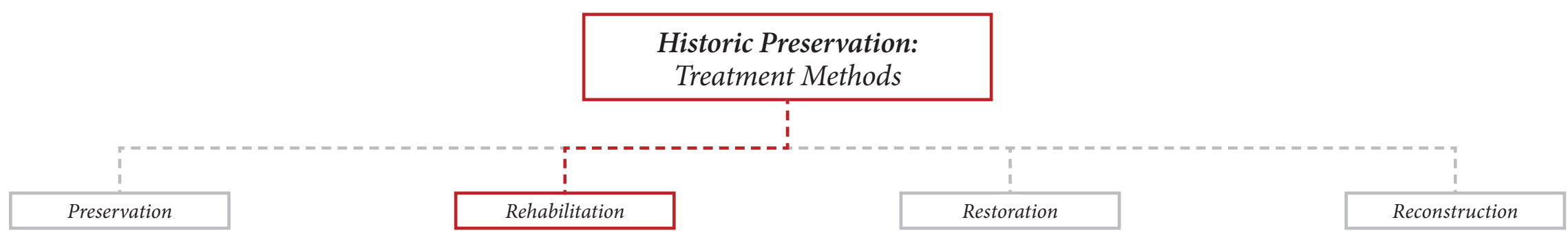

To retain the existing building in its found state. Without disturbing the building's patina, regular maintenance and repair are conducted to prevent further decay whilst making the building safe and avoiding the potential for other treatment methods to

$$
\text { be ever necessary. }
$$

(Brooker \& Stone, 2004; Dedek, 2014; ICOMOS NZ Charter, 2010)
The act of wholeheartedly altering the building. In many instances, a new function is necessary for the continued use of the building, however, any changes made to the building should be minimal, largely reversible, and preserve the features of the building that convey its cultural heritage value.

(Brooker \& Stone, 2004; ICOMOS NZ Charter, 2010; NPS, 2017)
Using materials and techniques of the period in which the building was originally built, through the meticulous process of reassembly, reinstatement, and removal if necessary, the condition of the building is accurately returned to its original state to strengthen its cultural heritage value.

(Brooker \& Stone, 2004; Dedek, 2014; ICOMOS NZ Charter, 2010; NPS, 2017).
The act of rebuilding or depicting elements of a non-surviving site through the introduction of new materials to replace those that have been lost through damage. Sufficient evidence is needed however to minimise conjecture when attempting to restore the building and preserve its cultural heritage value.

(ICOMOS NZ Charter, 2010; NPS, 2017).

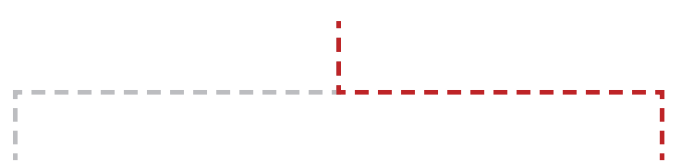

Access to interior documentation in order to assess the building's interior state and defining features.
No access to interior documentation or the site in order to assess the building's interior state and defining features.

How can the interior of a derelict, historic building be rehabilitated when no interior documentation of the building remains? 


\section{5 - THE SCOPE}

It is important for this research that a clear distinction is made between the different treatment methods of historic preservation, as per Figure 1.1. Although each treatment method is viable in its own right, and, any of them could be utilised to preserve the former Tramway Hotel, this research only deals with a rehabilitative approach. Due to the dilapidated state in which the site is in, and the absence of interior documentation, I argue that rehabilitation is the best way forward in preserving this historic building. Unlike the other treatment methods, rehabilitation embraces making additions and alterations to the building whilst maintaining a focus on preserving its key character-defining elements and thus its historical integrity (Dedek, 2014).

Also, it is important to note that due to the seismic vulnerability of the site, seismic mitigation strategies have been explored in order to strengthen the building in an appropriate and sensitive way. However, the author lacks a good understanding in this field and therefore what is proposed within the iterative and final design proposals are more suggestive rather than explicit.

Finally, the design proposal focuses on, and develops aspects of the interior and the front of house service in which patrons will engage. This includes the two bar areas, all dining areas, the two inserted function rooms, and, the two bathrooms on the first and ground floors. Everything else, such as the design of the kitchen are out of scope for the project and therefore have not been developed.

\section{6 - RESEARCH METHODOLOGY}

From the outset, this research has been informed by the notion that there is no such thing as a one-way, 'ideal' design process that designers undertake, any more than there is a single 'correct' design solution (Rowe, 1987; Faimon \& Weigand, 2004). As the research evolved, it has been driven by the cyclical, reflective and iterative nature of action research. This process has occurred throughout the project with the identification of a problem or constraint that needed to be resolved in some form. The project then proceeded with subsequent knowledge sought about the problem or constraint, wherever necessary, followed by cycles of evaluation, iteration, refinement and critical self-reflection (Rowe, 1987; Groat \& Wang, 2002; Swann, 2002; Faimon \& Weigand, 
2004; Riel, 2010-2017). This cyclical process continued as the critical reflective stages informed the progression of the action research cycle, and thus the progression of the research. In short, action research was chosen as a suitable methodology for this research as it is not a linear process but rather one that requires a flexible design process that works towards "develop[ing] practical and relevant solutions to the problems identified" (Crouch \& Pearce, 2012, p. 144).

The cyclical process of action research that this research has taken has been refined and characterised as identifying, planning, acting and then critically reflecting. The first stage involved identifying the parameters that need to be addressed or incorporated into each design iteration such as that of rehabilitation principles, the site conditions and constraints, the building's history and the research question. These parameters then informed the subsequent planning and action stages followed by a critical self-reflection stage. In this stage the design iteration developed is reflected against a generated iterative criteria to identify its strengths and weaknesses. This either informed the next iteration or, helped develop the progression of the iteration. If it was the former, the action research cycle repeated and a new iteration was developed.

As a means to better understand the chosen site, its context and its history, historic research was conducted and implemented throughout the course of this project. As Linda Groat \& David Wang (2002) explain,

by undertaking meticulous research through gathering as much empirical and deductive facts about the site as possible, a clearer narrative and physical evolution of the site can emerge. In response, the research investigated the site's built modification history in order to document how the building has evolved over its lifetime.

By doing so, I was able to gain a better understanding of the building as to what could be altered or removed in order to allow the building to persist, to live on without disrupting its historic integrity and character. What became apparent throughout conducting this historic research however, was the few available sources of information, but more specifically, the absence of any interior documentation of the site. And out of this, the project's research question and direction evolved. 


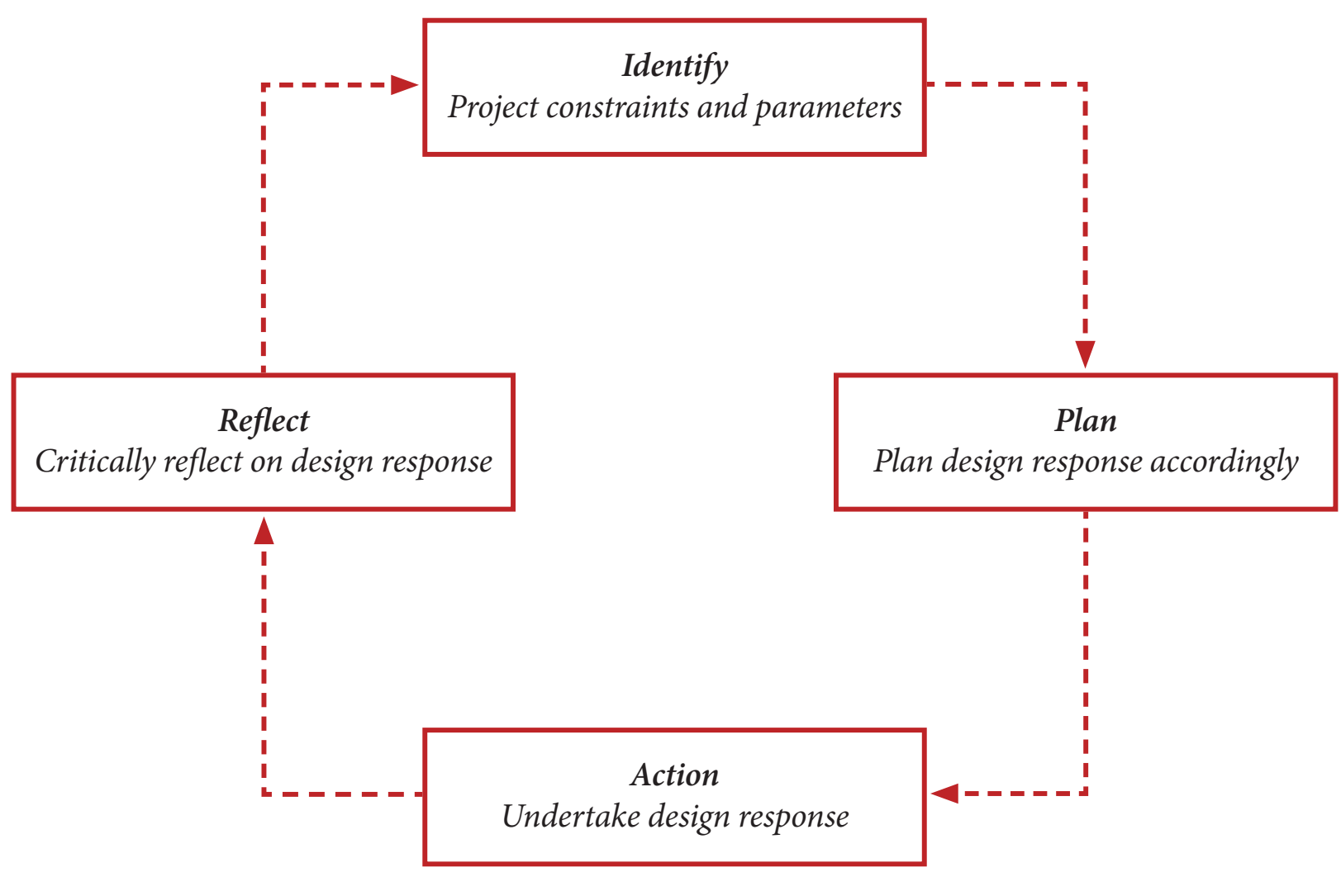

Figure 1.2: Action research cycle. 


\subsection{CONTEXT ANALYSIS}




\section{1 - OVERVIEW}

In this chapter, the site is explored in more detail with respect to its history and the context in which it resides.

Being an interior project with no interior site documentation to work off, a strong understanding of the site was necessary. By achieving this will it consequently help influence later design decisions such as the new programmatic function which is also investigated in this chapter. 


\section{2 - SITE SELECTION}

It is my belief that historic buildings have a right to live on within a city even if they have fallen into a state of disrepair. By assessing the structural integrity of each building to ensure they are not a serious risk to the public, I believe that if these buildings can be saved, they should be saved. Whether they are considered historic, or, simply just old, these buildings have helped define the cityscape and its history. For this thesis, the building in question is the dilapidated, heritage listed, former Tramway Hotel. As of 2011 it sits boarded-up, red stickered and languishing away without any clear direction for its future. In my opinion, the former Tramway Hotel currently sits at a crossroads between retention and demolition and without dedicated intervention, will see it receive the latter. While the site is not in close proximity to the majority of Wellington's heritage listed buildings, or any heritage areas, it nevertheless, is of significance. With its rich and colourful history, it has resonated with successive generations of Wellington residents. Further, the societal benefit of retaining the former Tramway Hotel is due to the Wellington City Council identifying Adelaide Road as an 'area of change'. Over the coming years, Adelaide Road will see significant development and investment as the council seek to regenerate the area. This in turn will see the way in which the street is used, change from being predominantly service based to become more pedestrian friendly. 


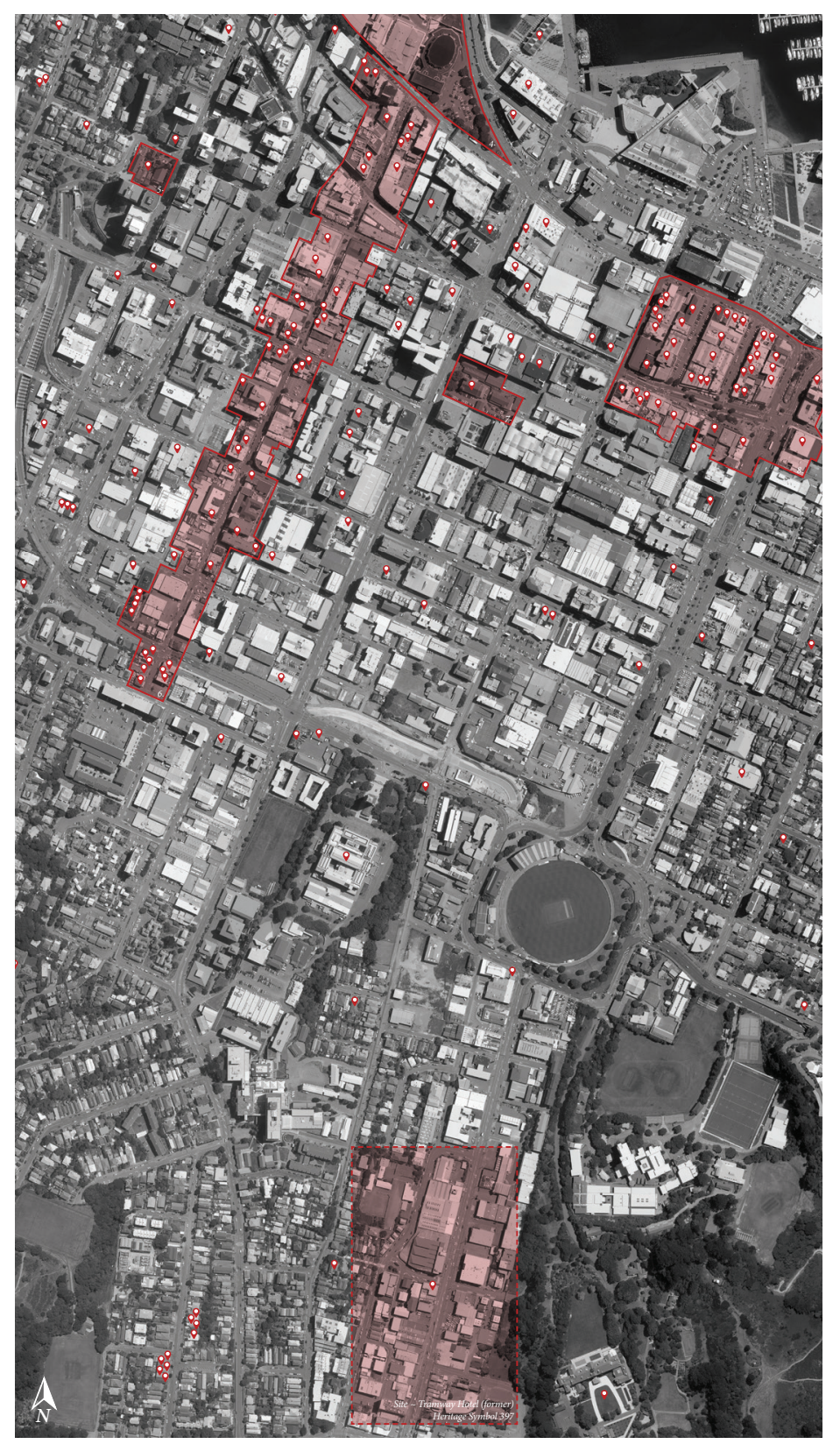

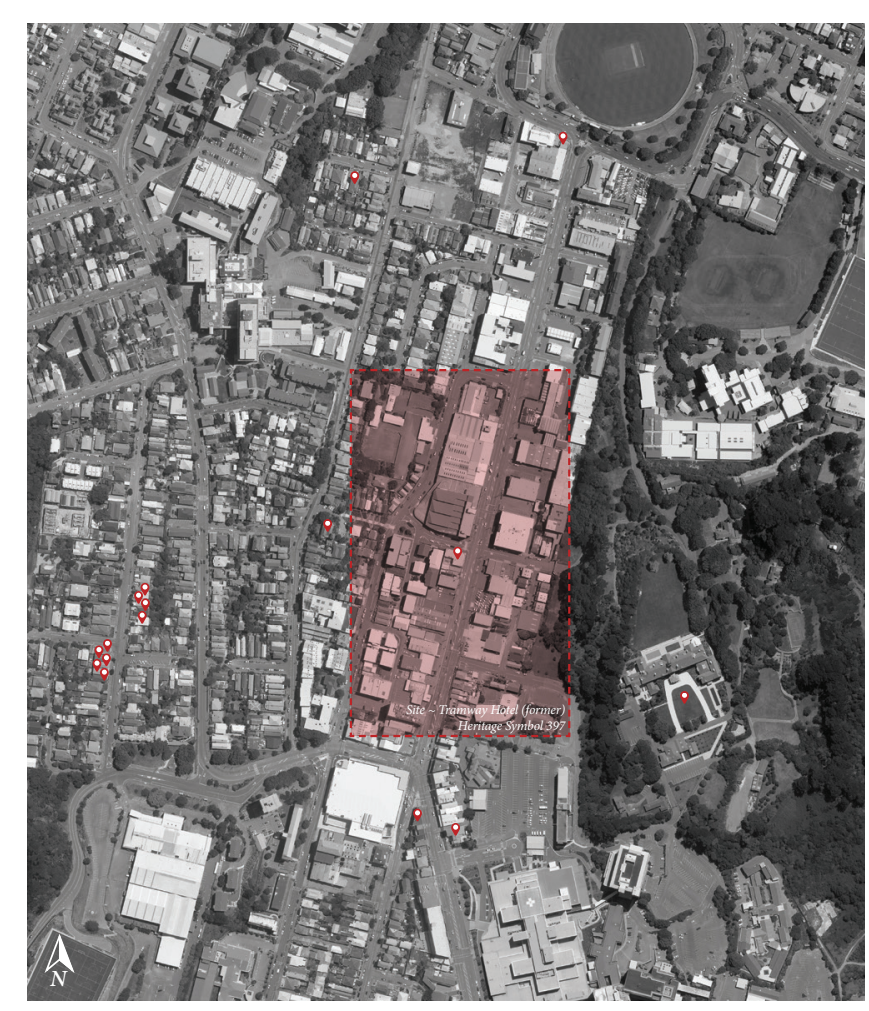

Figure 2.1 \& 2.2: Snapshots of Wellington's heritage listed areas and buildings. 


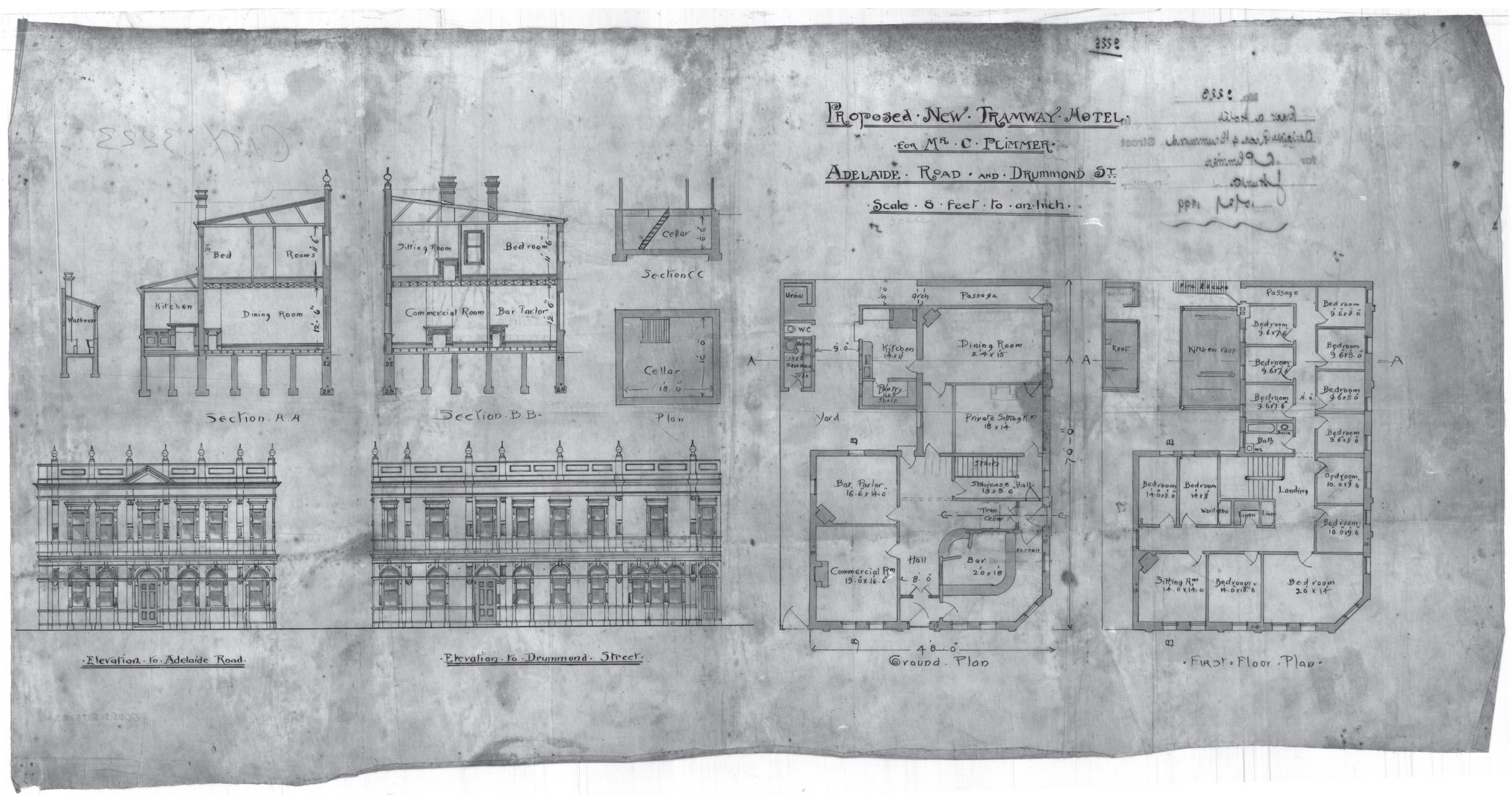

Figure 2.3: Original 1899 drawings for the masonry built Tramway Hotel.

Manipulated by author to adjust colour mode to greyscale. 


\subsection{1 - SITE ANALYSIS}

Originally built of timber in 1877 , adjacent to the later built tramway workshops and stables, the first Tramway Hotel was destroyed by fire on December 301898 (WCC Heritage, 2012). The hotel was insured however, and building plans "were submitted to the council to build a [new] masonry hotel on the site within weeks of the fire" (WCC Heritage, 2012, p. 3).

The plans of the new Tramway Hotel building have now been prepared by Mr J. O'Dea, architect, and they indicate a handsome two-story [sic] structure that should make a great improvement in the appearance of the locality. It will have a frontage of $48 \mathrm{ft}$ to Adelaide-road and $70 \mathrm{ft}$ to Drummond-street. On the ground floor there will be a handsome bar-room $20 f t x 18 f t$ a commercial room, bar-parlour, private sitting-room, dining-room $24 f t x 15 f t$, kitchen, pantry etc. On the top flat will be 14 bedrooms, drawing-room, bathroom, lavatories, etc. The front elevation of the building will be neatly finished in pressed redbrick, picked out with cement. There will be two main entrances, one from Adelaide-road and the other from Drummondstreet and careful provision is to be made in the way of fire escapes (Evening Post, 1899, p. 6).

The hotel later re-opened in August 1899 and although externally the site has undergone numerous modifications since, it has remained relatively unchanged since its construction. As Wellington's second oldest hotel it remains a rare surviving example of its time and architectural style (WCC Heritage, 2012). Although it has had the entirety of its original parapet removed and replaced due to damage from the 1942 Masterton earthquake, the site has retained its architectural authenticity and craftsmanship. Through such, it enables an insight into hotel design of the time to be understood whilst also contributing "to the sense of place and continuity for the changing townscape of Adelaide Road" (WCC Heritage, 2012, p. 13).

The hotel became heritage listed in the early 1990s after former owner Brian Le Gros, a major character in Wellington's adult entertainment industry, renovated the building to look like a colonial pub. By removing the existing exterior render and ceramic tile finish that was applied in the 1960s, the original brickwork beneath was revealed (WCC Heritage, 2012; Whitburn, 2011). Throughout its lifetime, the former Tramway Hotel has had a colourful history which has seen it as "a busy working-class hotel, home to a former Prime Minister, 
and a violent hotspot and murder scene" (Whitburn, 2011, para. 6). More recently however, following the 2011 Christchurch earthquake the site has been served a Section 124(1)(b) notice by the Wellington City Council which "prohibit[ing] anyone from using or occupying the building" (WCC, n.d.-b, para. 9). In 2011, the cost to seismic strengthen the building was estimated to be up to $\$ 800,000$, (Whitburn, 2011). Whether that figure is still the case currently today is unclear, what is clear though is the state of limbo that the site remains in. In 2016 however, the former Tramway Hotel was one of eleven heritage buildings in Wellington to receive funding towards seismic strengthening work and conservation in an attempt to make the city more resilient and retain our heritage building stock (WCC, 2016). Albeit it was only $\$ 30,000$, it is a step in the right direction in helping to preserve this piece of Wellington's cultural history. If the building is strengthened, if we allow the building to persist, to live on rather than face the bulldozer, when considering the social values of conservation, the former Tramway Hotel itself will not only live on, the lifestyles, customs and histories of our previous generations will live on too (Bullen \& Love, 2010).

\subsection{2 - SITE IN CONTEXT}

Situated along a major arterial route, the site's prominent corner site with elevations to both Adelaide Road and Drummond Street, accompanied by its late Victorian Italianate Palazzo style, has seen the former hotel become a compelling embodiment of the period in which it was built (WCC Heritage, 2012). Primarily a mixed-used area, Adelaide Road contains a highly diverse mix of building ages, types, and sizes, of which accommodate a range of activities. Characterised by a majority of utilitarian building stock, frontage setbacks and street edge treatments, mainly for car-parking purposes, are contributing to an underdeveloped streetscape (WCC, 2014). With a strong industrial and service-based amenity dispersion along the road, combined with being a major arterial route, it has resulted in the street becoming heavily vehicle dominated with a dire lack of public landscaping. To put it simply, the North-end of Adelaide Road lacks character, its monolithic commercial and industrial buildings overwhelm the streetscape. However, there are moments like the former Tramway Hotel that provide some respite. Not only does its historic façade provide a disparity from its industrial and commercial neighbours, it also provides a transition to the concentrations of residential dwellings to the site's West. 

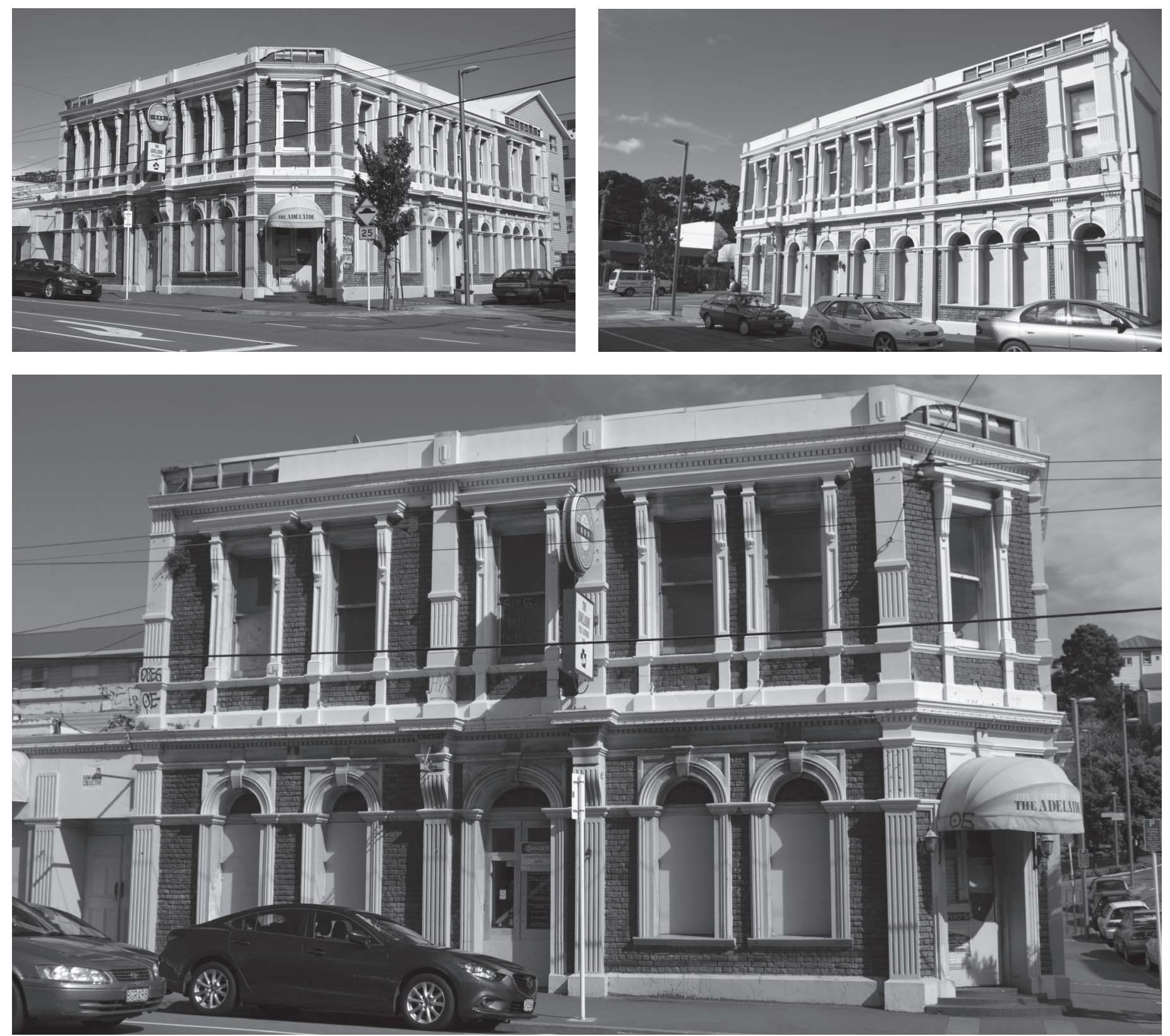


\section{3 - PROGRAMMATIC ANALYSIS}

As a means to better understand the site with respect to its surroundings, and in turn inform a programmatic selection, an amenity map was developed. By exploring the range of amenities that reside in close proximity to the chosen site, it sought to make connections to what is there, what is not there, and what needs to be there.

To further help inform a programme for the site, a radial visualisation was overlain at varying distances in order to understand the number, and nature of the local amenities. These radial distances are measured at $100 \mathrm{~m}$, $250 \mathrm{~m}$ and $500 \mathrm{~m}$ using the site as the epicentre.

Within the site's $100 \mathrm{~m}$ radius it sees a combination of both service-based amenities such as a variety of vehicle repairers, two gyms, a vehicle sales yard and an apparel store. Each is setback from the street edge to which it can be discerned that these amenities are more inclined towards those whom have a motor vehicle and are making a specific trip to the respective businesses. Furthermore, bar the former Tramway Hotel, there are no buildings of character within this radius. In short, these commercial buildings lend themselves to a utilitarian architectural approach which is a common thread along Adelaide Road.

At the $250 \mathrm{~m}$ radius, although the site is in close proximity to a number of amenities, particularly public service amenities, the majority of them are vehicular-based. Retail stores become more common, however, again, they are either for vehicles or orientated towards needing a vehicle to transport purchases, for example, home appliances, plumbing fixtures and furniture. One of the strengths to the site however, is its Western boundary which sees it adjoin to concentrations of residential dwellings with institutional buildings such as Massey University beyond that (WCC, 2014). By acknowledging the lack of amenities to the West, the site's programme could seek to tap into its vast residential surrounds. 


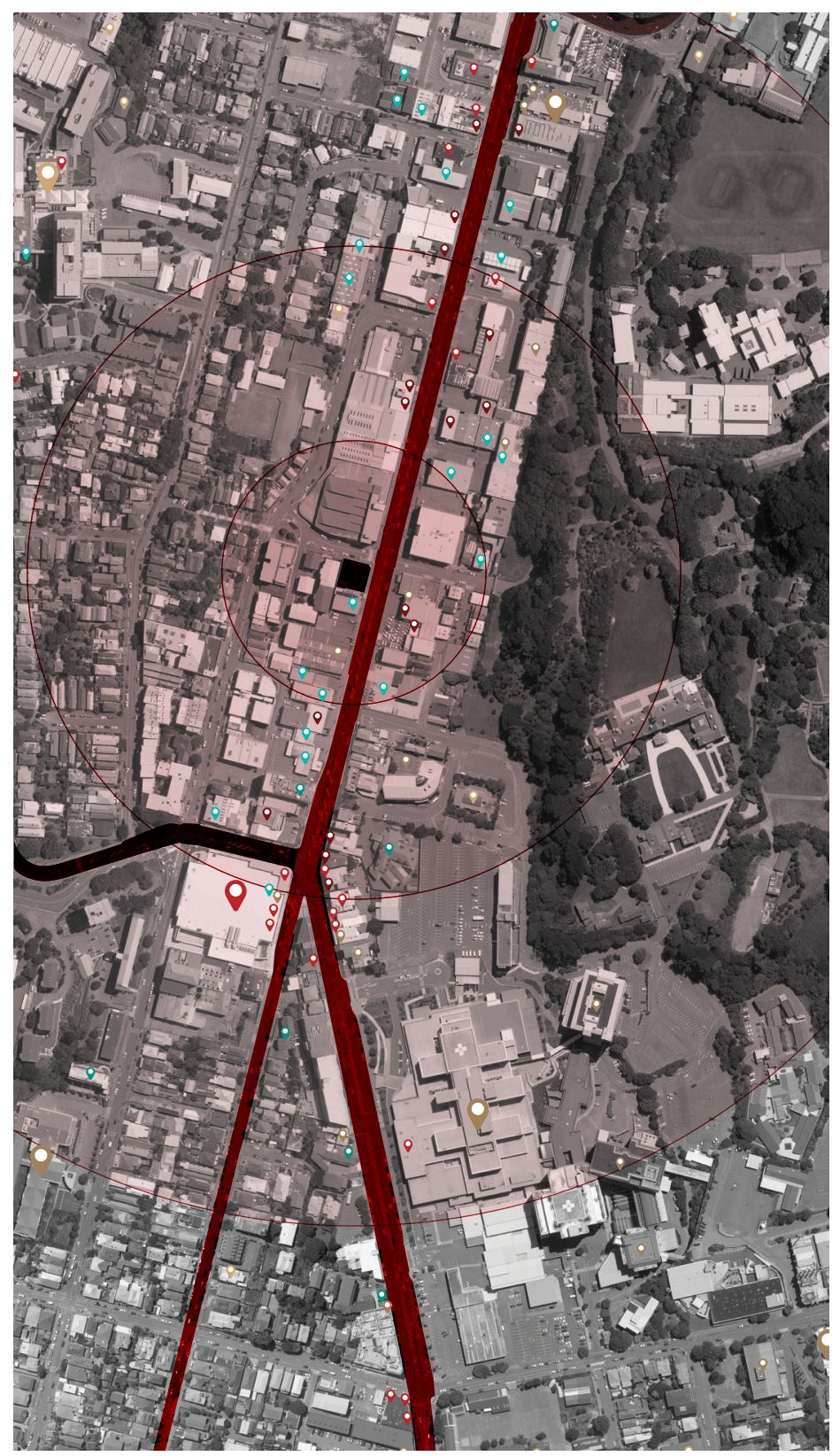

Amenity Key

Public Services

- Accommodative Facilities

Community Facilities

Health and Well-being Services

Food and Beverage Outlets

Retail Outlets

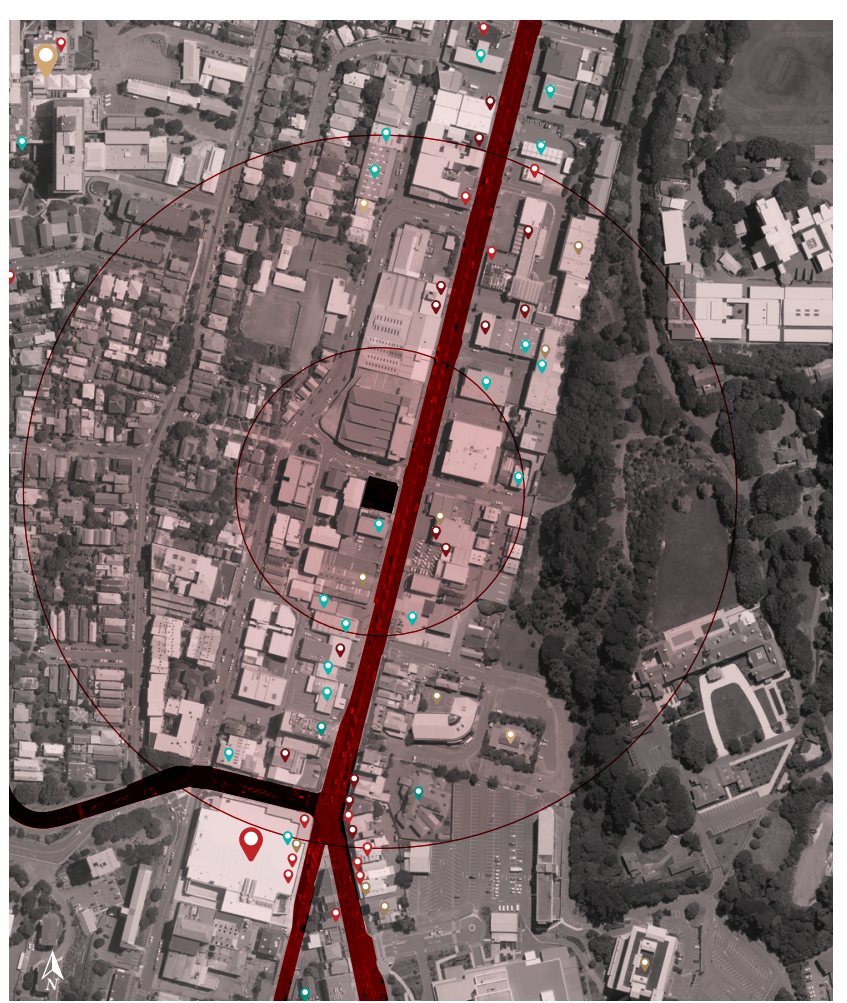

Figure 2.7 \& 2.8: Aerial maps outlining the local amenities surrounding the site.
State Highway 1

Principal Road

Collector Road 
Finally, at the site's 500m radius, it is in reasonable proximity to food and beverage outlets including cafes, fast food outlets and the large Countdown supermarket on the corner of Adelaide Road and John Street.

What it does lack is the accessibility to sit-down restaurants which are not apparent until one gets into the heart of Newtown. Community facilities such as kindergartens, schools, and Massey University also fall within this radius further reinforcing the idea of both young and older students in the area. Another strength is the site's proximity to Wellington Regional Hospital and independent accommodative facilities that litter its surrounds Albeit people visiting or staying at or around the hospital may be in dire situations, or have loved ones in such situations, they may seek escapism in the form of a sit-down restaurant within a rehabilitated historic building.

\subsection{1 - PROGRAMMATIC FINDINGS}

By exploring the amenities which surround the site and the arterial route in which it resides, what jumps out is the need for an investment and refocus towards forming a pedestrian friendly urban quarter that people enjoy dwelling in. Currently the streetscape is heavily industrial and service-based which lends little to a positive pedestrian experience. With this said, a major draw card to Adelaide Road and, therefore, a form of validation for the rehabilitation of the former Tramway Hotel, is due to Wellington City Council identifying Adelaide Road as an 'area of change'. Currently with the relatively low development and the openness of many sites fronting the street, it offers significant development potential to accommodate a significant regeneration and intensification to the North-end of the street (WCC, 2014). The Wellington City Council have expressed that such regeneration will "create a vibrant, mixed-use neighbourhood that includes high-quality public spaces, rapid bus links, and improved pedestrian and cycle links" (WCC, 2015, p. 61). In turn, this will see the support of an additional 2,500 new dwellings and 51,000 square metres of commercial space consisting of workspaces, shops, and cafes (WCC, n.d.-a). The nature of the Adelaide Road regeneration project, if done with a pedestrian designed focus, will likely help develop a new Southern 'hub' to the city which would likely see an influx of people to the area. 
By understanding both the cultural and architectural history of the building, the site's new programmatic function must be appropriate and respect its historic fabric whilst adding a new contemporary layer that adds value to the building (DEH, 2004; Misirlisoy \& Günce, 2016). Bearing this in mind, by acknowledging the large contingency of both residents and students in close proximity to the site, orienting towards a more pedestrian friendly future streetscape, and identifying the lack of sit-down restaurants and bars in the vicinity, the site's programme has responded by accommodating a two-storey restaurant and bar. The rehabilitation of the former

Tramway Hotel, if done successfully, has the means to help contribute to the regeneration of the surrounding area (Brooker \& Stone, 2004). Therefore, it could be said that the regeneration plan for Adelaide Road and the rehabilitation of the former Tramway Hotel would have a symbiotic relationship where each will benefit the other to turn a currently unwelcoming commercial street into a pedestrian friendly urban quarter with character. 


\subsection{LITERATURE REVIEW}




\section{1 - OVERVIEW}

This chapter explores the vast amount of literature surrounding the different treatment methods that can be employed when undertaking a historic preservation project, and, consequently, explains why a rehabilitative or adaptive approach is suitable for the nature of this thesis. The chapter also examines different rehabilitative methods that could be applied to a historic building, and, irrespective of which method is chosen, what the value is of rehabilitating such a building could be. Lastly, it investigates a range of different seismic mitigation strategies in adherence to the site's seismic vulnerability and evaluates them based on their appropriateness within the context of the site. 


\section{2 - HISTORIC CONSERVATION - TREATMENT METHODS}

There are varying degrees of intervention or treatment methods that architects can use when working on historic buildings. The purpose for employing such treatment methods is to retain, and conserve our cultural heritage for both our current and future generations (ICOMOS NZ Charter, 2010). Methods range from preservation to rehabilitation depending on the type of conservation project and its desired outcomes. In many instances, more than one method may be used (ICOMOS NZ Charter, 2010). A brief overview of each treatment method ordered in increasing degree of intervention are as follows:

- Preservation: to retain the existing building in its found state. Without disturbing the building's patina, regular maintenance and repair are conducted to prevent further decay whilst making the building safe and avoiding the potential for other treatment methods to be ever necessary (Brooker \& Stone, 2004; Dedek, 2014; ICOMOS NZ Charter, 2010).

- Restoration: using materials and techniques of the period in which the building was originally built, through the meticulous process of reassembly, reinstatement, and removal if necessary, the condition of the building is accurately returned to its original state to strengthen its cultural heritage value (Brooker \& Stone, 2004; Dedek, 2014; ICOMOS NZ Charter, 2010; NPS, 2017).

- Reconstruction: the act of rebuilding or depicting elements of a non-surviving site through the introduction of new materials to replace those that have been lost through damage. Sufficient evidence is needed however to minimise conjecture when attempting to restore the building and preserve its cultural heritage value (ICOMOS NZ Charter, 2010; NPS, 2017).

- Adaptation / Rehabilitation: the act of wholeheartedly altering the building. In many instances, a new function is necessary for the continued use of the building, however, any changes made to the building should be minimal, largely reversible, and preserve the features of the building that convey its cultural heritage value (Brooker \& Stone, 2004; ICOMOS NZ Charter, 2010; NPS, 2017). Peter Dedek further explains that "the goal of rehabilitation is to balance historic integrity with modern function and current building codes” (2014, p. 151). 
Although each of these treatment methods are viable and beneficial for a conservation project in their own right and, that the ICOMOS NZ Charter (2010) advocates that the least degree of intervention consistent with their charter should be employed where possible, for the purposes of this thesis as mentioned in its scope, will focus on a rehabilitative or adaptive method. Due to the dilapidated state in which the site resides in, its earthquake vulnerability, its interior being inaccessible, and, that there is an absence of interior documentation preventing an accurate interior restoration of the building to occur, I argue that rehabilitation is the best treatment method for the former Tramway Hotel. Rehabilitation opens up possibilities of what the building could become as the method embraces making additions and alterations whilst maintaining a focus on preserving the key characterdefining elements of the building and thus, its historical integrity (Baum, 2012; Dedek, 2014).

\section{3 - REHABILITATION THEORY}

Rehabilitation and reuse is not a new phenomenon; it has occurred in the past due to those either not wanting to invest the amount of time, energy, and money required to demolish and construct a new building, or, those of whom wanting to adapt an existing building to fit new functions or purposes (Plevoets \& Van Cleempoel, 2011; Velthuis \& Spennemann, 2007). It took until the 19th century however for a theoretical approach to be established in which Eugène Emmanuel Viollet-le-Duc "recognised adaptive reuse as a way a preserve historic monuments" (Plevoets \& Van Cleempoel, 2011, p. 156). He argued that "the best way to preserve a building is to find a use for it, and then to satisfy so well the needs dictated by that use that there will never be any further need to make any further changes in the building" (as cited in Plevoets \& Van Cleempoel, 2011, p. 156).

Contesting Viollet-le-Duc's theory, John Ruskin believed regular care and maintenance was the best approach to preserving historic buildings (Plevoets \& Van Cleempoel, 2011; Scott, 2008). Writing in Chapter XX of 'The Lamp of Memory' from his book 'The Seven Lamps of Architecture', Ruskin argues that for past buildings "we have no right whatever to touch them. They are not ours. They belong partly to those who built them, and partly to all the generations of mankind who are to follow us. The dead have still their right in them ... we have no right to obliterate" $(1849$, p. 300). Furthermore, it would seem from his writings as though Ruskin's attitude 
is to want to remove past buildings from everyday use in the name of preservation (Scott, 2008). So in comparing these two great theorists and their differing points of view, as Fred Scott explains, "Viollet-leDuc was the despoiler, and Ruskin the protector of old buildings" (2008, p. 47). Although each argument has merit, I see my stance on the matter falling somewhat in the middle of the two and sharing a lot of the same attitudes as Rodolfo Machado. In his essay 'Old Buildings as Palimpsest', Machado adds an interesting and thought provoking contribution to the theoretical debate through the use of metaphorical connection between rehabilitation and writings on a palimpsest (Scott, 2008). Fred Scott describes Machado's thinking as:

[Machado] sees the processes of serial alteration through the ages as being like the writings on a palimpsest ... it was inscribed with the point of a metal stylus, and once the message was conveyed, the surface could be scrapped back and a new message written. As the palimpsest wore, traces of the previous messages would remain ... he makes the comparison with how a building might also be like this, that is written over, partially erased and written over again so that traces of the previous writings remain discernable (p. 39).

So in essence, what Machado suggests is that all work carried out on building throughout its lifetime, whether restorative or adaptive, should be considered as authentic and is now part of the building's 'original condition' (Scott, 2008). Therefore, through the close reading of the building and by exposing its historic layers, it has the means to develop an interior design response (Brooker, 2006). Albeit that my personal stance and attitude aligns more with Machado, due to the absence of interior documentation for the former Tramway Hotel, understanding what remains internally and thus its 'original condition' is unattainable. In response to this, for this thesis, I believe that the best way forward in preserving this particular historic building is developing a design response that encompasses a combination of all three theories - embracing the historic layers or features of the building that are known to remain, updating the programmatic function of the building, and, henceforth, undertaking regular care and maintenance on the building especially on its historic façade. 


\section{4 - WHY REHABILITATE?}

Locally and globally, an increasing trend has seen a growing shift to rehabilitation within the built environment and with it has seen the practice become more accepted and respected within the field of architecture (Brooker \& Stone, 2004; Bullen \& Love, 2010; Bullen \& Love, 2011b). Considering the fact that the majority of the built environment around the world is still made up of existing buildings, how we deal with these buildings is one of the biggest challenges architects and those in the building industry face today (Klanten \& Feireiss, 2009). Rehabilitation offers a viable and beneficial solution that can work on many levels especially in helping develop a more sustainable built environment (Bullen, 2007). Beyond improved sustainable ramifications, if rehabilitation is done well, it can allow a building to remain an active part of its cities' urban fabric and contribute to urban regeneration through helping to rejuvenate the surrounding area (Baum \& Christiaanse, 2012; Brooker \& Stone, 2004; Bullen \& Love, 2010; Bullen \& Love, 2011a). The most successful rehabilitative projects are those "that best respect and retain the building's heritage significance and add a contemporary layer that provides value for the future" (DEH, 2004, p. 3).

More particularly, for the matters of this thesis, rehabilitation offers a viable and beneficial way to deal with our historic buildings especially when they fall into a state of dilapidation such as in the case of the former Tramway Hotel. Despite its current state, rehabilitation provides the means to breathe another life into the building's old bones and allow it to remain an active part of society. Like fellow historic buildings it is part of Wellington's history and it has helped develop the character and identity that Wellington is known for. Therefore I raise the question, should it not be conserved for the future? The following points outline the value of rehabilitation: 


\subsection{1 - ECONOMIC VALUE:}

Granted, that for many, the financial cost is the most important factor in the decision whether to rehabilitate an existing building - especially if the project has a conservation aspect to it, as this can drive up the cost (Clark, 2008; Heritage Council of NSW, 2008). However in comparison to demolition and rebuild, the rehabilitation of historic buildings makes economic sense (Heritage Council of NSW, 2008). Not only does the rehabilitation provide a new use that can add financial value to the building, but by reusing the building, many if not all of the structural components, utilities, services and materials already exist and may just need to be updated or modernised, potentially saving a lot of money (Brooker \& Stone, 2004; Bullen \& Love, 2011b; Clark, 2008). Depending on the building's location and the legislation in place, tax or other financial incentives can also help with historic related costs lowering the burden on developers (Clark, 2008; DEH, 2004).

In her book, 'The Death and Life of Great American Cities', Jane Jacobs explains that cities need to retain its blend of older buildings, as unlike new buildings, "the economic value of old buildings is irreplaceable ... [they are] created by time" (1961, p. 199). She adds that historic buildings also need to be retained for diversity purposes as they provide the shelter for smaller businesses such as the art studios, the music stores and the neighbourhood bars who cannot necessarily afford the associated costs of new construction (Jacobs, 1961). Although there is no definitive evidence on the matter, more than just small businesses, older buildings, particularly historic buildings, are also more popular than their modern counterparts due to their originality and historic integrity (DEH, 2004). In short, by rehabilitating historic buildings, not only do they provide a point of difference for local businesses, but they also provide a unique market opportunity and investment for owners (DEH, 2004). 


\subsection{2 - ENVIRONMENTAL / SUSTAINABLE VALUE:}

Beyond the sustainable benefits mentioned earlier, by extending the life of an existing building, rehabilitation supports the three tenets of sustainability by lowering material, transport and energy consumption and pollution (Bullen, 2007; Bullen \& Love, 2011b). With growing environmental concerns globally driven by the need for lower resource consumption, the rehabilitation of older buildings whether historic or not, provides the means to circumvent the wastefulness of demolition and reconstruction and opens up the potential for developing new, valuable community resources from unproductive property (Bullen, 2007). Moreover, by avoiding demolition and reconstruction, rehabilitation retains the building's 'embodied energy' which can be described as all of the energy exerted throughout the production of the building - from chopping down a tree to framing a wall, and everything in between (DEH, 2004). As awareness continues to grow, it is likely that we will continue to see more and more rehabilitative projects underway as we as a society continue to seek to develop a more sustainable built environment.

\subsubsection{SOCIAL / CULTURAL VALUE:}

Historic buildings brim with meaning, and their stature play an important role in shaping a city's collective identity and character (Baum, 2012). They extend beyond purely the aesthetic by enhancing our urban experience through embodying our history, providing a notion of continuity, and, by forming an enduring connection and glimpse into our past, present, and future (Baum, 2012; Brand, 1994; Bullen \& Love, 2010; Coles \& House, 2007; Dedek, 2014). Simply, they resonate with people. Despite the fact that many historic buildings are falling into disuse due to an outdated programmatic use, they remain powerful, unique locations that are still full of potential just waiting to be reactivated, to once again, provide its community with valuable resources to be used and appreciated (Baum, 2012; Bullen, 2007; DEH, 2004). Furthermore, by rehabilitating historic buildings we are not only preserving the rich cultural history housed within their weathered walls, but we are preserving and continuing the lifestyles, customs and histories of our previous generations too (Bullen \& Love, 2010). 


\begin{tabular}{|c|c|c|c|c|}
\hline \multicolumn{4}{|c|}{ Design Strategies } & Architectonic Expressions \\
\hline Robert, 1989 & Brooker \& Stone, 2004 & Jäger, 2010 & \multicolumn{2}{|c|}{ Cramer \& Breitling, 2007} \\
\hline Building Within & Insertion & Transformation & Modernisation & Correspondence \\
\hline Building Over & & & \multirow{5}{*}{ Adaptation } & \multirow{4}{*}{ Unification } \\
\hline Building Around & \multirow{3}{*}{ Intervention } & Addition & & \\
\hline Building Alongside & & & & \\
\hline \multirow{2}{*}{ Adapting to a New Function } & & Conversion & & \\
\hline & Installation & & & Junction and Delineation \\
\hline Building in the Style of & & & Replacement & \\
\hline Recycling Materials of Vestiges & & & Corrective Maintenance & \\
\hline
\end{tabular}

Figure 3.1: Reconstruction of Plevoets \& Van Cleempoel's (2011) graph: 'Analogy between described strategies towards adaptive reuse'. 


\section{5 - REHABILITATIVE METHODS}

There are a range of conversion methods used by architects depending on how they want to approach and subsequently undertake a rehabilitation project. Although each case is different, based on the architect, the building, and the context of the project, similar conversion methods can be grouped together into categories. Bie Plevoets and Koenraad Van Cleempoel (2011) provide an insight into the extent of contemporary literature on adaptive reuse within the field of historic conservation and architecture. In their review they identify three approaches within the literature: typological, technical, and architectural strategies, however, for the purposes of this thesis, only their strategic approach will be explored. "The strategic approach focuses on the process and strategies applied for converting significant buildings" (Plevoets \& Van Cleempoel, 2011, p. 160). In their review, Plevoets \& Cleempoel go on to compare and contrast four author's concepts and strategies of conversion in which their analogies are outlined in Figure 3.1.

From this graph, this thesis has then focused and been driven by Graeme Brooker and Sally Stone's 2004 book, 'Rereadings: Interior Architecture and the Design Principles of Remodelling Existing Buildings'. They have developed and defined their strategies by reviewing exemplary case studies with the underlying notion that "the most important and meaningful factor in the design is, of course, the original building” (Brooker \& Stone, 2004, p. 79). Their view that the original building is the most important factor in the design is the reason why it was chosen to drive this thesis. It aligns with my stance that a building's interior rehabilitation, in whatever form it should take, should always seek to serve and enhance the existing building as its main objective due to the fact that the "new could not exist without the original" (Brooker \& Stone, 2004, p. 79). Since there is no remaining interior documentation for my chosen site, the strategies that Brooker \& Stone put forward will be essential in helping develop iterative design responses that adhere to the research question.

Brooker and Stone use three categories to define its strategies: 'intervention', 'insertion', and 'installation':

- 'Intervention' describes an approach in which the new design fully merges with the existing building to develop an intimate relationship where the two become intertwined.

- 'Insertion' describes the approach where new elements are introduced into, between or around the existing building to form an intense relationship. 
- Lastly, 'installation' describes the approach where the new and the existing exist together however in many cases form little rapport - such as an exhibition.

\section{6 - SEISMIC OVERVIEW}

Many unreinforced masonry buildings in existence such as the former Tramway Hotel, have become entwined with the "cultural and historical heritage of the towns where they are located, and as such have become irreplaceable" (Tumialan, \& Nanni 2001, p. 100). However, many buildings like these pose a significant seismic risk in the event of future earthquakes (Aguilar, 2016). As it stands currently, the site remains red-stickered and languishing away. In an attempt to rehabilitate such, a plan of action must be developed that not only articulates a detailed adaptive design but also includes effective seismic mitigation strategies that respond to both the site's seismic risk, and its historic character. Considering such, various strategies have been researched in response, to gain a better understanding of how the design proposal could begin to address the site's seismic vulnerabilities. Furthermore, due to the site's heritage, interventions must be chosen and applied sensitively. As these seismic interventions develop within the design, whether they are hidden or exposed, they must respect the character and integrity of the spaces in which they are implemented (Aguilar, 2016). Upon reflection, the majority of seismic mitigation strategies researched and articulated diagrammatically in Figures 3.2 and 3.3 cover primarily conventional methods that in a sense degrade the historic integrity and, or, are simply unfeasible for the particular site. 


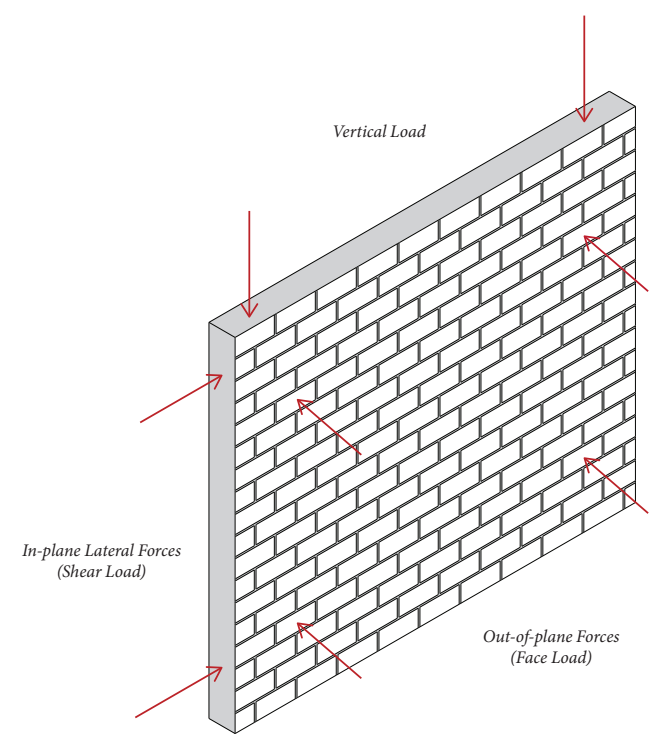

Understanding Loads

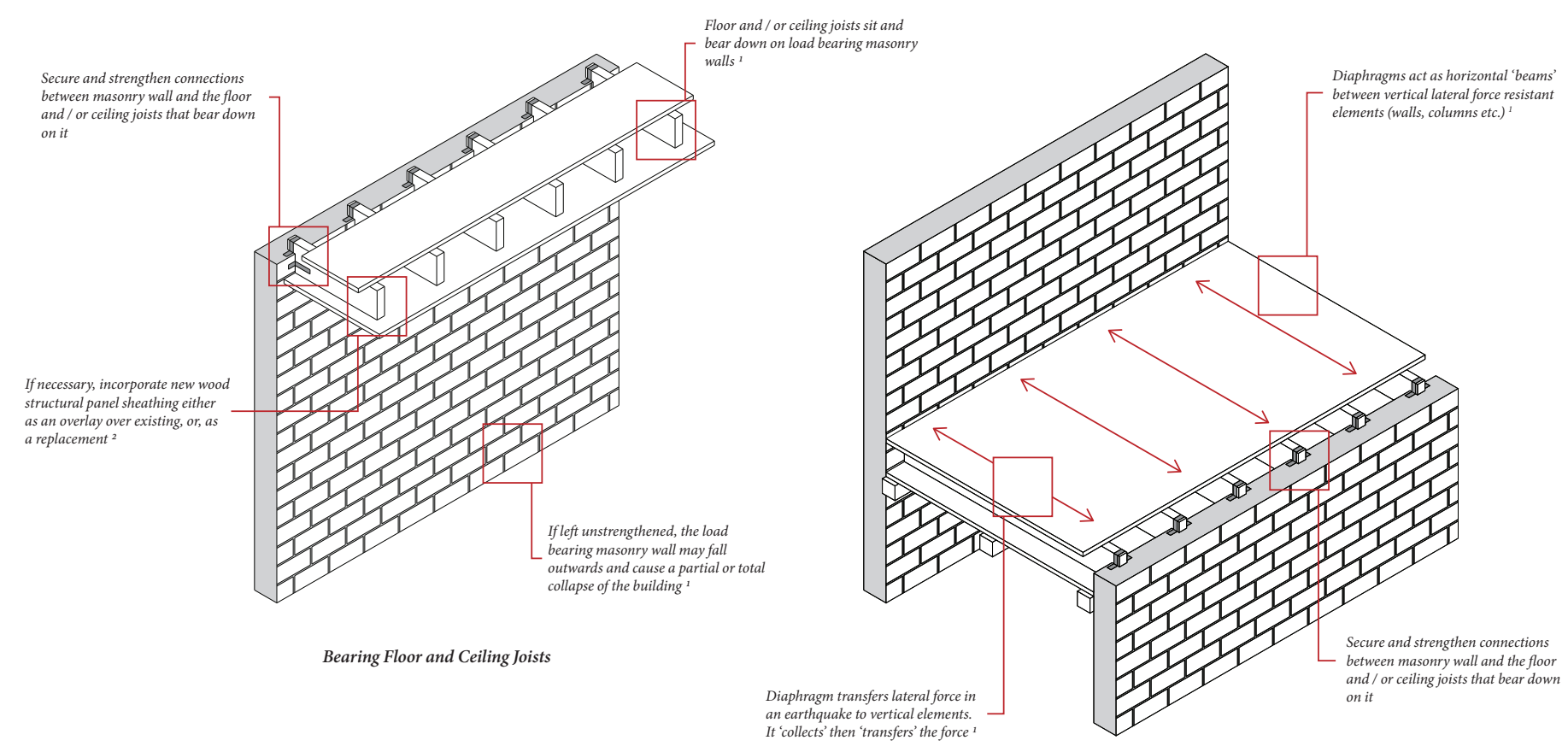

Understanding Floor Diaphragms

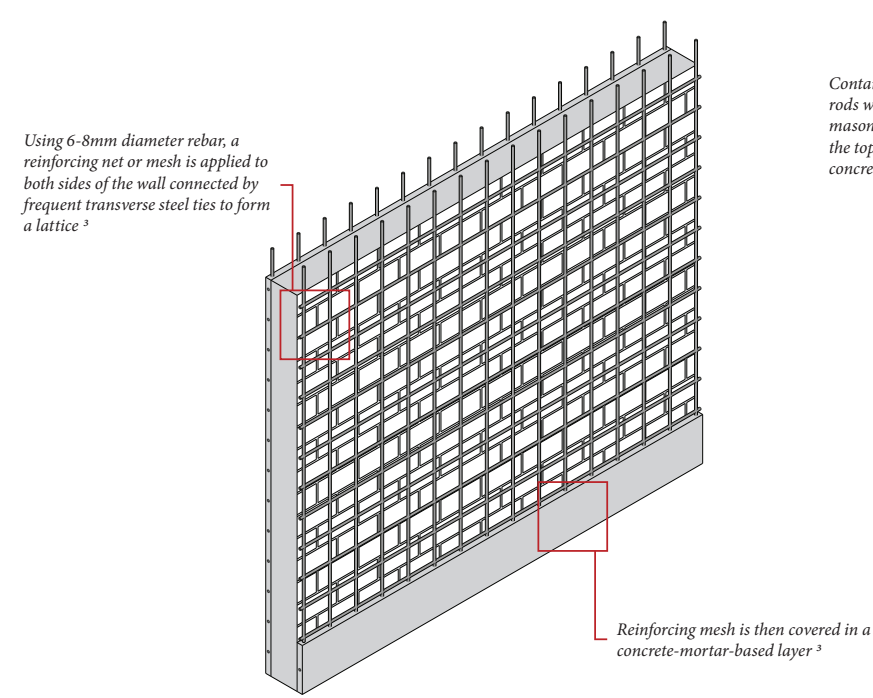

Wall Jacketing: Existing Wal

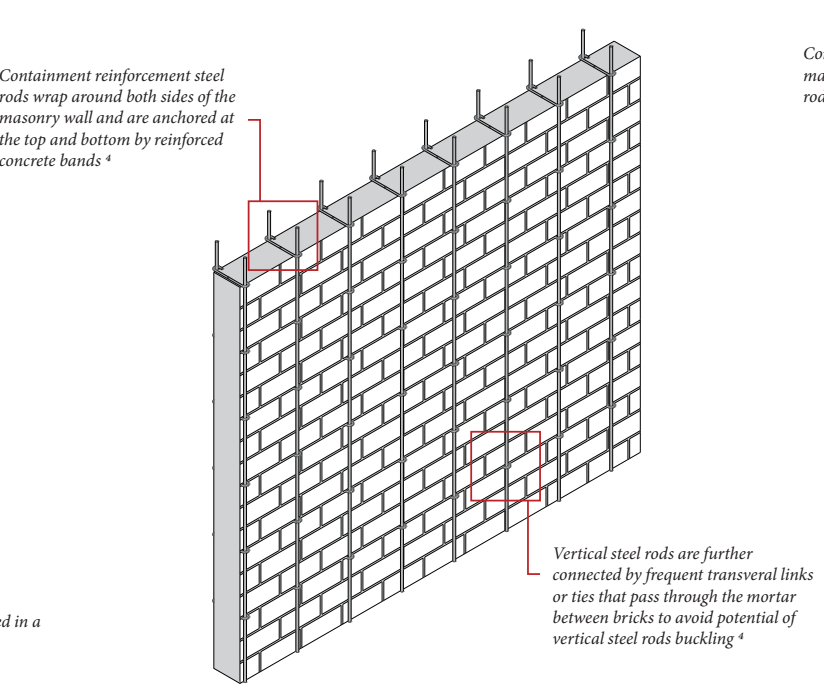

Containment Reinforcemen

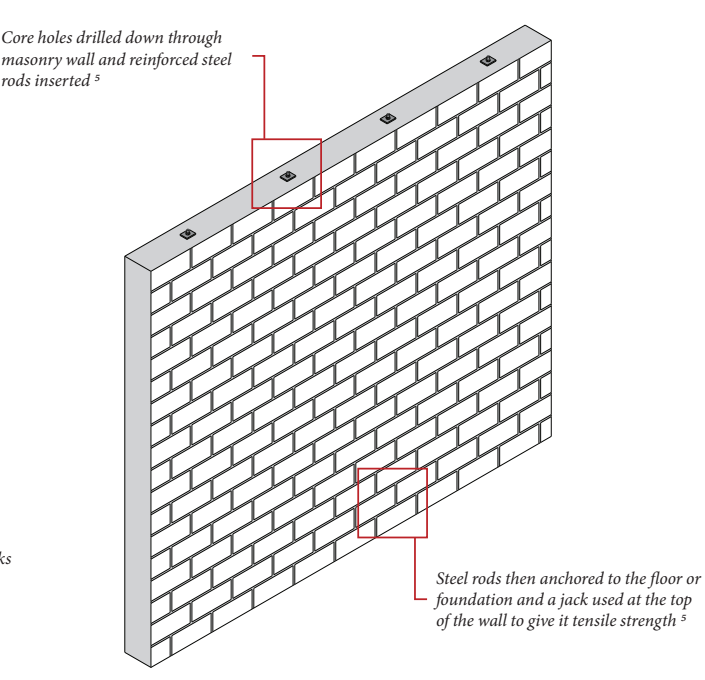

Post-tensioning 


\subsection{1 - SEISMIC MITIGATION STRATEGIES}

Strategies such as that of wall jacketing and container reinforcement would not be appropriate for the seismic strengthening of the site due to the prerequisite that they require both sides of the masonry wall to be wrapped in either reinforced steel bars or reinforced mesh for it to be effective (Frumento, Giovinazzi, Lagomarsino, \& Podestà, 2006; Nanjunda Rao, Raghunath, \& Jagadish, 2004). Since the majority of the masonry walls within the site are load bearing perimeter walls, implementing reinforcing meshes would require wrapping the exterior façade too. Moreover, the steel bars or meshes are then covered in a cement-mortar based layer to secure them but in doing so, it covers the very character that the masonry wall possesses in the process (Frumento et al., 2006). On the other hand, albeit post-tensioning does not affect the aesthetics and character of the masonry wall requiring strengthening, and it is one of the most efficient mitigation strategies, it is also not a viable option (Guh \& Altoontash, 2006; Tumialan \& Nanni, 2001). This is because its installation requires access to the top of the masonry wall in order to drill core holes down through the masonry to insert and then tension the steel tendons (Guh \& Altoontash, 2006; WCC, n.d.-c). Which, in the case of the former Tramway Hotel, is inaccessible due to the building's roof structure and parapet.

Steel moment and braced frames, inter-floor supports and concrete shear walls are all viable and typical methods for increasing the strength and stiffness of the building however, it is key to understand that their addition can add considerable mass to the structure (Aguilar, 2016; Tumialan, Myers, \& Nanni, 1999).

Consequently, this can result in an increase in seismic forces attracted and then applied on structural elements throughout the building which can affect how the building responds in a seismic event (Tumialan, Myers, \& Nanni, 1999; Tumialan \& Nanni, 2001). In addition, if applied within the design, their placement and orientation will need consideration to not disrupt the space plan and character of the spaces that they are implemented within. An advantageous characteristic of both steel moment frames and inter-floor supports however, is due to their minimal fixing to the masonry wall, they provide a high degree of reversibility with little damage to the underlying material (WCC, n.d.-c). This allows for the removal and replacement with future, improved strengthening systems when such systems become available. 


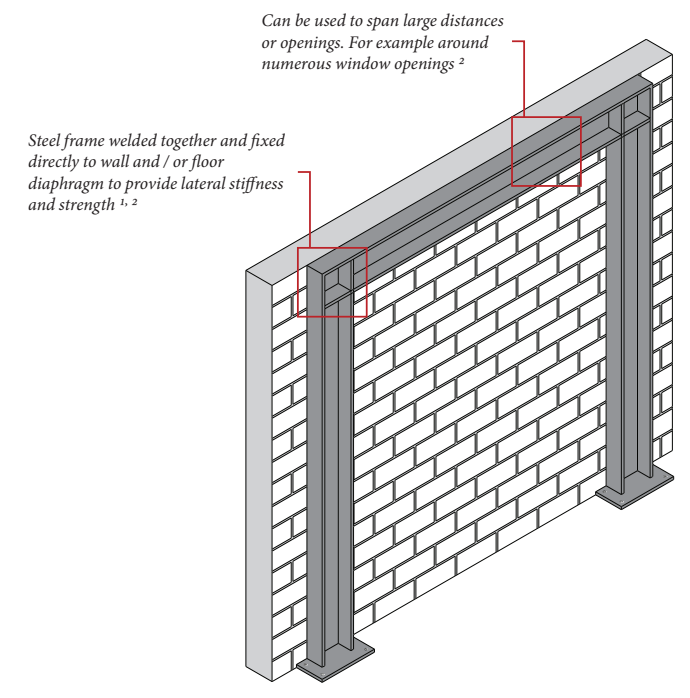

Steel Moment Frame

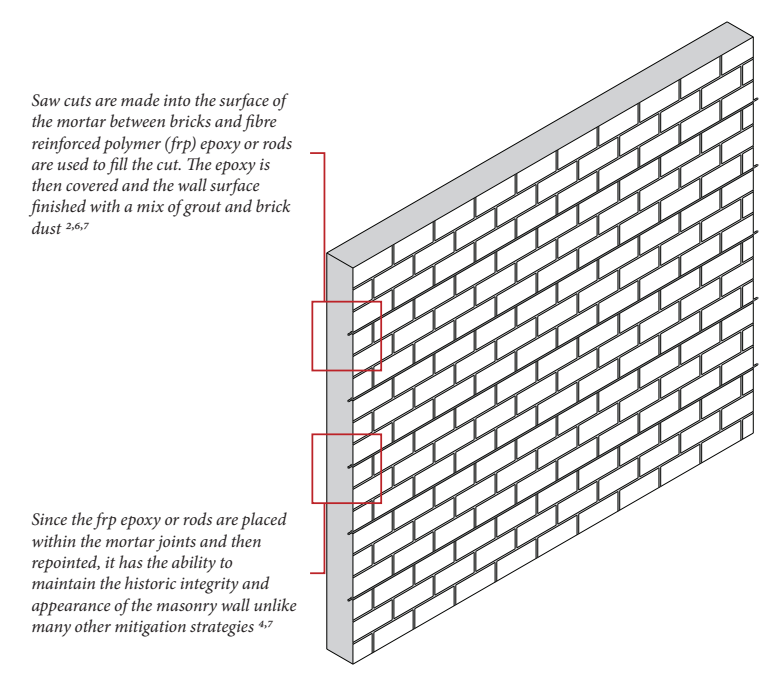

Near-Surface Mounting (NSM)

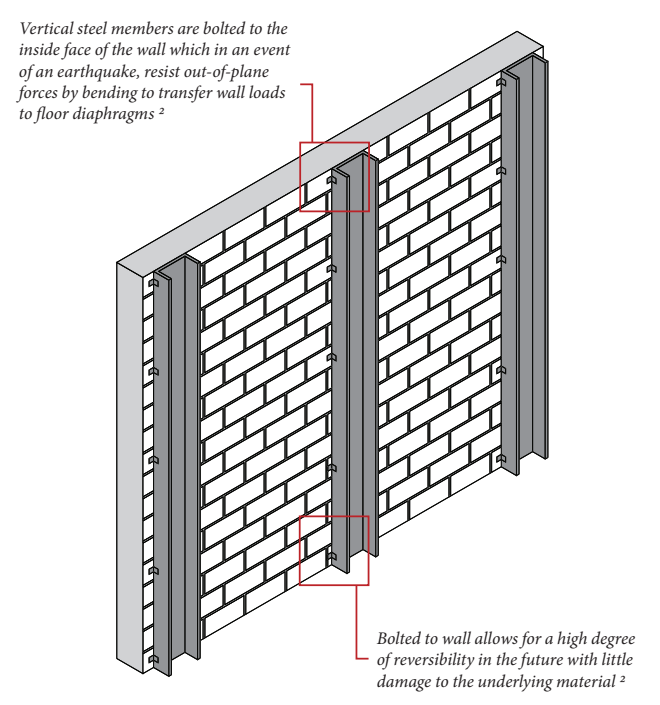

Inter-floor Wall Supports

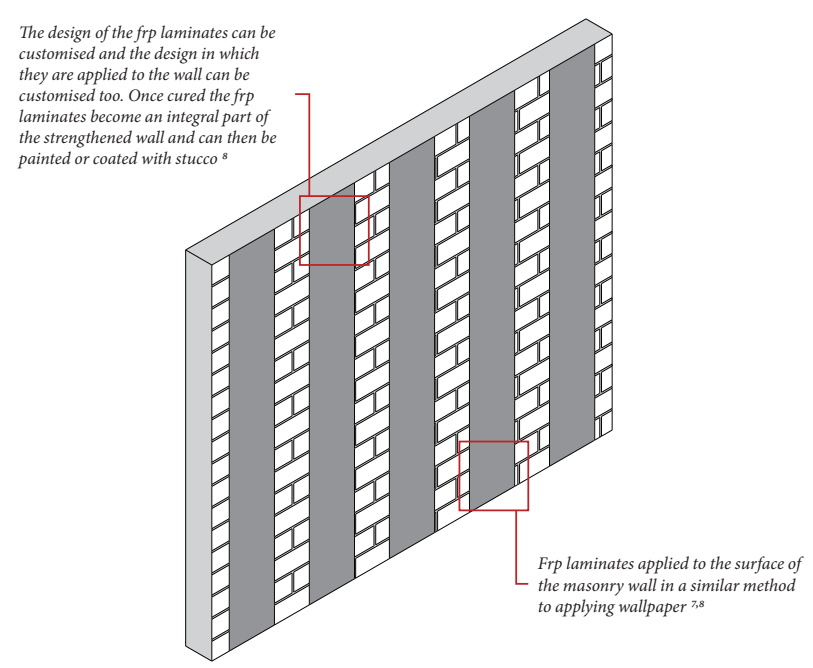

Fiber Reinforced Polymer (FRP) Laminate

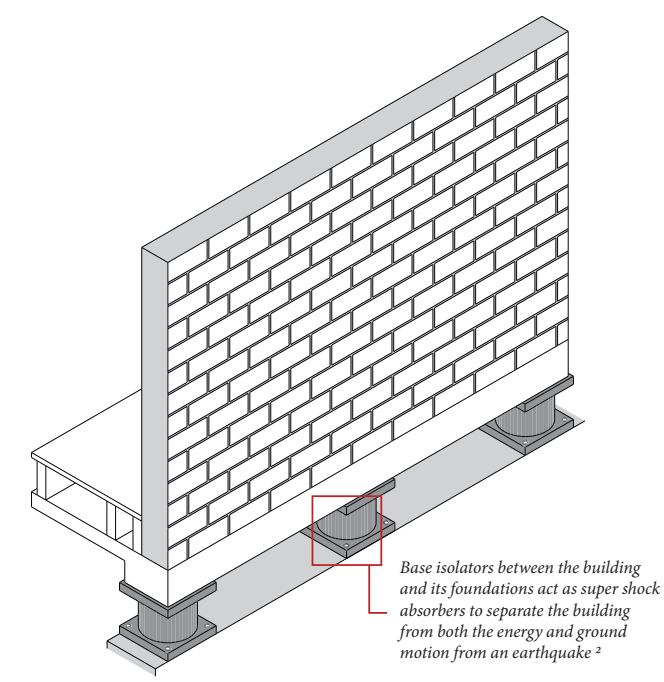

Base Isolation

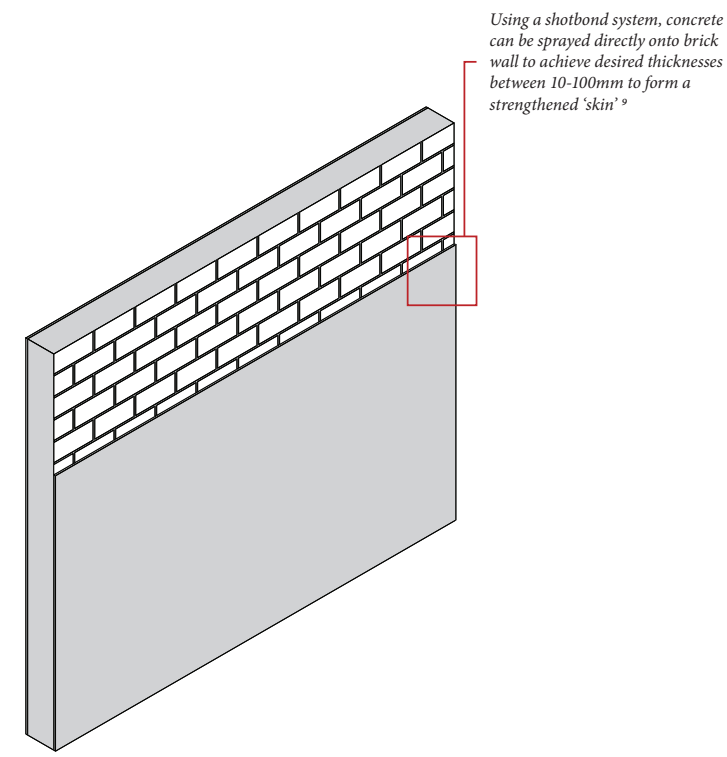

Flexus Bendable Concrete: Engineered Cementitious Composite (ECO) 
Lastly, different installation techniques of fibre-reinforced polymers (FRP) present unique benefits in an attempt to improve the site's seismic resilience. By using a combination of near-surface mounting and FRP laminates within the design, it will dramatically increase both the out-of-plane flexural strength, and, in-plane shear strength whilst improving the ductility of the unreinforced masonry walls in which they are applied to (Tumialan, Myers, \& Nanni, 1999; Tumialan \& Nanni, 2001). Furthermore, by undertaking near-surface mounting and subsequent FRP structural repointing, the FRP rods placed within the mortar joints between the brickwork have the ability to maintain the historic integrity and appearance of the masonry wall unlike many other mitigation strategies making it an attractive and sensitive approach to the site's seismic rehabilitation (Tumialan \& Nanni, 2001).

\subsection{2 - SEISMIC SUMMARY}

Undertaking this research was valuable in gaining a better understanding of seismic mitigation strategies not only for the purpose of this thesis, but also for expanding my personal knowledge. Albeit many of the mitigation strategies are not viable for this particular project due to the constraints that the site poses, through implementing a combination of strategies that work in cohort with one another, they have the means to improve the site's seismic resilience. To achieve such, the eventual design response will look to incorporate a combination of steel moment frames, near-surface, mounting and FRP laminates. It is essential however, that through their implementation the interventions respect the building's historic fabric as best they can with respect to both their placement and transparency. Whether they are exposed to develop a new interior aesthetic, or, hidden in an attempt not to disrupt the character and space plan of the building, further consideration and iterative workings will be necessary in order to make the seismic interventions best work within the context of the former Tramway Hotel. 


\subsection{PRECEDENT ANALYSIS}




\section{1 - OVERVIEW}

This chapter continues on from the previous chapter by investigating a range of successful rehabilitative projects. As mentioned in the previous chapter, as a method for advancing the direction of both the thesis and the design work, exemplary case studies have been chosen and examined that explore how Brooker \& Stone's (2004) strategies for undertaking a rehabilitation project have been translated into built form. The following three case studies have been chosen due to the historic nature of each building, the various conditions that the buildings were in prior to their rehabilitation, and, the various strategic approaches that have been employed in order to rehabilitate such. 

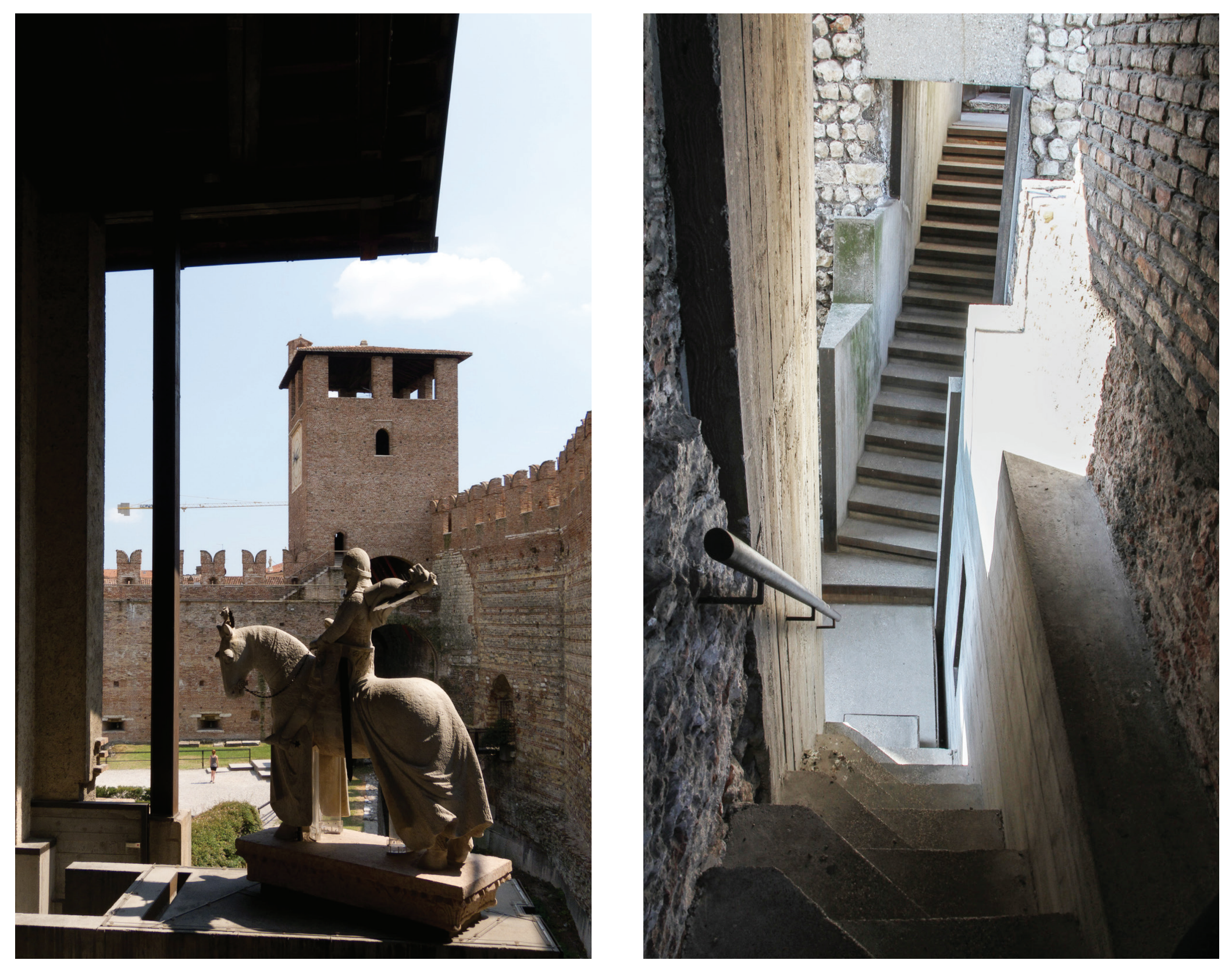


\section{2 - CARLO SCARPA: THE CASTELVECCHIO MUSEUM IN VERONA, ITALY}

Born in Venice, Carlo Scarpa is a famous Venetian architect best known for his attention to detail, craft, and innate approach to materials (Stott, 2017). Many of his works are notable for the fact that he was able to retain the original integrity of the building, none more so than his rehabilitation of the Castelvecchio museum in Verona (Hass, 2016). Completed in three phases between 1957 and 1973, it is one of Carlo Scarpa's most renowned works and remains one of the great examples of interventional design that is still celebrated to this day (Scott, 2008).

The Castelvecchio museum is composed of an amalgamation of buildings, courtyards, gardens and towers of the Scaliger castle built in the 14th century (Brooker \& Stone, 2004). Due to the complexity and confusion that had developed throughout numerous adaptations over the years, Scarpa removed as much as he added to the Castelvecchio (Brooker \& Stone, 2004). Via the use of 'selective demolition', the building's historical "layers were scraped away or exposed until clarity was achieved" (Brooker \& Stone, 2004, p. 247) which then paved the way for his 'creative additions' (Rab, 1998).

Scarpa's close reading and understanding of the site, not to mention, as Fred Scott (2008) puts it, the 'luxury' of time he was granted to spend on the project, led Scarpa to be able to implement a sympathetic and modest approach that contributed to the accumulation of the rich history of the museum complex. A contemporary, facilitating layer if you will. Through a series of carefully thought out and composed interventions throughout the museum, although different in their material qualities and language, each are related and inspired by the former fortress (Brooker \& Stone, 2004). By intensively studying and documenting the site, Scarpa was able to make informed decisions, whether destructive or constructive, balancing the new and the old "in order to reveal new or hidden meanings” (Brooker \& Stone, p. 81). Through such, as Samia Rab explains, Scarpa’s thoughtful interventions throughout the Castelvecchio "create deliberate breaks between different historical parts of the building, each of which is designed to create an 'authentic' historic experience” (1998, p. 443). The outcome is that the Castelvecchio remains true to its former self and retains its integrity even through the extensive intervention work it has undergone which speaks volumes to Scarpa's work. The dialogue established between what is retained and what has been added to the site, especially through the attention to detail Scarpahas shown, 
helps to further juxtapose and reaffirm the relationship between the original and new elements so that the "two do not exist independently but become intertwined" (Brooker \& Stone, 2004, p. 87). In short, the Castelvecchio is a true testament to Scarpa's skill and historical reading of a site and has become a benchmark for all rehabilitation projects since (Brooker \& Stone, 2004).

\subsection{1 - CASTELVECCHIO SUMMARY}

Thinking back to Machado's palimpsest metaphor, Scarpa's rehabilitation of the Castelvecchio has a strong connection. It could be considered that the Castelvecchio is a result of serial alterations throughout its lifetime where Scarpa, acting as its curator, either removed, added, or exposed sections of its historical strata to develop the successful design response that it is. By approaching the project like he approached all others, as John Kurtich and Garret Eakin explain:

Scarpa achieved three things with his adaptive reuse project. First, he accepted and presented parts of the building complex as historically pre-existing, therefore maintaining their original integrity. Second, he lay bare through conceptual surgery all the genuine survivals of the Castelvecchio. Finally, he added new parts, which would bind together the entire complex and fill in the gaps without destroying the patina or even the mishaps or wounds of time (1993, p. 26).

A noteworthy aspect to Scarpa's practice is his thoughtfully considered detailing and material choices throughout his projects, especially that of the Castelvecchio. As Brooker and Stone (2004, p. 248) explain, Scarpa "took care in the choice of materials as these emphasized the nature of the exhibits, the movement between them and the perception of the building." By considering the building by curating new materials atop, below, or around existing materials, and, employing sympathetic and appropriate interventions within the former Tramway Hotel, like Scarpa, it will seek to enhance and reaffirm the relationship between the new and the old whilst adding a contemporary layer to the history of the building. 

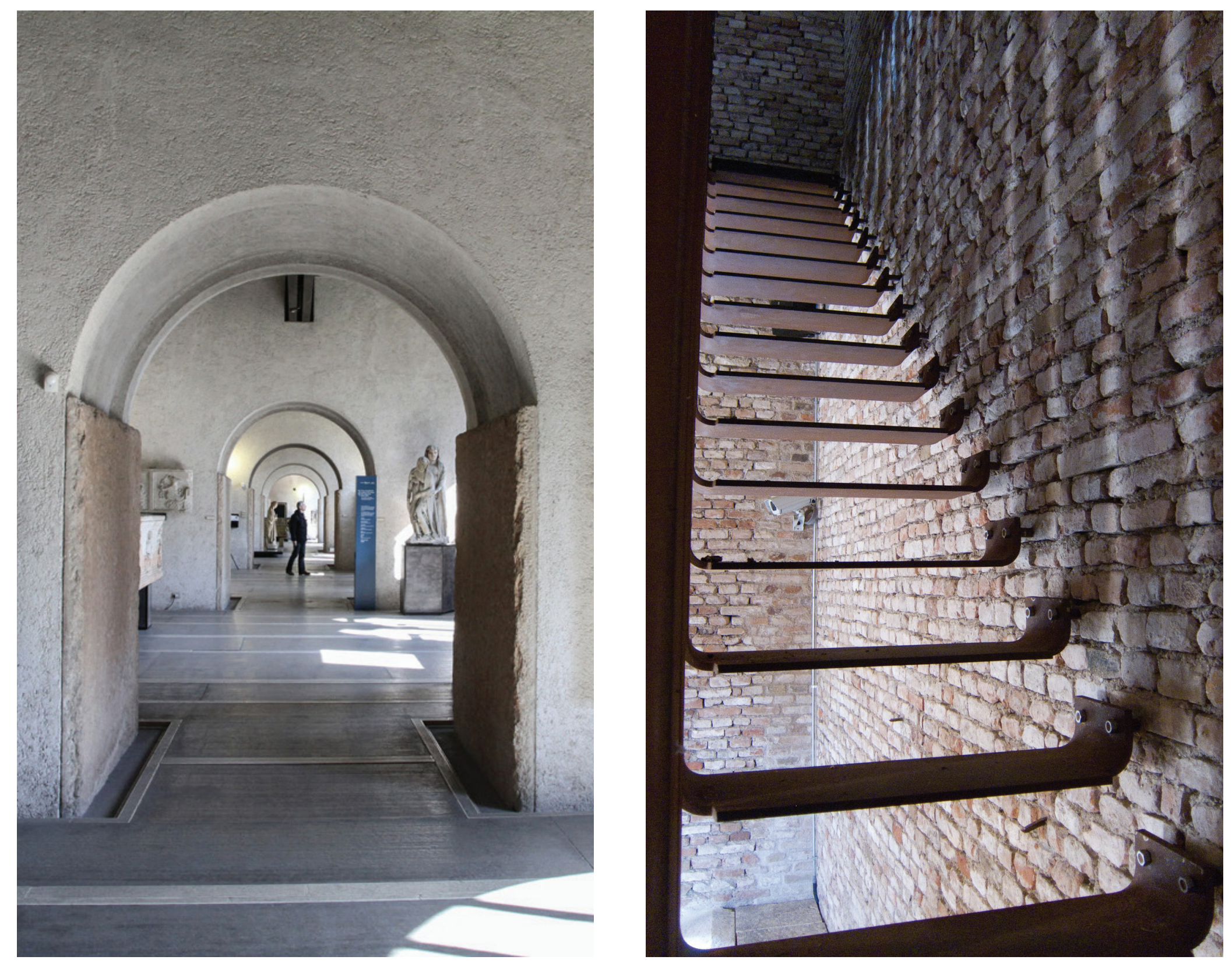
An inspiration to many, and rightfully so, Scarpa’s consideration and implementation of detailing has seen him praised by theorists as the 'master of the detail' (Rab, 1998). The way in which Scarpa's detailing articulates the differences between the exposed historical strata, the nature of the museum's exhibits and his new interventions, adds so much depth and meaning to the Castelvecchio. With the thesis having a focus on aspects of the interior and front of house service in which patrons will engage, the design would benefit from taking inspiration from Scarpa's attention to detail. Whether it is forming a void between the floor and wall planes to highlight the squared floor plate of the gallery spaces in the Castelvecchio, or, placing new stair treads with partial openings over the existing treads to provide a visual connection to the building's history in the Olivetti Showroom, Scarpa's use of detailing, always purposeful, not only accentuates the building's historic fabric in which he is designing, but it also provides delight and intrigue for visitors and thereby enhances their experience. 

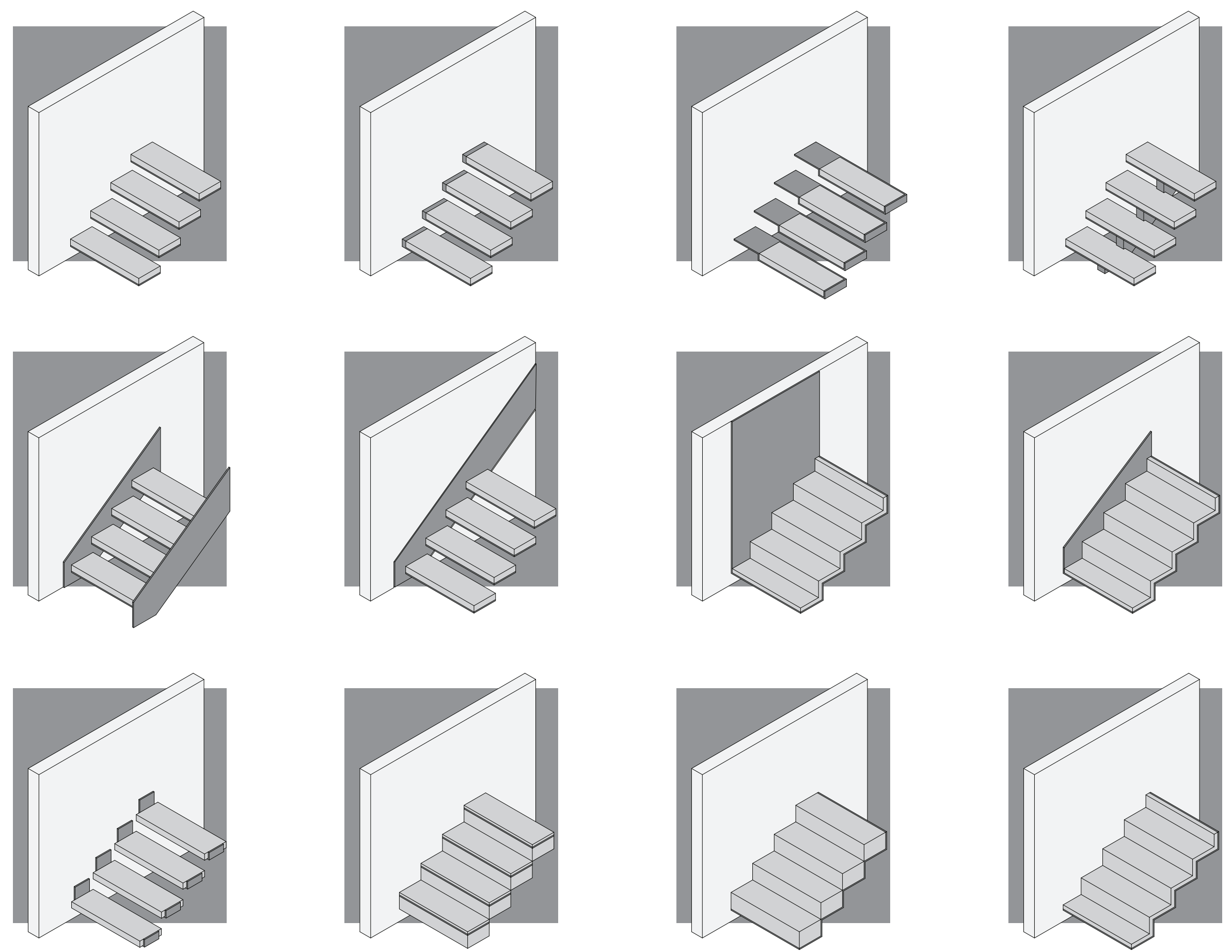

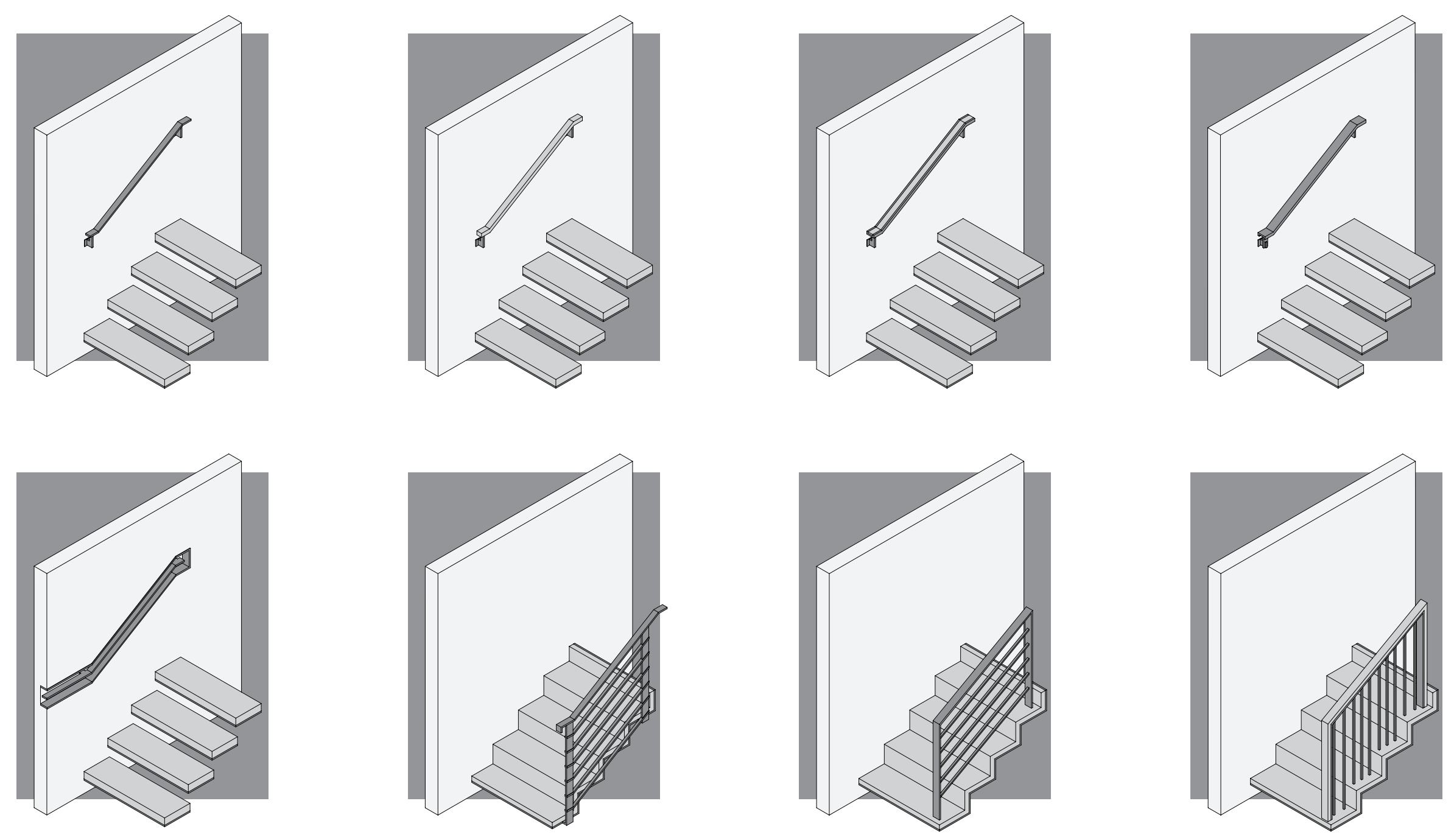

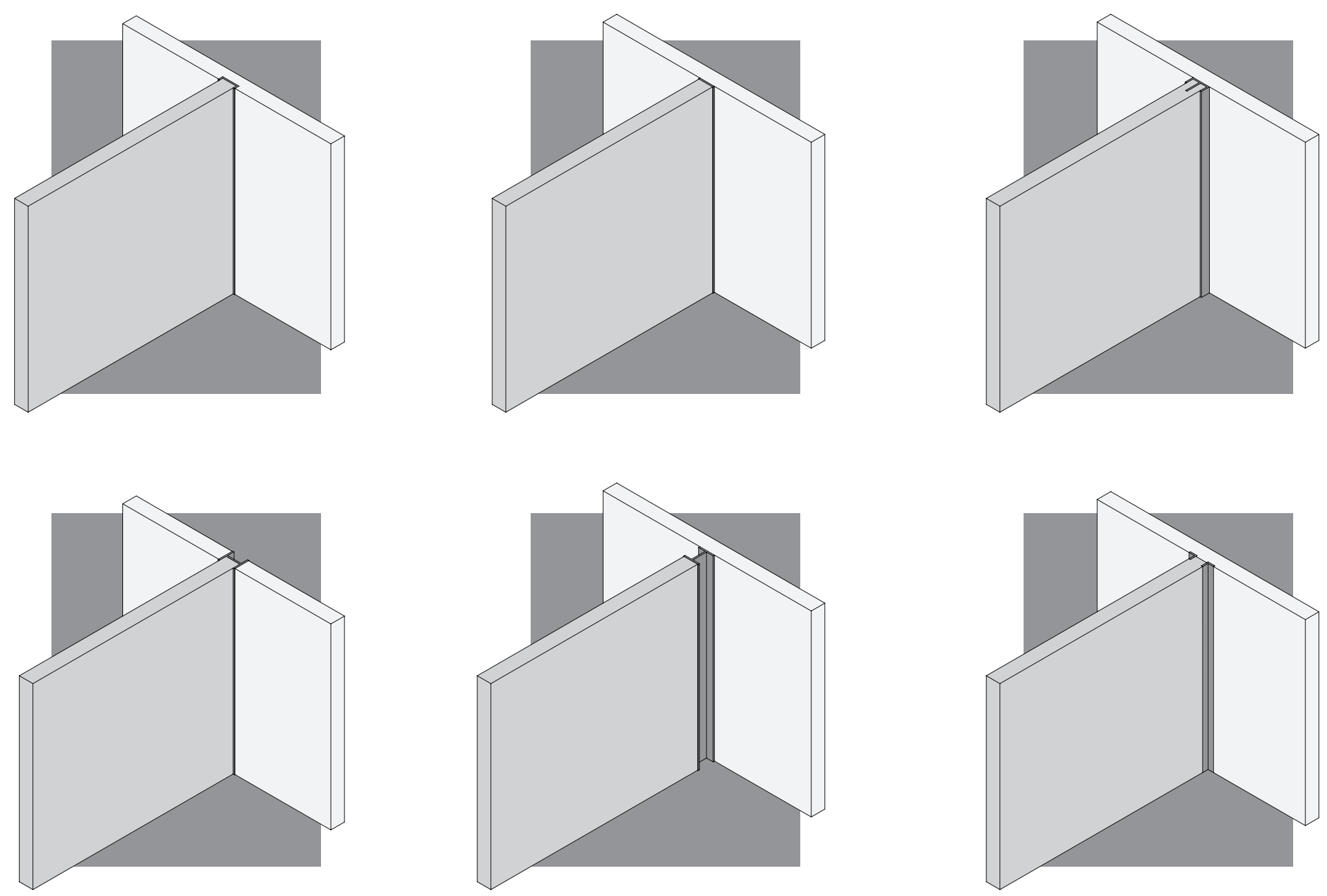


\section{3 - DAVID CLOSES: CONVENT DE SANT FRANCESC IN SANTPEDOR, SPAIN}

Sat ruined since 1835 and avoiding the fate of demolition by the state, the surviving church of the convent of Sant Francesc, located in the Catalan town of Santpedor has undergone a skillful rehabilitation by David Closes. Although the church, and in particular its interior was in ruins, what remained, possessed unique spatial qualities that due to partial roof collapses, were enhanced by natural light flooding in (ArchDaily, 2012; Closes, 2012). In response, rather than simply reconstructing the church, by alternatively embracing it's found state, and purposefully leaving the wounds of time apparent whilst cleverly deploying contemporary insertions, as Closes explains,

"The intervention has just consolidated the old fabric distinguishing clearly the new elements executed from the original ones. The renovation carried out allows to read historical wounds and the building's most important spatial values without giving up the use of contemporary language in the new elements" (2012, para. 7)

The result is a design that successfully accentuates and preserves the church's surviving historic fabric through the insertion of newly built elements. Closes' contemporary insertions through their contrasting materials, language, style, and character, develop a strong dialogue and relationship between themselves and the existing building. The new insertions implanted in, out and around the deteriorated sections of the church has preserved the "historical heritage of the building and simultaneously add[ed] new values which highlight and singularize the ancient church in a contemporary way" (Closes, 2012, para. 9). 


\subsection{1 - CONVENT DE SANT FRANCESC SUMMARY}

As mentioned, with a focus preserving all aspects of the building's past, Closes cleverly uses the crumbling remains of the church to frame his contemporary insertions and form a sense of unity between the two architectures.

His choice of material palette and the design of his new insertions consolidate this statement by enabling a crisp and clear distinction to be established between the two architectures. Although disparate at times, Closes' contemporary insertions do not detract from the historic fabric of the church in which they serve, but rather it is due to these contrasts in both form and language that "strengthen and reinvigorate the existing building allowing it to be looked at afresh, as though new life had been drawn into it" (Brooker \& Stone, 2004, p. 102).

Granted that the former Tramway Hotel is not in the same state as the church was, much can be learned from the way in which Closes' responded to the building to develop his designs. By considering both the history and condition of the church, its new, proposed programmatic function, and, the unique spatial qualities that it possesses, Closes was able to develop and employ, like Scarpa, sympathetic and appropriate interventions that enhance the church. Due to a lack of remaining information of the interior within the former Tramway Hotel, using Closes' work as inspiration, rather than 'patching' the church's historical wounds with contemporary insertions to accentuate them like Closes, one strategy for this thesis could investigate how inserting contemporary elements within the confines of the building's façade could subsequently be used to inform the building's interior. Either way, whatever direction the eventual design response takes, similar to what Closes achieves, the design will seek to attain a level of clarity and contrast between new and existing elements as the two architectures develop a "strong relationship of attracting opposites, each complementing and enhancing the other, generat[ing] a building of a new and greater worth" (Brooker \& Stone, 2004, p. 103). 


\section{4 - HERZOG \& DE MEURON: CAIXAFORUM MADRID IN MADRID, SPAIN}

Nestled within the shell of a converted electrical power station, the CaixaForum in Madrid was envisioned by Swedish firm Herzog \& de Meuron as an 'urban magnet', drawing visitors in, both for its programme and seemingly floating silhouette (Herzog \& de Meuron, 2008; Klanten \& Feireiss, 2009; Ng, 2015). Thoughtfully considered and inserted with finesse, the building's complementary additions, underscored by their diverse contrast of materials are juxtaposed elegantly to form a contemporary reinterpretation of a historic building. With only the masonry façades left useable from the previous power station, in order to insert their new additions, the interior and other redundant parts of the existing building were surgically removed (Herzog \& de Meuron, 2008). Albeit it was this process in which developed the eventual form of the building, its result however could be seen as a form of façadism. Yet, in the case of the CaixaForum, although it is only the façade that remains of the former power station, as Amelyn Ng explains:

"Instead of a flimsy one-sided facade that would only suggest loss of a richer history, the CaixaForum's exterior suggests dynamic addition. Here, the heritage power station can be circumambulated and read up close in its full volume, as if it were still standing there, intact in the city. The datum of the roofline is silhouetted against a dark sheath of corten steel, made to weather naturally along with its heritage counterpart" (2015, para. 5).

Where Herzog \& de Meuron's contemporary, exterior additions help accentuate the building's historic fabric, their interior decisions on the other hand do not. Although the CaixaForum's contemporary interior with its faceted, metallic finishes and multi-leveled experience provides an intriguing spectacle for visitors, by covering up the building's masonry walls, the design intervention develops little relationship or dialogue between the interior rehabilitation and the building's history. Whether many of the interior decisions were driven by the requirements of the exhibition spaces or not, either way, the "CaixaForum's interior experience is highly dissociated from its monumental exterior" (Ng, 2015, para. 10). 

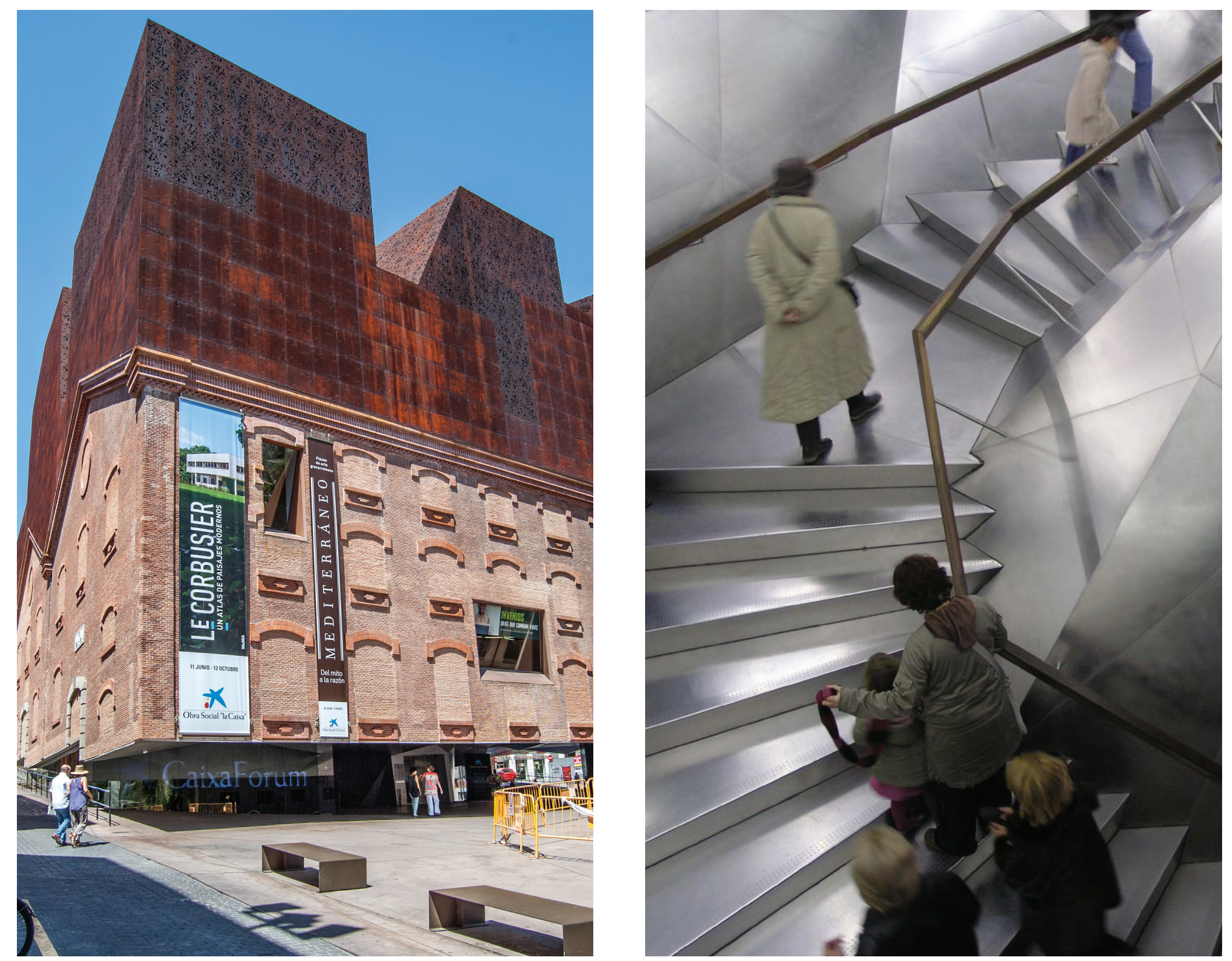


\subsection{1 - CAIXAFORUM MADRID SUMMARY}

The CaixaForum Madrid exhibits from an exterior perspective, an interesting and successful adaptation of a former industrial building. What is most intriguing about this project, at least in relation to this thesis, is the way in which Herzog \& de Meuron have exhibited the building's façade with a contemporary twist.

They have enabled one to be able to take in the details of the building and understand the design of its time without degrading the building's historic integrity. This will be key in developing a successful design response for the former Tramway Hotel. With its lack of interior documentation, how the building's façade is dealt with in relation to the inserted contemporary additions and architectural shifts will become a crucial aspect in retaining its historic integrity. As I do not agree with blanketing a historic interior with a contemporary aesthetic thereby essentially masking the historic elements of the building like in the case of the CaixaForum, the design response for this thesis, as previously mentioned, will seek to develop an amalgamation of materials, language, and, history to reinvigorate the building whilst enriching the user experience. 


\subsection{THE PROCESS}




\section{1 - OVERVIEW}

This chapter explores the process that the project underwent in order to reach the eventual design proposal. Many of the design iterations that have been developed begin with, or only really explore the site's façade in detail. This is due to the absence of any interior documentation, which sees the building's façade being one of the only remaining known historic features of the building. Due to this, the facade was used as a starting point for ideas, however, some ideas did not progress further than this point and were therefore not translated into the site's interior. It is to be noted that although many of the rehabilitative techniques that have been explored in the following design iterations did not work for the chosen site, that is not to say that they cannot be applied and subsequently work better, given a different site and context. 
Spatial insertions enhancing the existing building

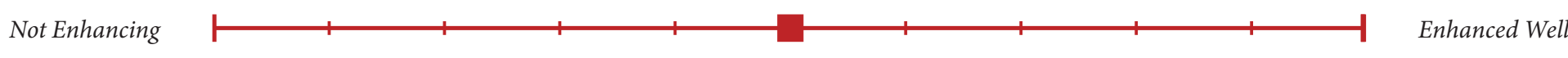

Balances historic integrity with modern function

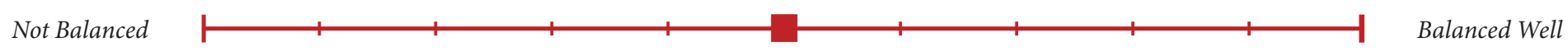

Dialogues established between new and existing elements

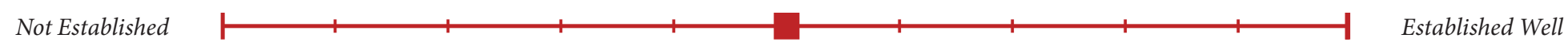

Responds to seismic vulnerabilities whilst balancing historic integrity

Responds Poorly

Circulation paths appropriate for the site's programme

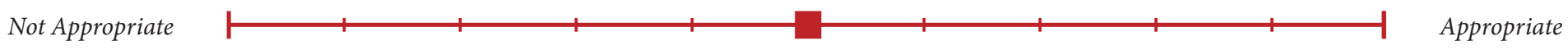

User experience

Negative

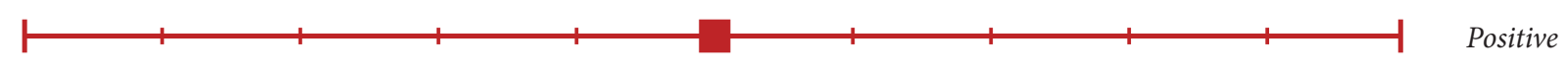

Figure 5.1: Self-reflective scales to critique each design iteration against.

Note, if a criterion is grey it is inapplicable for the design iteration. 


\section{2 - ITERATIVE CRITERIA}

In order to refine the design work produced, each design iteration was developed and then critically reflected upon against a set of generated self-reflective criteria. As mentioned in Chapter One, by establishing this selfreflective criteria as the research progressed, it enabled an identification of both the strengths and weaknesses of each design iteration. This reflection either informed the next iteration or helped to develop the progression of the iteration. However, generally speaking, each reflection tended to reveal the need for developing new iterations in order to respond to the project's constraints and parameters.

The criteria has been generated based upon literature that this research has covered and is appropriate for the site, its context, and the chosen programme. With no interior documentation remaining and thus the potential for endless design possibilities, the criteria has been purposely developed to be limiting. The intention for such was to help refine both the design direction and scope so that each iteration could build on its predecessor in an attempt to develop a more resolved final design proposal. Finally, the criteria has then been simplified into a set of sliding scales as a means of visually representing the critical reflection of each design iteration as seen in Figure 5.1.

- $\quad$ Are new spatial insertions enhancing the existing building? (Brooker \& Stone, 2004)

- Does the design balance the building's historic integrity with modern function as per the goal of rehabilitation? (Dedek, 2014)

- With the insertion of new built elements, are clear dialogues established between the new and the existing? (Brooker \& Stone, 2004)

- Are the seismic mitigation strategies inserted sensitively to address the building's seismic vulnerability whilst retaining its historic integrity? (Aguilar, 2016)

- Are the circulation paths appropriate for the site's programme? (Hamer, 2016)

- Are the architectural elements within the design such as materiality, light, and the space plan helping to facilitate a positive user experience? (Gander, 2016) 


\section{3 - DESIGN ITERATIONS}

The following design iterations illustrate the journey in developing the final design response. By first studying the building and its history, similar to that of Scarpa, responsive interpretations could be made. As the design process progressed, the iterations explored more of the building and its constraints which ultimately lead to the introduction of more radical shifts. Critically and retrospectively, a lack of a theoretical framework guided the evolution of the iterations until much later in the process. Consequently, this hindered the overall output of design work produced, which I have acknowledged and will use to improve my personal design practice and future projects.

\section{DESIGN ITERATION 1}

Referencing the site's history using its façade and character defining elements to inform interior decisions.

As an initial response, the site remains a two-storey structure with the addition of a large interior light well and courtyard, and a rooftop terrace and bar. Albeit intervention was at a minimum at this point, it began by exploring the idea of incorporating wall, door and window detailing such as that of wainscoting and cornicing that make reference to the Victorian period and style in which the site was built. In essence, what was discovered about the site's history, façade and character defining elements informed interior decisions.

What was most lacking in this iteration however, was that the design was not explicit enough in articulating which elements were preexisting and which had been introduced into the space. Due to the aesthetic interventions not being well articulated, it lead to poor dialogues between new and existing elements. As the iteration developed and more interior decisions were made, a decision was made to stop progressing it further By taking a step back from the design and reflecting on it, it was determined that the iteration read more as a restorative project rather than a rehabilitative project, which is not the aim of this research project. 

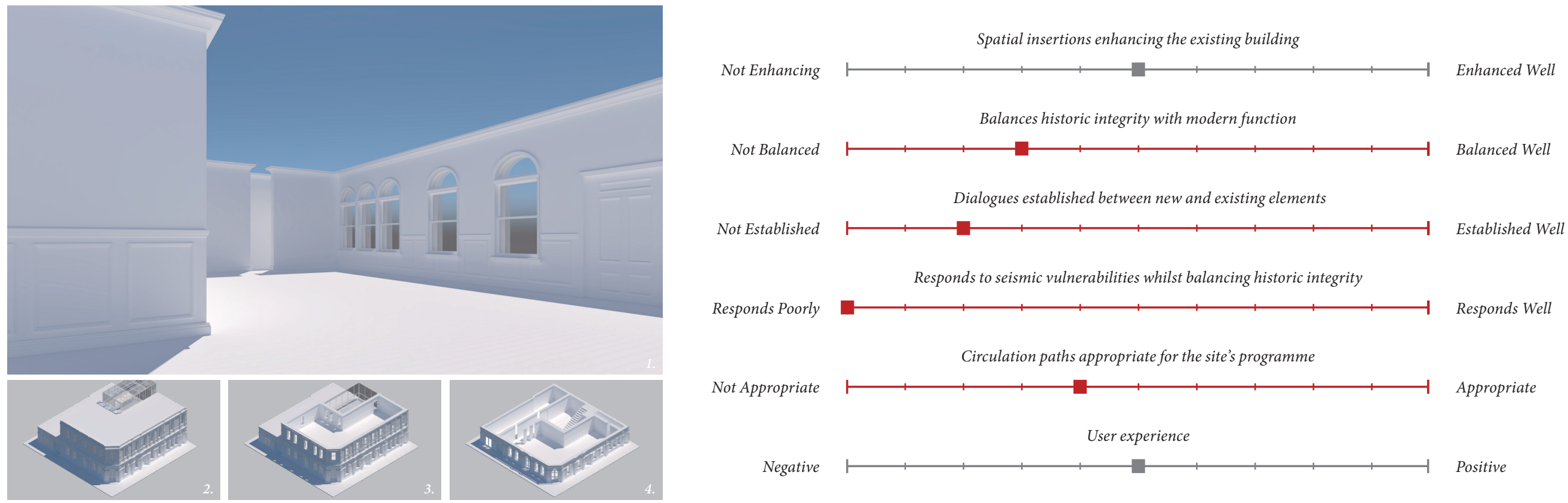
Responds to seismic vulnerabilities whilst balancing historic integrity
Responds Poorly

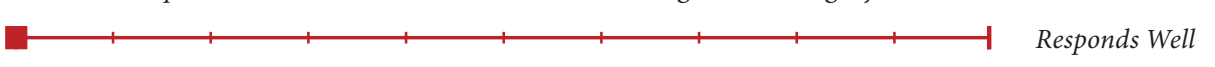

Circulation paths appropriate for the site's programme

Not Appropriate

User experience

Negative -

Positive

1. Ground Floor Perspective.

2. Rooftop $\sim$ Terrace and Bar.
3. First Floor $\sim 24 / 7$ Cafe and Collaborative Working Space.

3. Ground Floor Restaurant and Main Bar. 


\section{DESIGN ITERATION 2}

Mapping previous wall positions to form a new space plan.

This design iteration sought to begin exploring the role in which former internal walls had on the space plan of the building. Instead of simply constructing new interior walls throughout the space, by curating an amalgamation of known walls that used to reside within the space, a new space plan that alludes to the building's history and lifetime is formed. The former internal walls that have been reintroduced into the site have been articulated through the use of colour to represent the period in which the wall existed. Steel, distinguished by its grey colour in this iteration, was chosen as a material to be incorporated throughout the design as a means to form a material transition between existing, new, and reintroduced elements to help form a design aesthetic throughout the interior and, albeit not implemented in this iteration, to help provide structural strength to the building due to its earthquake frailty.

Due to not wanting to remove any of the site's numerous existing entrances to maintain the building's historic integrity, it was decided to form designated entrances that will help to develop circulation paths throughout the space. Through the reintroduction and curation of prior interior walls and circulation paths, it began to balance the historic integrity of the building with modern function, however, the concept lacked rigor. The site suffers from a fragmented interior layout and with nothing but colour to differentiate between new and existing elements, a poor user experience would likely ensue. Therefore, more thought needed to occur regarding the articulation and dialogue between new and existing elements. Currently, each wall treatment and finish is the same and that lends little to expressing the historic fabric of the building. What is most lacking in this iteration however, and thus required immediate attention is research and subsequent implementation of seismic mitigation strategies within the site. By realising this research, the following iterations could begin to address the building's seismic vulnerability. 

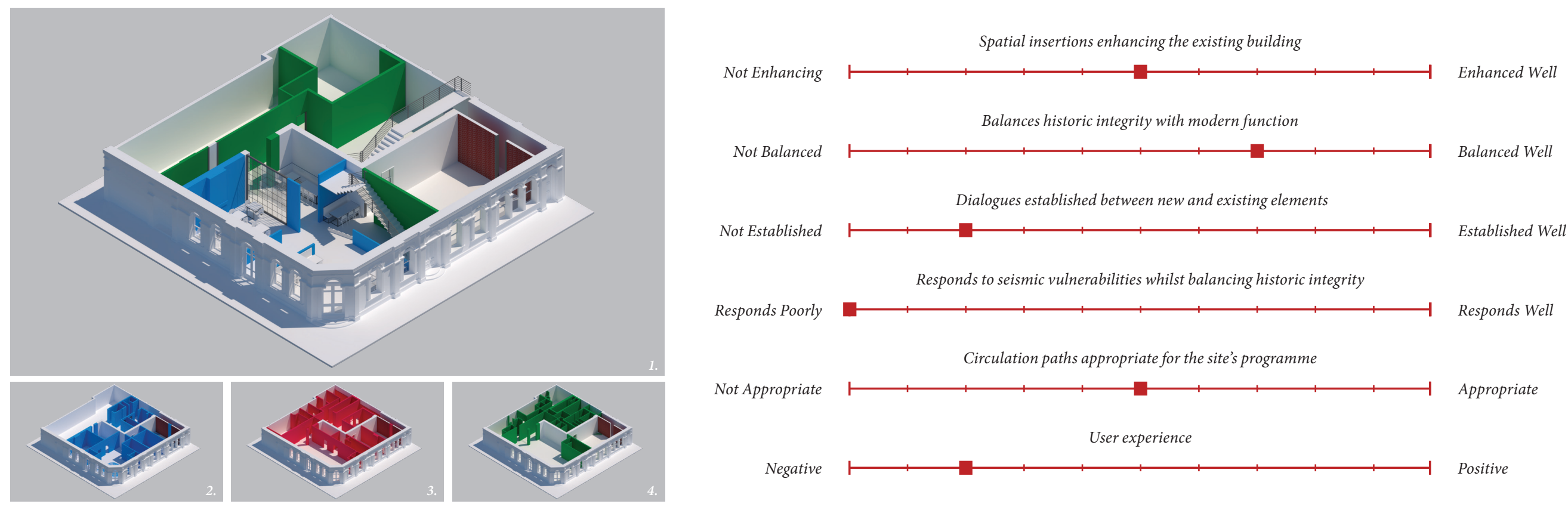

1. Amalgamation of Previous Interior Walls.
2. Ground Floor Plan $~ 1899$.
3. Ground Floor Plan $\sim 1957$.

4. Ground Floor Plan $\sim 1995$. 


\section{DESIGN ITERATION 3}

Variations of steel moment frames applied within the site.

Building on prior seismic mitigation research outlined in Chapter Three, various configurations of steel moment frames were inserted within the space. The steel moment frames were implemented to not only help mitigate the site's seismic vulnerability in a reasonably non-invasive way, but by exposing them, sees the contras between the new structural layer begin to form a dialogue between the different stratas of the building's history. Each variation has been developed based on the existing known elements within the space such as entrances, windows, load-bearing walls, and stairwells with as much consideration as possible given to how they affect both the space plan and circulation paths of the spaces. However, considering both in-plane and out-of-plane forces that will be placed on each of the outlined masonry walls, it should be noted that some of these variations would likely be inadequate in transferring the seismic forces or, there is simply too much structural steel that would drastically alter how the building responds to an earthquake.

The challenge with this iteration was how the supportive steel beams positioned centrally within each of the spaces are developed into the ever-evolving interior architecture. Simply, their positioning affected the space plan and circulation paths and therefore one's user experience. As the design builds up however, interior walls, partitions, furniture and alike have the means to reduce its influence on the space. 

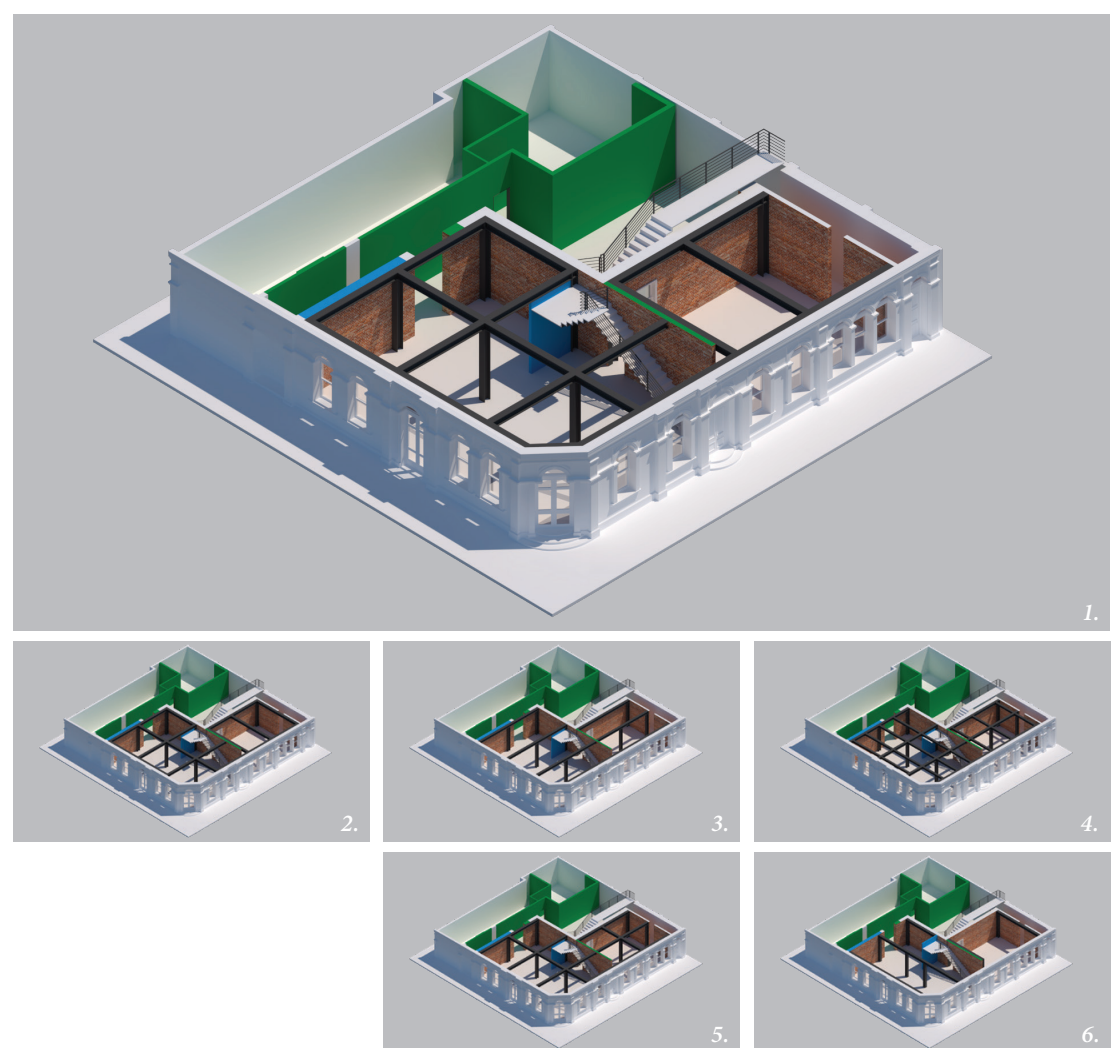

Spatial insertions enhancing the existing building

$$
\text { - }
$$

Balances historic integrity with modern function

Not Balanced

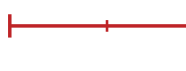

Not Established

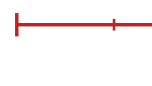

Responds to seismic vulnerabilities whilst balancing historic integrity

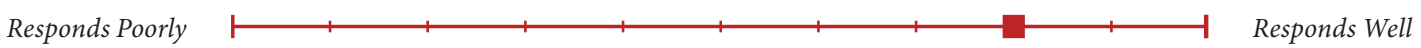

Circulation paths appropriate for the site's programme

Not Appropriate

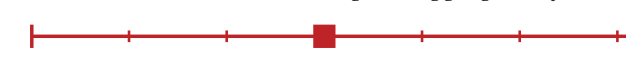

User experience

Negative

\section{Enhanced Well}

Balanced Well

Established Well

Responds Well

Appropriate

Positive

Steel Moment Frames $\sim$ Variation

Steel Moment Frames $\sim$ Variation

Steel Moment Frames $\sim$ Variation

Steel Moment Frames $\sim$ Variation

Steel Moment Frames $\sim$ Variation

Steel Moment Frames $\sim$ Variation 


\section{DESIGN ITERATION 3.1}

Wrapping the exterior masonry with fibre-reinforced polymer (FRP) laminates.

This iteration explored the effect of applying fibre-reinforced polymer laminates to the exterior faces of the site's masonry façade. The risk was that if left without strengthening, the load-bearing masonry wall may fall outwards and cause a partial, or total collapse of the building. Due to the laminates being either a carbon or glass makeup, with a fibre orientation that were either unidirectional or biaxial, the laminates dramatically altered the exterior appearance and character of the site's façade and in doing so, impacted the site's historic integrity. However, it is a non-invasive application that could be painted or covered. FRP laminates are bonded to the wall surface similar to that of wallpaper, so in essence, this mitigation strategy took an interior technique and applied it to the exterior of the building.

Applying the laminates did not retain the integrity that the current masonry façade possesses, having the ability to cover the laminates opened up the possibility of incorporating a motif that referenced the site's history and subsequently allowed for the reading of the building in a new light. In short, what this iteration sought to question, which was ultimately decided against and then put aside, was whether or not losing the site's historic integrity and character to increase its seismic resilience through a contemporary interpretation of the building was worth it. 

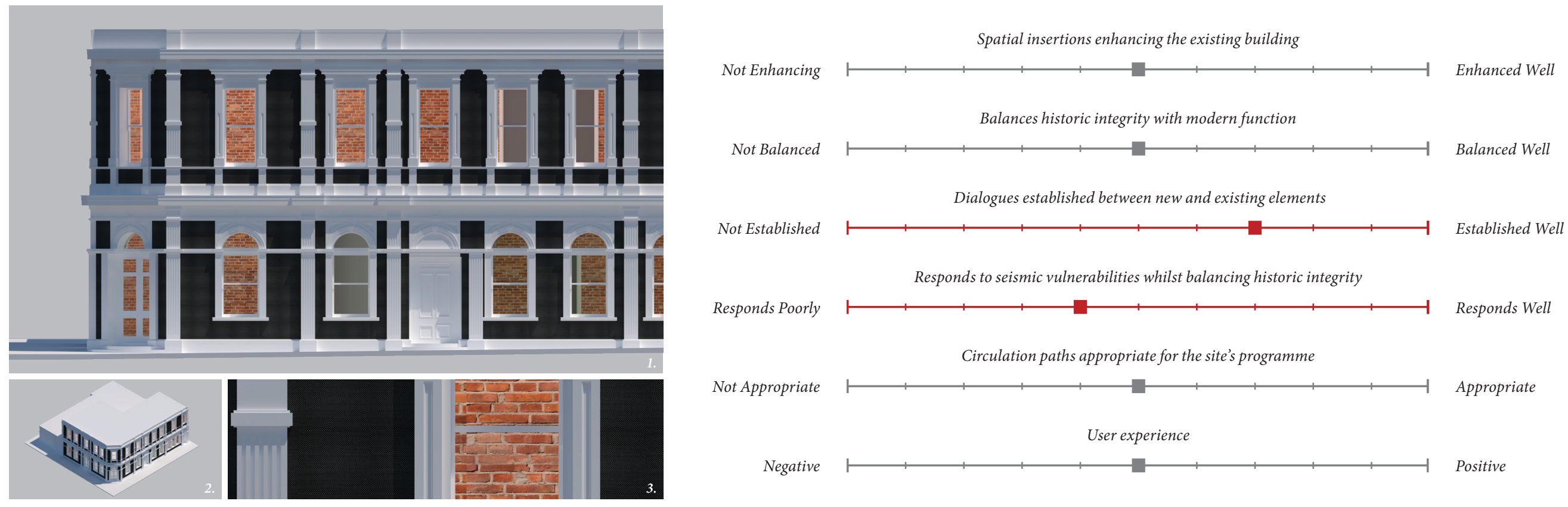

1. Drummond Street Elevation illustrating how the use of FRP dramatically changes the look of the building's façade.

2. FRP laminates cover the building's exposed masonry facade. 


\section{DESIGN ITERATION 4}

Initial explorations with steel moment frames implemented.

Focusing back on the interior, this iteration explored how the steel moment frames impacted the interior space plan when furniture and other elements were introduced. The iteration retains a number of reintroduced walls which are articulated through the use of colour, however, the walls that have been retained at this stage are few and far between. Due to the nature of the space, the numerous windows and entrances, and the steel members littered throughout, the incorporation of booth seating was one way that could improve the layout of the space by providing a cleaner alternative to seating along a reintroduced wall. Incorporating a variety of different seating types will be required to better adhere to the site conditions and provide a means of visual interest for diners. The iteration has also retained the window and door detailing that was developed in the first design iteration in order to make small, subtle references to the period and style in which the site was built. Contrasting these subtle cues with a contemporary rehabilitation of the space seeked to develop an interior aesthetic that is welcoming whilst paying homage to the building and its history.

The insertion of previous wall positions barely enhanced the building, and like the second design iteration, their positions were not developing an effective space plan or circulation paths leading to fragmented subspaces. Again, like previous iterations, there was a poor dialogue between new and existing elements as there was no differentiation due to their style, language, materials, and character being the same. As Brooker and Stone (2004) explain, the dialogues between new and existing elements are at their strongest and most surprising when their features and language are different. Another aspect of the iteration that needs to be addressed is a rethink of how circulation could be enhanced and how that could then influence how the space operates and is planned out. 

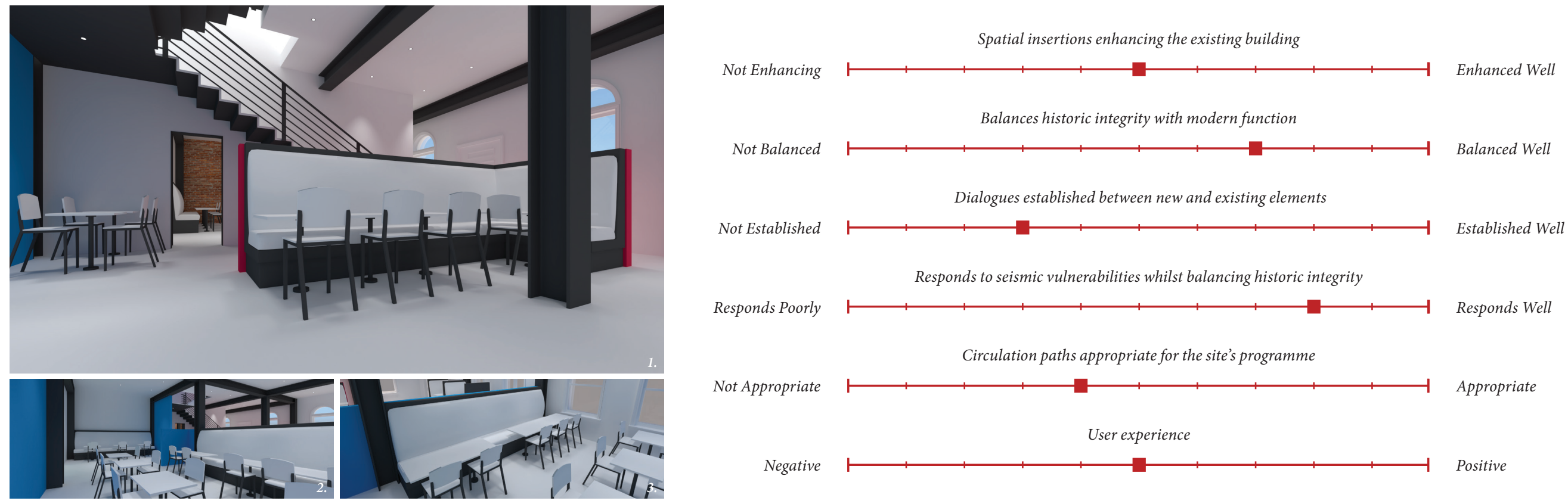

Seating options developed based on the reintroduced walls and structural elements within the space

Space plan further informed by reintroduced walls and structural elements.

3. Ibid. 


\section{DESIGN ITERATION 5}

Series of iterative explorations that begin to inhabit the space.

The next several iterative variations, of which only a few are shown, sought to begin to inhabit the space following an improved steel seismic strengthening configuration and new accessible interior and exterior staircases introduced within the space. These shifts in the design improved the utilisation of available floor space on the ground floor. Inserting two accessible staircases within the site not only enabled the design iteration to become more inclusive, but it also sought to facilitate a more positive user experience. The newly inserted interior staircase enhance the existing building by forming an arterial route from the first floor to Drummond Street, greatly improving circulation throughout the building. The new staircases will repurpose timber taken from the existing staircases and integrate it within their treads to make reference to the building's history. This aspect is not articulated in the renders however, and therefore diagrammatic drawings will need to be undertaken to represent this shift.

In an attempt to make reference to the building, its history and its grandeur, a range of tufted furniture were developed and, or, sourced as a means to help develop an interior aesthetic that both complemented, and contrasted the introduced steel. However, all of the variations lacked character and looked very similar. They were uncreative and stark, and the dialogue that formed between the furniture choices, reintroduced walls, and the new seismic frames was not strong enough. Furthermore, even with improved circulation, the numerous entrances to the building continued to fragment the interior circulation paths. This also made the dining tables become either too cluttered, or too dispersed which lent little to positive user experience. In short, too much was caught up in trying to develop an effective space plan that the character, visual interest and meeting other criteria went lacking. A step back and subsequent rethink had to occur in order to better align future iterations with the reflective criteria. 


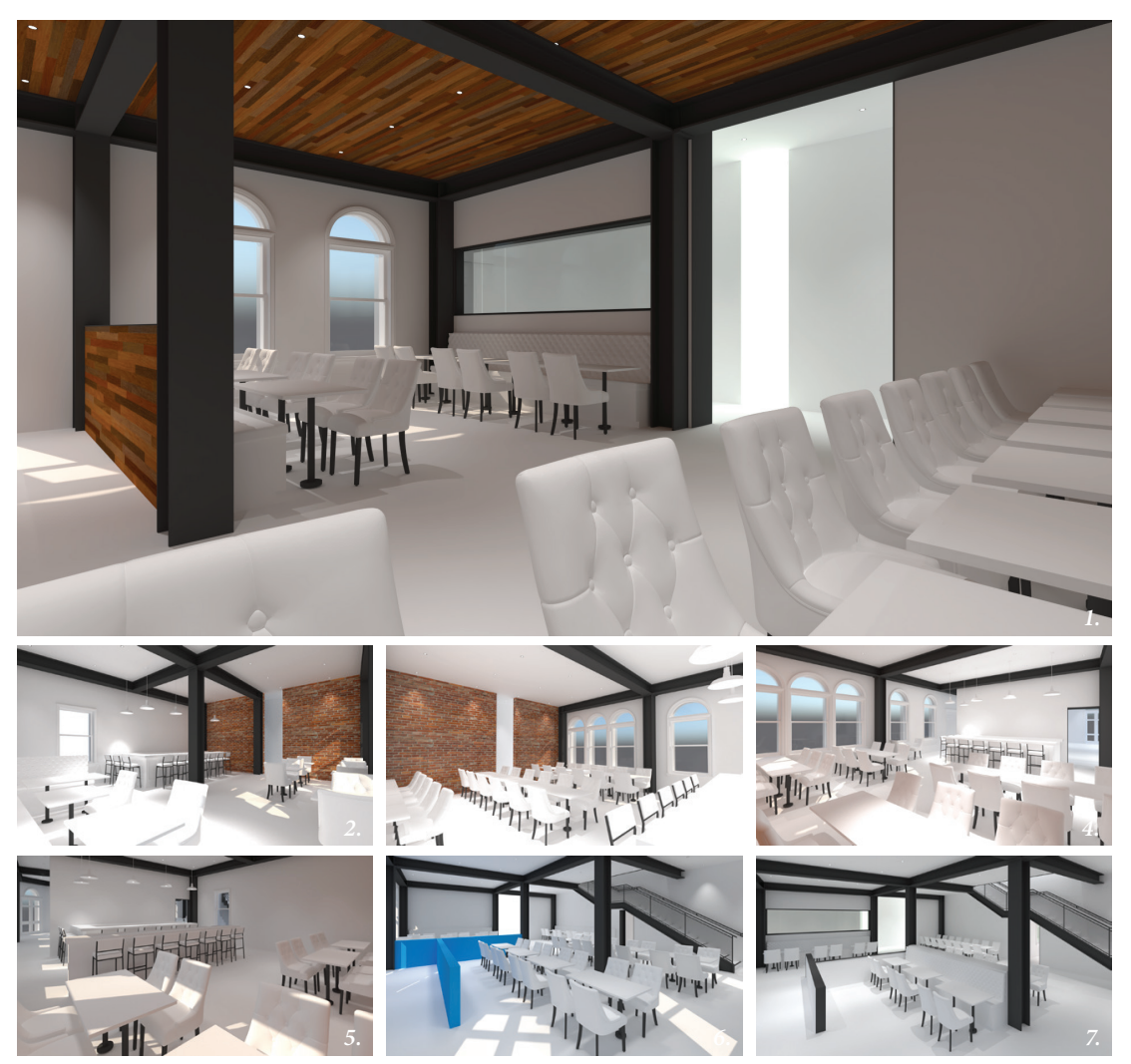

Incorporating partition walls based on previous wall positions to develop dining areas whilst maintaining open feel of the overall space. Developing the restaurant bar. Seating is developed around maintaining a circulation path through the space.

3. Rearranging the space plan to accommodate more diners in the space.

Rearranging the space plan and moment frame configuration to lessen disruption on the circulation paths through the space.

. Central island bar incorporated to increase variance within the space without impacting circulation paths.

- Space plan focused on accommodating a large number of diners. Interior walls incorporated to help develop circulation paths and

guide diners as they enter and exit the space.
Spatial insertions enhancing the existing building

Not Enhancing

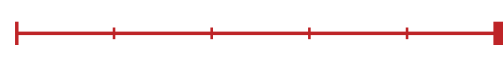

$$
\text { - }
$$

Not Balanced

Balances historic integrity with modern function

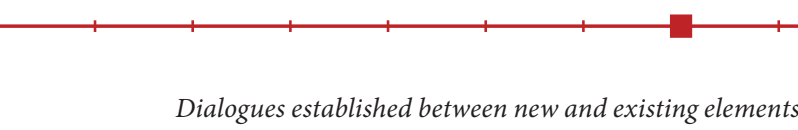

Not Established

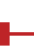

Responds Poorly

Responds to seismic vulnerabilities whilst balancing historic integrity

\section{(a)}

Not Appropriate
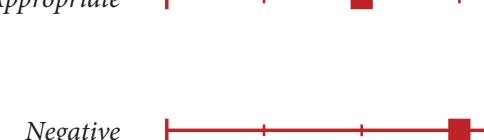

Established Well

Balanced Well

Responds Well

Appropriate

Positive 


\section{DESIGN ITERATION 6}

Projection mapping to overlay exterior façade elements onto the interior faces.

Taking a step back and looking at the research from a different perspective, this iteration attempted to explore how the building's narratives could be visually expressed through a digital medium to potentially inform a new direction for the project. Although this iteration did not adhere to the majority of the reflective criteria, through projection mapping, this iteration sought to overlay the line work of the exterior façade elements across the interior walls. The projection worked out pretty much how it was intended, however the workflow between Sketchup and Autodesk 3ds makes this method both thoroughly time consuming and fiddly. This method requires both the cameras in Sketchup and $3 \mathrm{~d}$ s to align so that there is no distortion between the linework taken from Sketchup, and the projection and rendering in $3 \mathrm{ds}$.

In terms of forming a dialogue between new and existing elements it was the most promising idea to date. However, the way in which it is represented and subsequently visualised needed work. Due to the workflow issues, it was decided that this concept would not be taken any further for this thesis. If it were to be progressed further though, whether it is the building's intangible stories, its construction makeup, or something else entirely, how the narratives of the building are then extended into its interior architecture to develop a space plan requires a lot of consideration. 

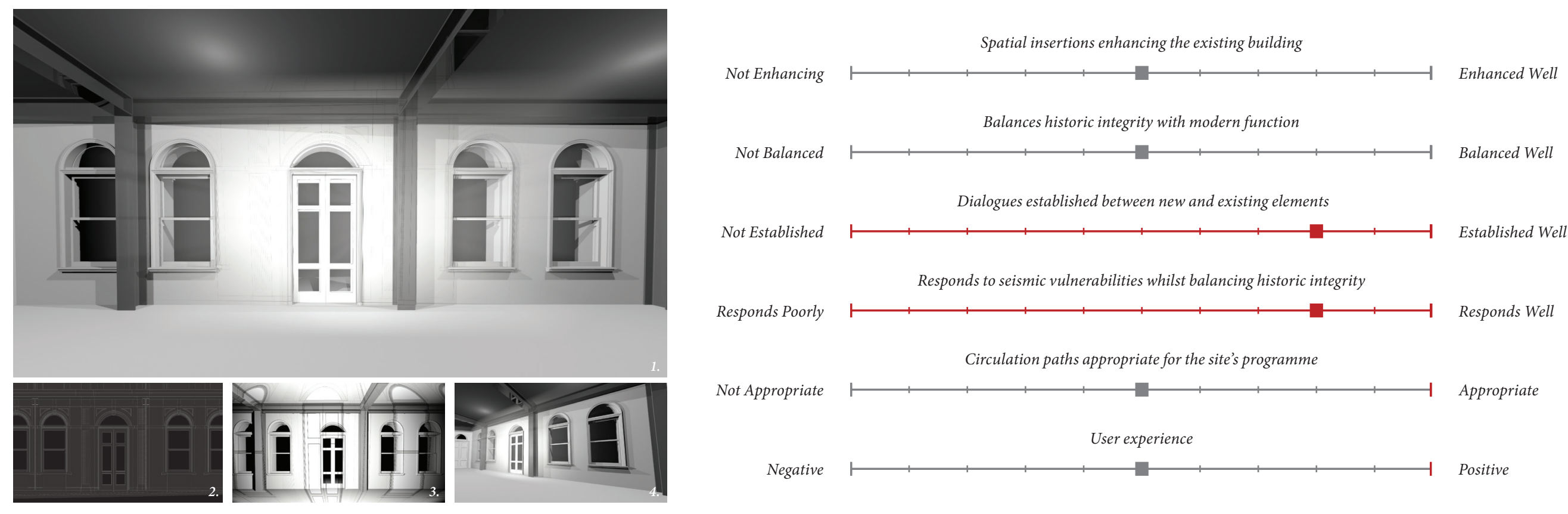

1. Projection mapped onto the interior wall faces however with a slight distortion.

2. Linework taken from model to project on to interior faces.

3. Adjusting the aspect ratio in an attempt to not stretch the projection.
4. Perspective showing the projection on the interior wall faces and detailing. 


\section{DESIGN ITERATION 7}

Exploring how exterior qualities can be introduced into the interior in an attempt to express narratives of the space.

Again, looking at the site's narratives, this iteration sought to create a tangible response to the violent, trouble spot that the site and the surrounding area became known for during the 1970's and beyond. By introducing exterior elements and qualities within the space it sought to evoke a literal response. Through the new spatial insertions, circulation paths were improved via the incorporation of new interior walls to guide those who enter through either the accessible, or main entrance to a singular area to be seated. In conjunction with the newly designed arterial staircase from the previous design iteration, the newly formed circulation paths also improve the flow of people throughout the space and thereby allowing for a better dining experience. Also, by extending the interior walls to the first floor ceiling, it not only changes the interior aesthetic and atmosphere dramatically, they also have the means to double as internal shear walls to add further seismic strengthening to the site.

Even without materiality and lighting introduced, the space begins to adopt a character and visual interest that previous iterations lacked whilst developing interesting dialogues between new and existing elements. However, the concept of incorporating exterior qualities that begin to allude to dark alleyways or similar unsettling areas is simply not strong enough. It lacked the conceptual rigor that is required to make this a convincing design response, it raised more questions than answers about the interior decisions and, it attempted to, but did not express the narratives or traces of the building's history clearly like it intended. Although this iteration lacked strength conceptually, it was useful to go on a tangent to develop and visualise a new interior space plan. In turn, it generated new perspectives of the site and what could be achieved internally that hadn't been considered before. 

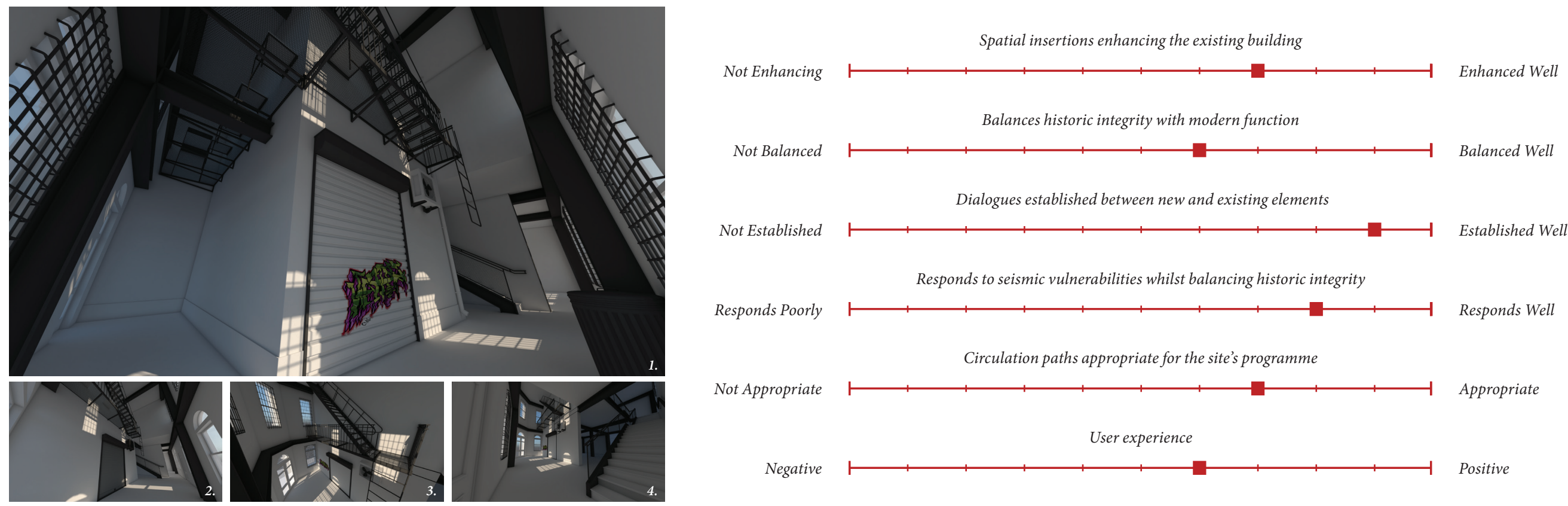

Rearranging the interior walls from the earlier versions to incorporate more exterior qualities and dining areas whilst also developing a circulation path beginning at the accessible entrance.

列 the sense of scale and atmosphere within the space.

4. Illustrating how the perception of space changes with the walls extended to the ceiling rather than simply to the first floor. 


\section{DESIGN ITERATION 8}

Fusing modern and traditional architectural styles.

Another step back and re-evaluation occurred prior to undertaking the next iteration. Looking back at previous iterations and through discussions with peers, the fusion of historic and modern architectural influences was identified as a being a core driver for the project. In response, this iteration explored how fusing the contemporary, seismic strengthening layer of the steel moment frames with ornamental detailing can begin to reimagine the space. The iteration exhibited some nice qualities, however, it lacked an effective space plan and enough modern influences to compensate with the historical ones. So similar to the first design iteration, the design read more as a restorative project rather than a rehabilitative project which is not the aim of this research project. 


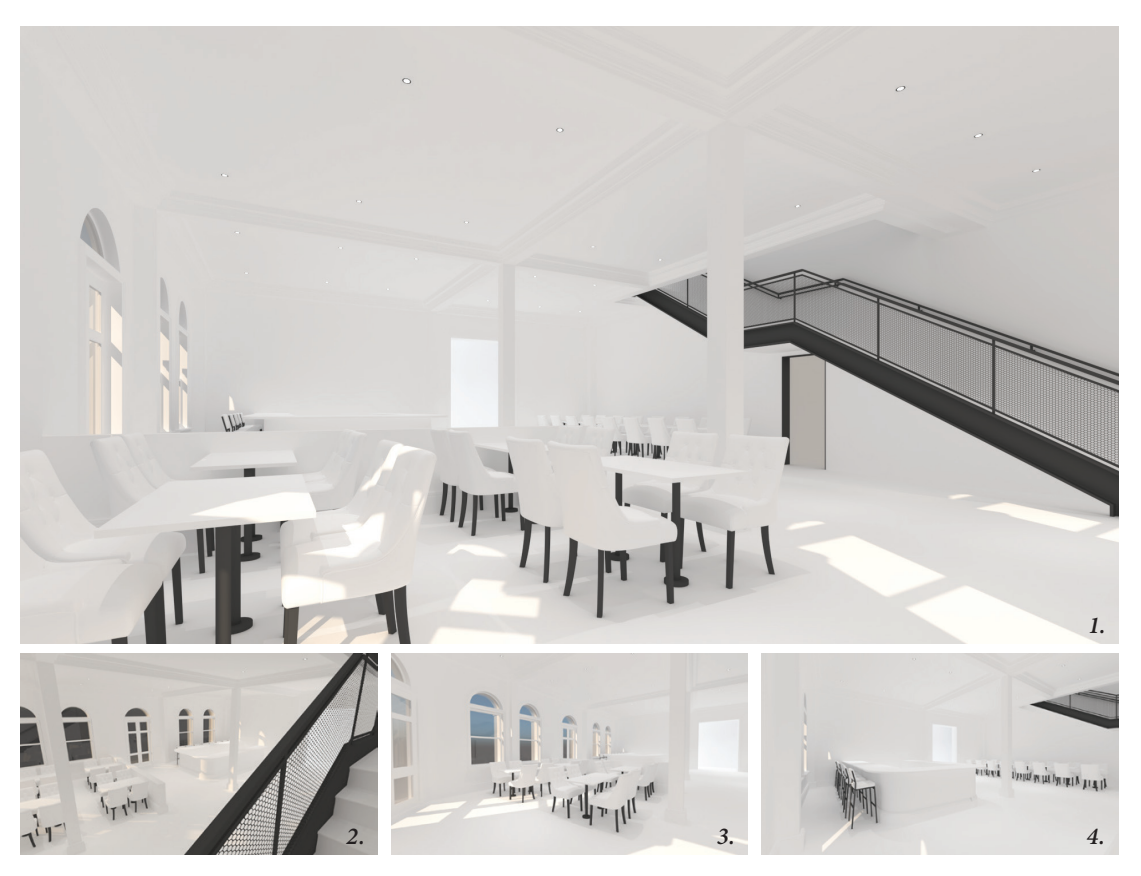

1. Interior perspective illustrating the ornamental detailing around the steel frames.

2. Interior perspective.

4. Investigating a new placement for the large bar and how that impacts the circulation paths.
Spatial insertions enhancing the existing building

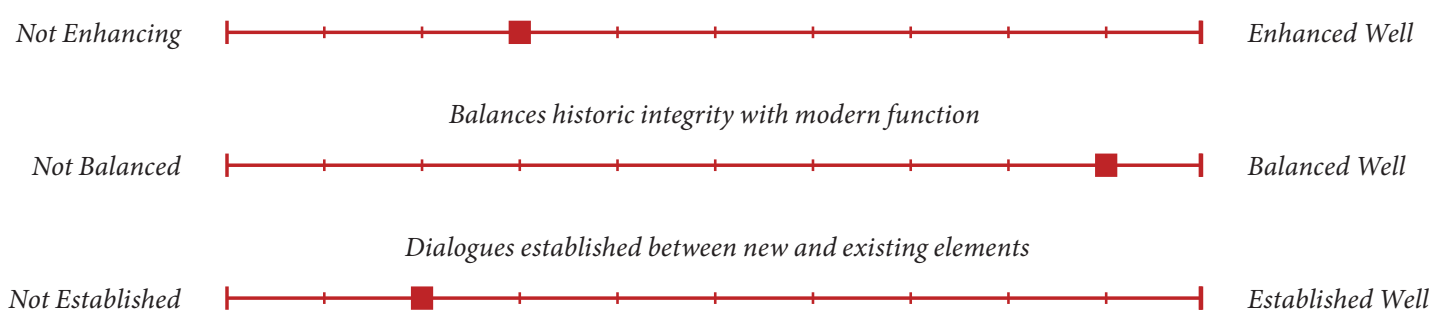

Responds to seismic vulnerabilities whilst balancing historic integrity

Responds Poorly

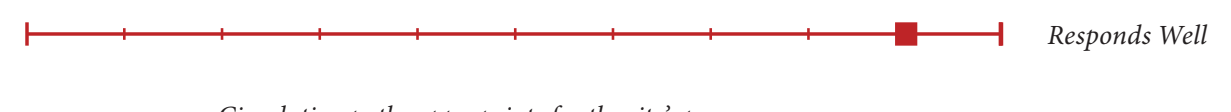

Circulation paths appropriate for the site's programme

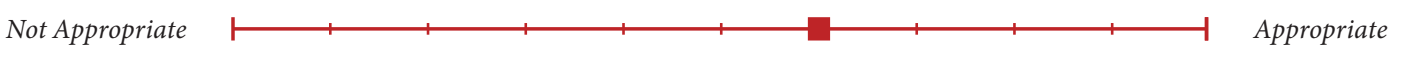

Negative 


\section{DESIGN ITERATION 9}

Slicing the building and inserting new built elements.

In an attempt to break the conservatism of the majority of the iterations to this point, a more radical approach was actioned. This iteration explored how slicing the building and inserting newly built elements could influence the reading of the site. Two variations were explored, the first looked at maintaining the site's historic façade with new elements inserted behind it, and the second, removing part of the façade and juxtaposing the two architectures next to one another. Using the façade as a starting point was useful as it allowed to quickly test the idea of this iteration without spending time developing the interior. Through evaluating the iteration what became clear was that although the juxtaposition between new and existing architecture styles evoked interesting dialogues, the iteration went too far in which the historic integrity of the building suffered. 

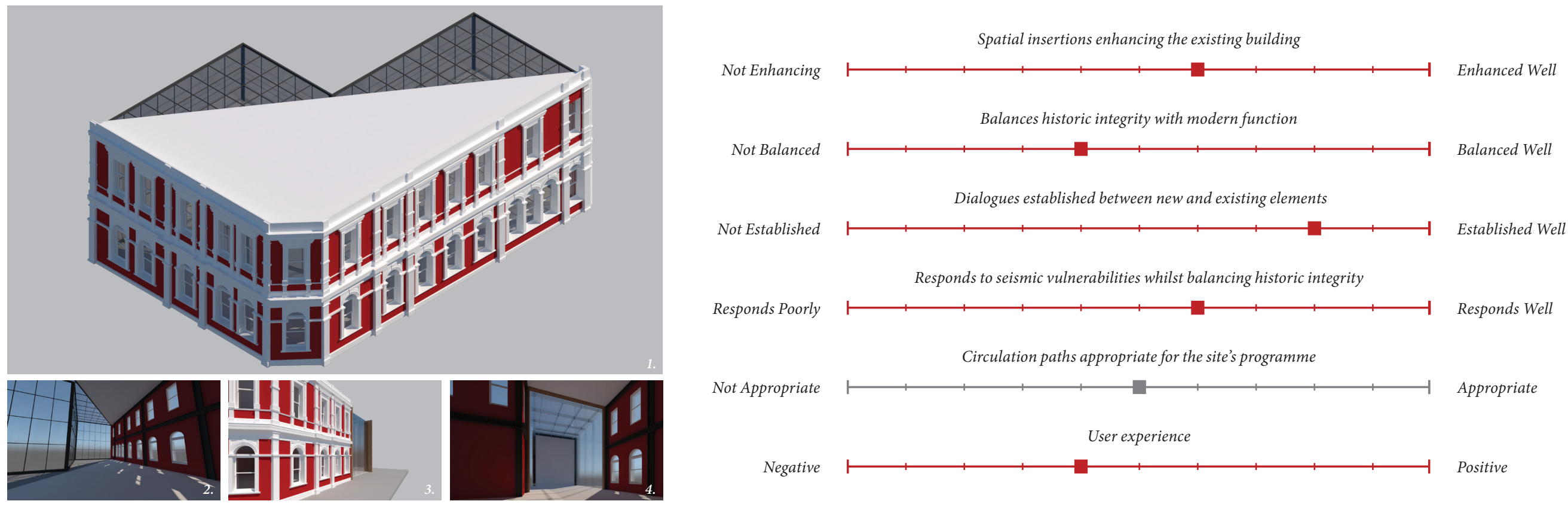

Isometric illustrating the slice through the building and the inserted glass structure behind.

The new and old architectures converge.

a dialogue through the juxtaposition of the two architecture styles.

The new and old architectures converge. 


\section{DESIGN ITERATION 10}

Slicing and folding façade elements due to the insertion and outward shift of newly built elements.

Progressing from the previous iteration and with further thought and discussion with peers, this iteration sought to focus the radical changes to the existing building in a more 'surgical' manner. Through slicing and folding the façade elements, new additions could be inserted and then shifted outward to take the place of the façade. Using the nature and rhythmic elements of the façade as a guide, logical slice points were identified in order to fold it as desired whilst maintaining the building's historical integrity. As Peter Dedek explains, "historic integrity is the degree to which a property has retained its original historic features. To have integrity, a building has to look similar to the way it did when it was constructed or at least resemble the way it looked during its period of historical significance" (2014, p. 97). Although sections of the façade are folded either upwards or downwards to accommodate the newly built elements, unlike the previous iteration, the façade and the building can still be read as originally designed however with a contemporary twist.

It is my belief that a historic building can be altered quite radically as long as care is taken to preserve the building and its integrity, and, that the character of the two architectural styles, if new built elements are added, are balanced equally. In essence, a rehabilitated or adapted historic building could be considered as a form of 'new historic'. In the case of this design iteration, the design improved in all criteria from its predecessor, however, the form and language of the new insertions were simply too dominant and were overshadowing the historic façade. 


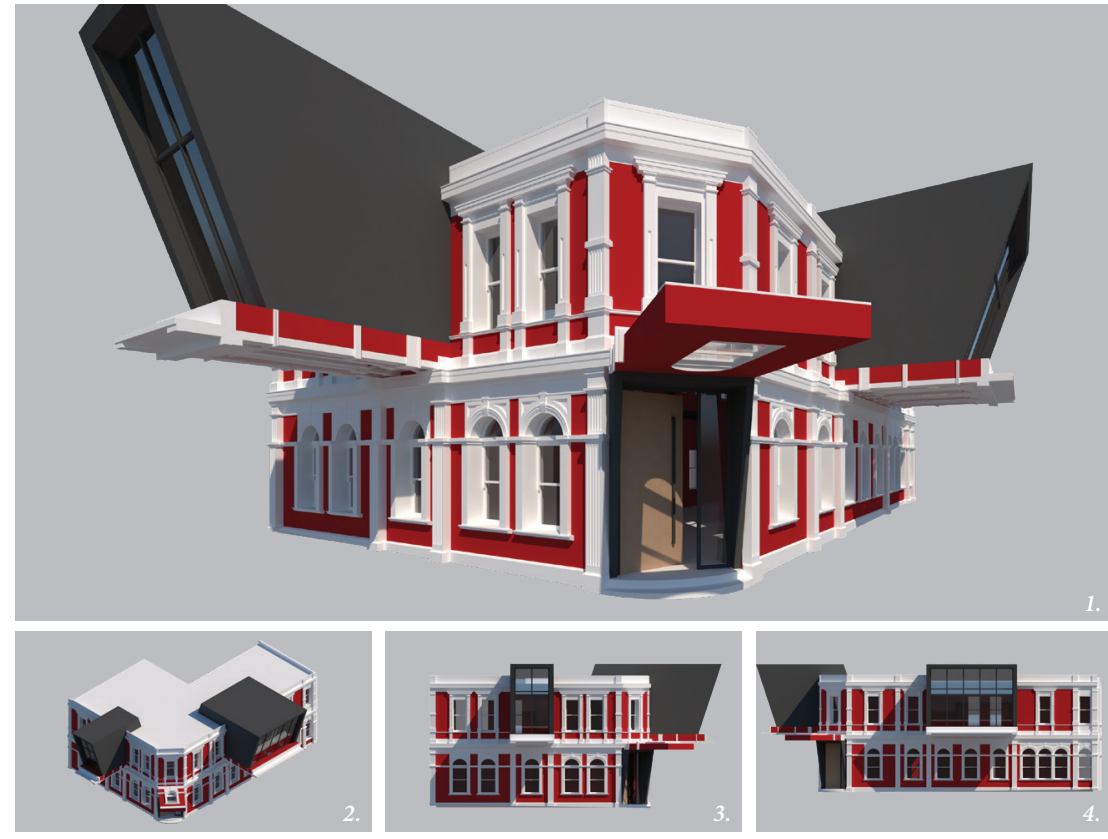

Perspective illustrating the new elements shifted out of the confinements of the existing building and the facade elements folding to compensate.

Isometric illustrating the different languages the two architectures have.

4. Elevation from Adelide Road.

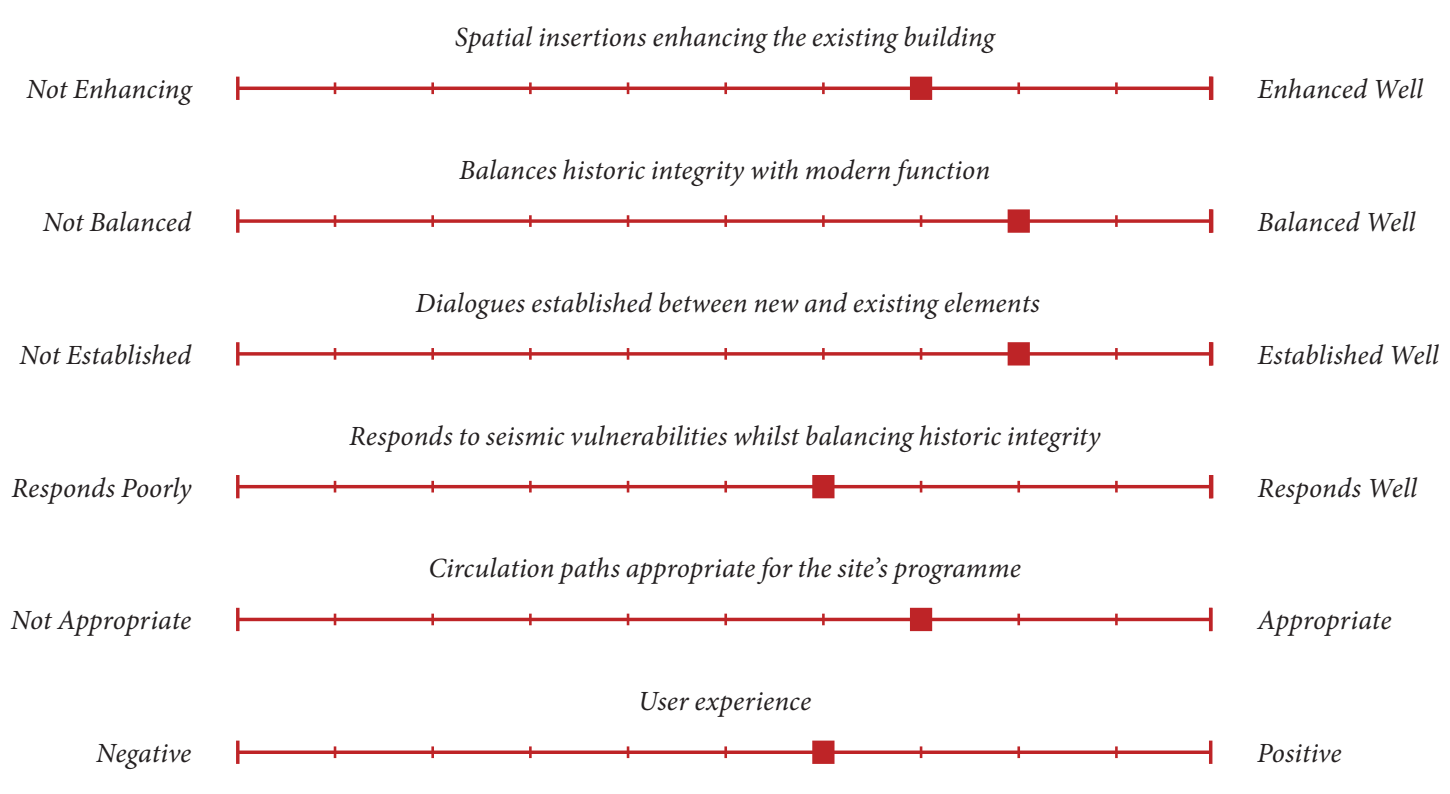




\section{DESIGN ITERATION 11}

Refining the form of the façade and new, shifted built elements.

With the direction decided, this iteration sought to refine the form of both the façade, and the newly inserted additions. Hence, cuboid forms were chosen with windows strategically cut and positioned to capture certain views surrounding the site. The folded façade was also refined to better match the width of the sidewalk so to not interfere with vehicular traffic flow, to make it more structurally viable and, to provide further visual interest and dialogue between the two architectures. Even though the juxtaposition between the two architectural styles is still quite pronounced, the simplistic form of the contemporary insertions enabled both the historic and the contemporary elements to stand on their own without one becoming subservient of the other. Their relationship and the subsequent tension that is formed helps to "strengthen and reinvigorate the existing building allowing it to be looked at afresh, as though new life had been drawn into it" (Brooker \& Stone, 2004, p. 102).

Like the previous iteration all but one entrance has been removed in order to form a singular entrance to the building. This coupled with the load bearing interior walls that support the inserted function rooms whilst dividing the interior, have formed more appropriate circulation paths for the space. Also, in order to make the most out of the building's interior footprint for a patron's dining experience, it was decided that the kitchen and ground floor restrooms would need to be housed in an extension outside the confines of the former Tramway Hotel. By doing such, this will also enable a secondary, or fire exit to be inserted in the case of an emergency. Overall, this iteration improved on its predecessor, however, with the insertion of the newly built function rooms, the iteration required another seismic strengthening system to be designed and implemented to accommodate such. 


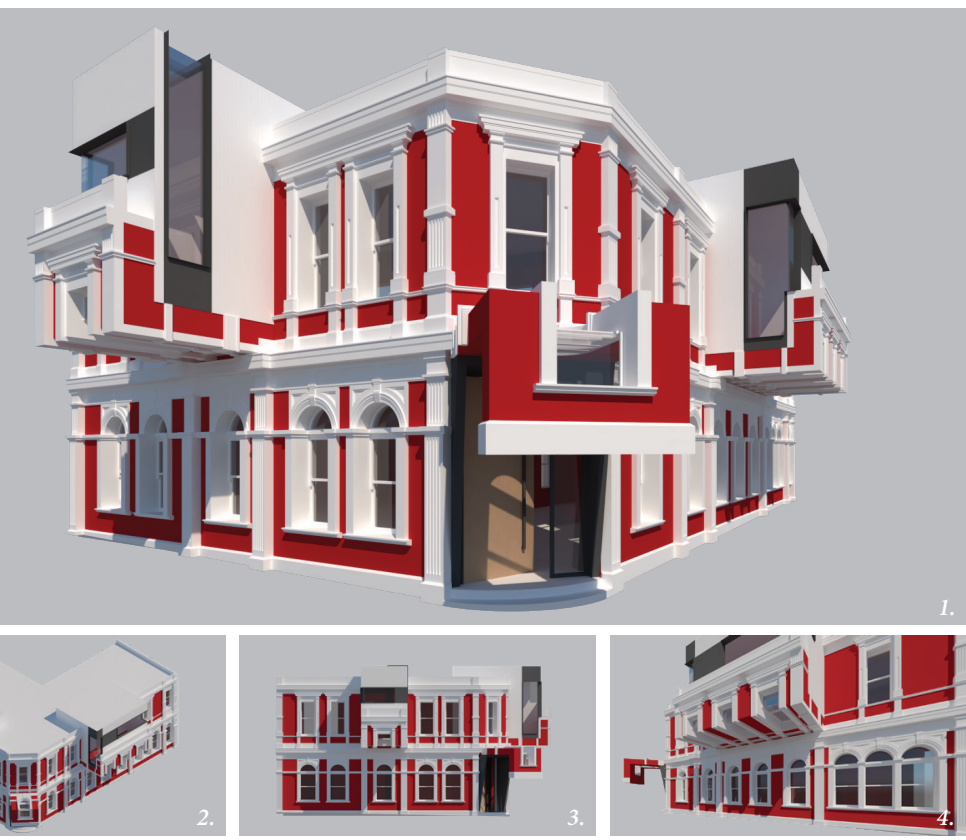

Perspective illustrating the refined newly built elements which has resulted in a more balanced juxtaposition between the two architectures.

Isometric illustrating the different languages the two architectures have.

4. With the refinement of the folded facade, new interesting perspectives develop both internally and externally.

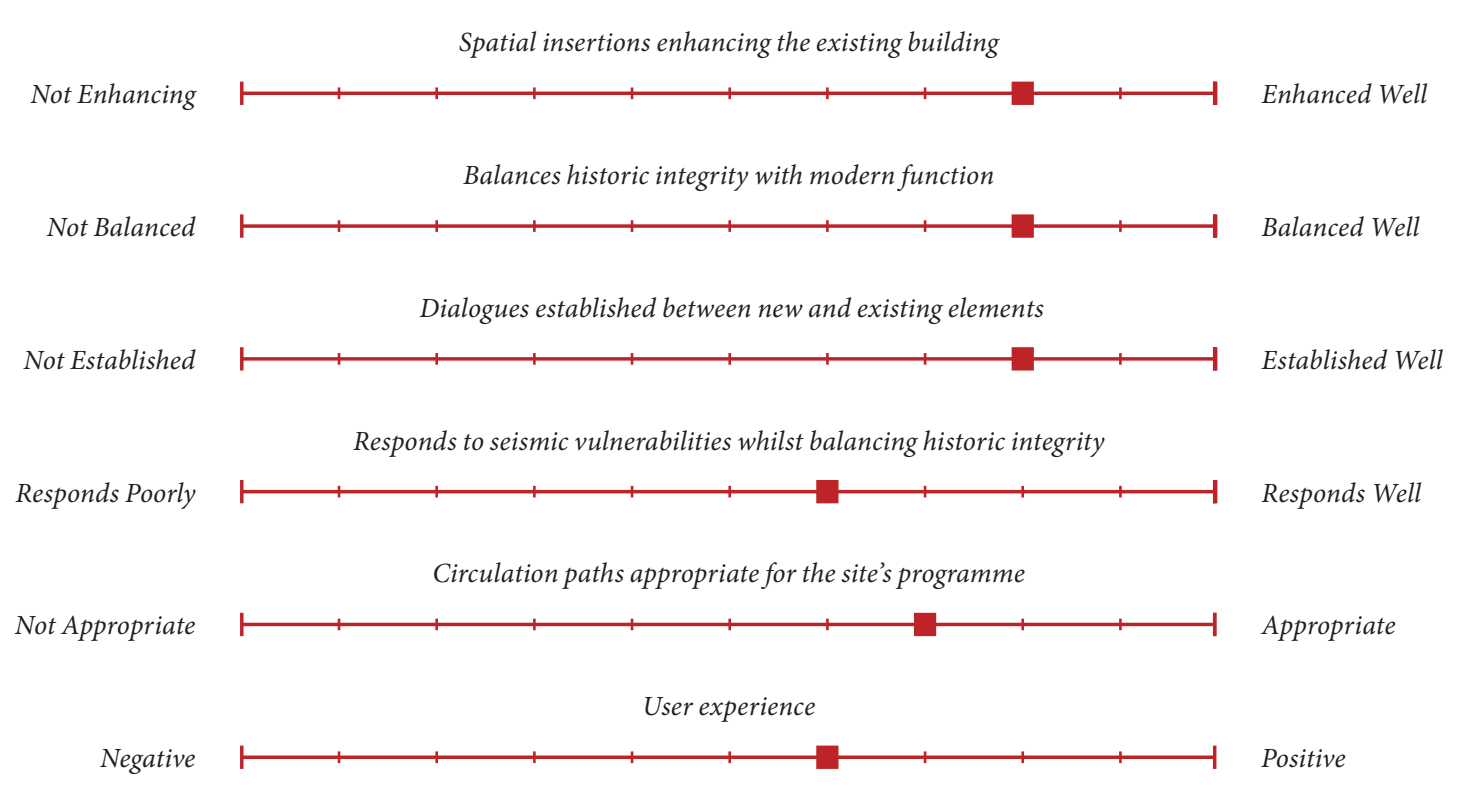




\section{DESIGN ITERATION 12}

Series of interior shots as the design response developed.

The next several iterations, again of which only a few are shown, document the process in developing an effective space plan and circulation paths, the interior aesthetic, and ambience within the site as I worked towards the final design proposal. The existing brickwork was embraced throughout the interior which saw new elements, materials and lighting introduced that sought to enhance this relationship. With this addition of materiality and lighting, the building developed a character that had been lacking in previous design iterations and thus would improve a diner's experience.

The layout of the space was developed around accentuating the key architectural shifts within the building such as the large voids that were left behind following the outward shift of the new function rooms. The voids form a visual connection between the first and ground floors improving light dispersion and visual interest for diners whilst always conveying the notion of the architectural shifts. The new function rooms have been designed to provide a point of difference from other dining areas by providing various seating and lighting alternatives. Albeit the new insertions form clear and interesting dialogues with the exterior façade, on the interior it was not the case. Therefore, the interior wall treatments required further thought in order to better articulate and reflect the difference between the two architectural styles.

Lastly, as mentioned in the previous iteration, this iteration also saw the reintroduction and then adaptation of the site's boundary walls, and exterior courtyard to accommodate for the kitchen and ground floor restrooms as well as a fire exit. 

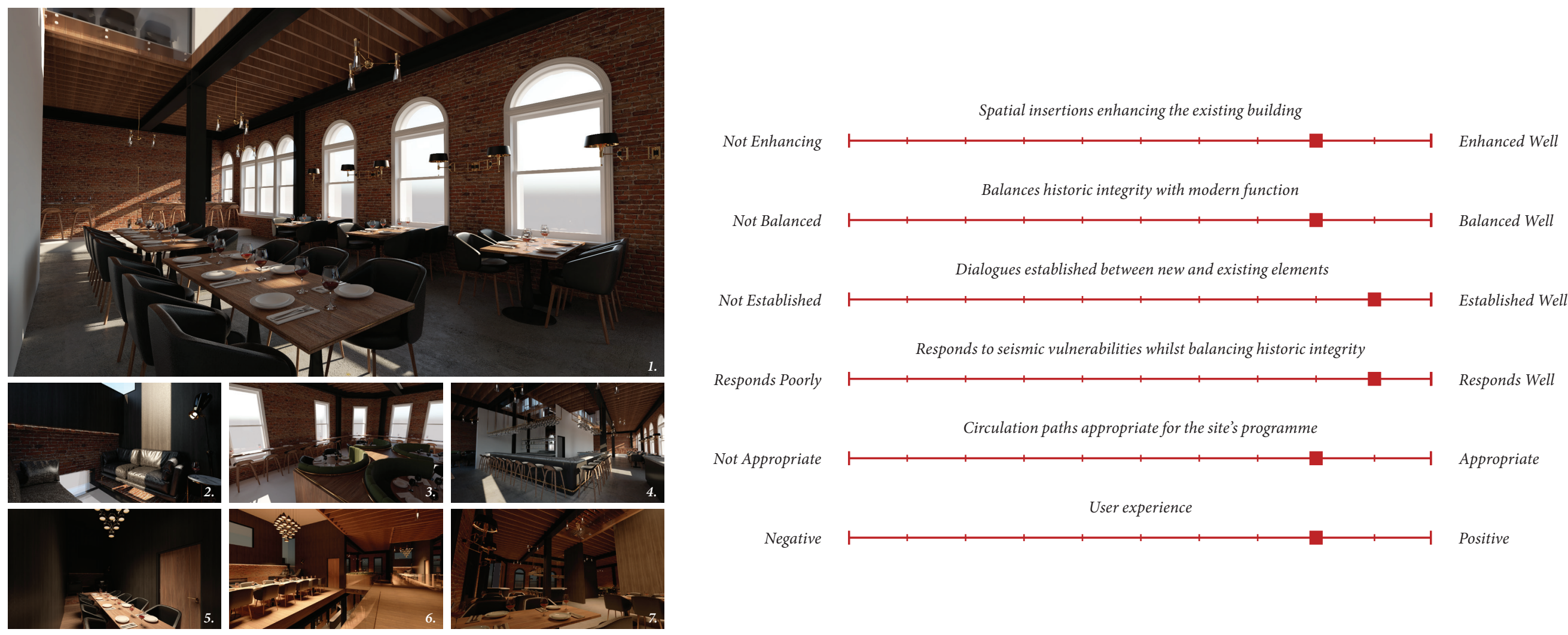

Early rendering with both furniture and lighting fixtures introduced.

Close-up of the shifted Adelaide Road finction

Incorporating booths and high tables to mane the most of the space plan.

6.

lining within the Adelaide Road function room.

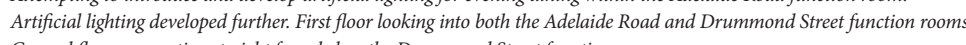

Ground floor perspective at night from below the Drummond Street function room. 
Are new spatial insertions enhancing the existing building?

Does the design balance the building's historic integrity with modern function as per the goal of rehabilitation?

With the insertion of new built elements, are clear dialogues established between the new and the existing?

Are the seismic mitigation strategies inserted sensitively to address the building's seismic vulnerability whilst retaining its historic integrity?

Are the circulation paths appropriate for the site's programme?

Are the architectural elements within the design such as materiality, light, and the space plan helping to facilitate a positive user experience?

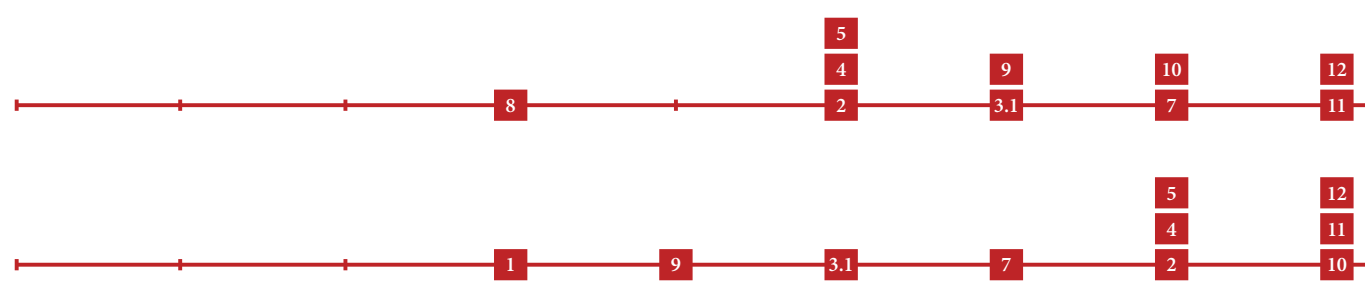

$\frac{12}{11}$
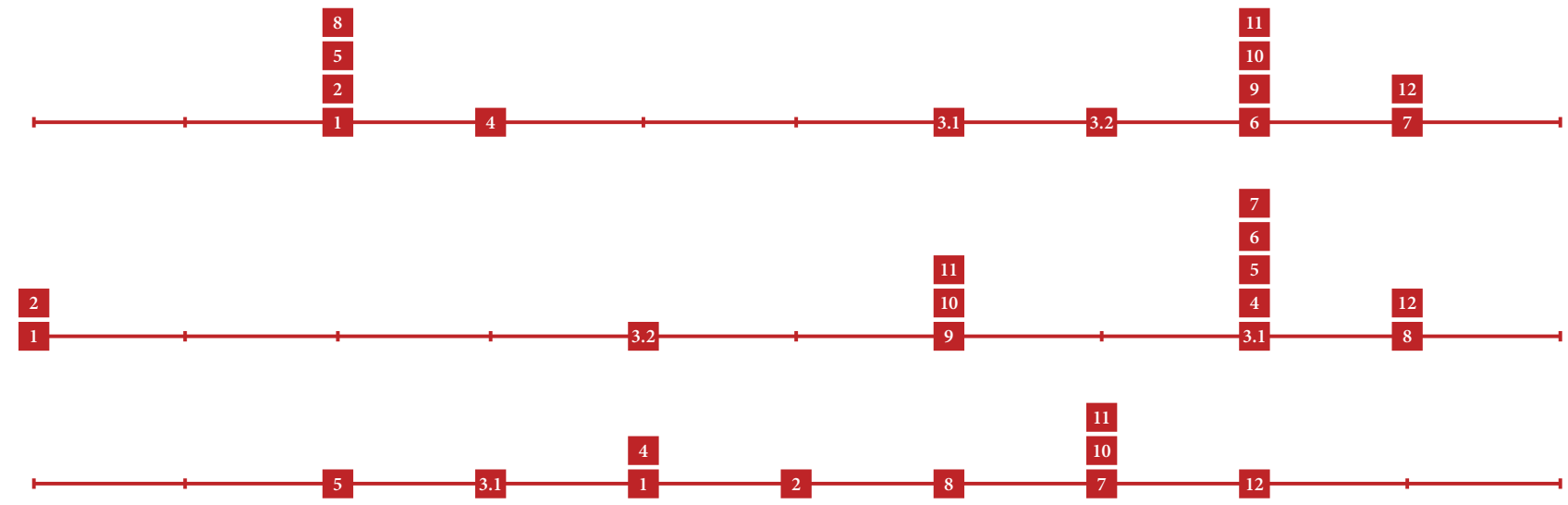

$\frac{9}{\frac{6}{3.2}}$

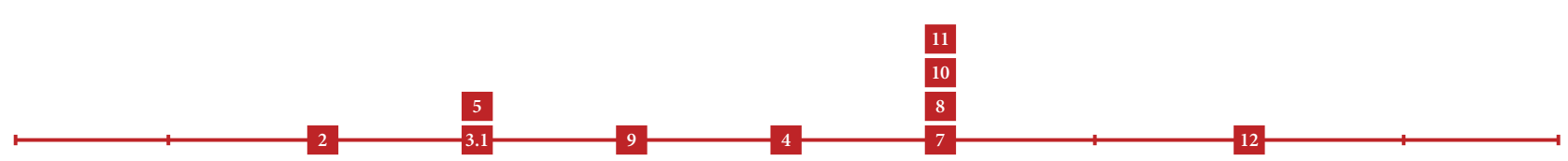

\begin{tabular}{|c|}
$\frac{6}{3.2}$ \\
\hline 1 \\
\hline
\end{tabular} 


\section{4 - CRITERIA REFLECTION}

So, by taking each of the iteration reflections and mapping them against one another and the criteria,

what begins to emerge are the strengths, weaknesses and gaps in the design work produced. Generally speaking, it can be observed that for the most part, with each iterative development and improvement, the execution against each of the criteria also improved. There is still definite room for improvement against all criteria, however, the design has improved immensely from where it started.

The stripping of interior qualities such as materiality and textures throughout the iterative process may have been purposeful for both limiting file sizes, and to allow focus on exploring the ideas of each iteration without getting too caught up in how it looked. However, on hindsight, this has also been somewhat of a hindrance on the project as the interior qualities within the space lacked a thorough exploration. By exploring these qualities throughout the iterative process a more imaginative and compelling interior may have developed. This would have likely lent itself to facilitating a more positive user experience which was one criteria that was poorly executed throughout the project.

Developing appropriate circulation paths for the space was also poorly executed throughout the project. Due to the fact that this the building is being rehabilitated into a two-storey restaurant and bar and therefore will see a large volume of foot traffic moving through the space, circulation paths should have been one of the main focuses throughout the development of the design iterations. There was a hesitancy in early iterations of not wanting to remove any of the numerous entrances to the building, however, in order to alleviate the subsequent fragmentation of interior subspaces, this should have occured much sooner. Effective circulation paths could have then been developed and less time would have been wasted trying to make all the entrances work internally. Generating diagrammatic drawings would have also been useful as they would have not only helped express the depths of my understanding of the building, but by evaluating potential foot traffic throughout the space at different times of the day, it would have helped inform what was needed, or not needed within the design to guide patrons and staff through the space more efficiently. If anything, these diagrams would have further supported and explained my method and thinking behind design decisions especially for elements and details that required more commentary. 


\subsection{DEVELOPED DESIGN RESPONSE}




\section{1 - OVERVIEW}

This chapter details the developed design response that evolved out of the iteration process in the previous chapter. Much of the work presented in the design response is similar to those described in iterations ten

through twelve however, with further refinement and clarification regarding specific elements of the design. Moreover, each part of the design response is accompanied by an honest and critically reflective insight into both my personal design process, and, to the research question and its wider topic. 


\section{2 - DIAGRAMMATIC THOUGHT PROGRESSION}

The diagrams on the following pages, (Figures 6.1 - 6.5), illustrate the progression of thought that developed into the final design response for the former Tramway Hotel. Beginning with the existing building as it stands currently, what has occurred throughout the site's modification history is the addition of numerous entrances. In order to help develop clear and efficient circulation paths through the interior spaces, it was decided that three secondary entrances would be removed and replaced with windows to form one main entrance on the building's chamfered corner. Also, as mentioned in the more recent iterations in the previous chapter, based on one of Graeme Brooker \& Sally Stone’s (2004) strategies for undertaking a rehabilitation project, newly built function rooms were strategically designed and inserted within the existing building to fit within the exterior columns of the façade. A radical move yes, but by considering the form and rhythm of the building's façade, logical slice points were chosen in order to slice and subsequently fold the façade elements out, and then back on itself whilst maintaining the historic integrity of the building, albeit with a modern interpretation. This then allowed the previously inserted newly built function rooms to be shifted outwards and into the space generated through the slicing and folding of the façade. And in doing so, it developed a new interior layout through the traces left behind by the outward shift. 


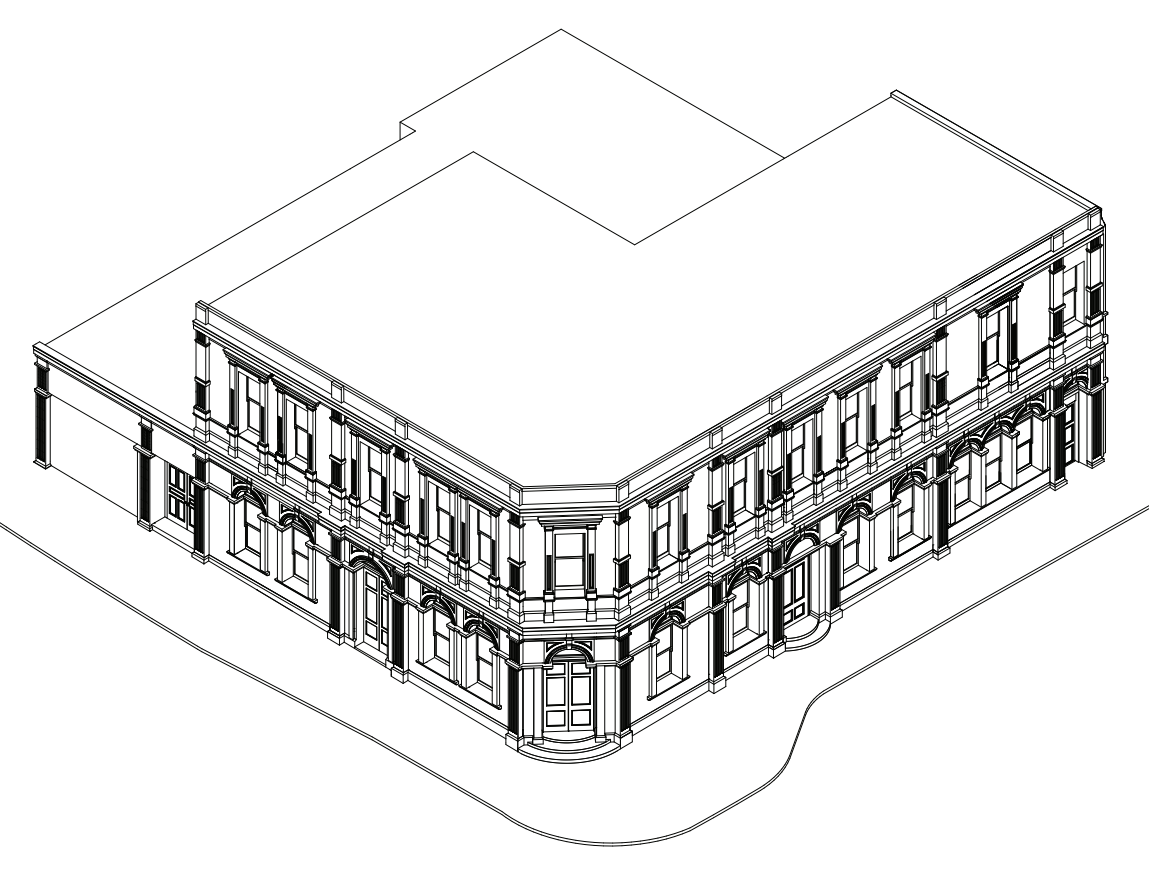

Figure 6.1: Existing Building.

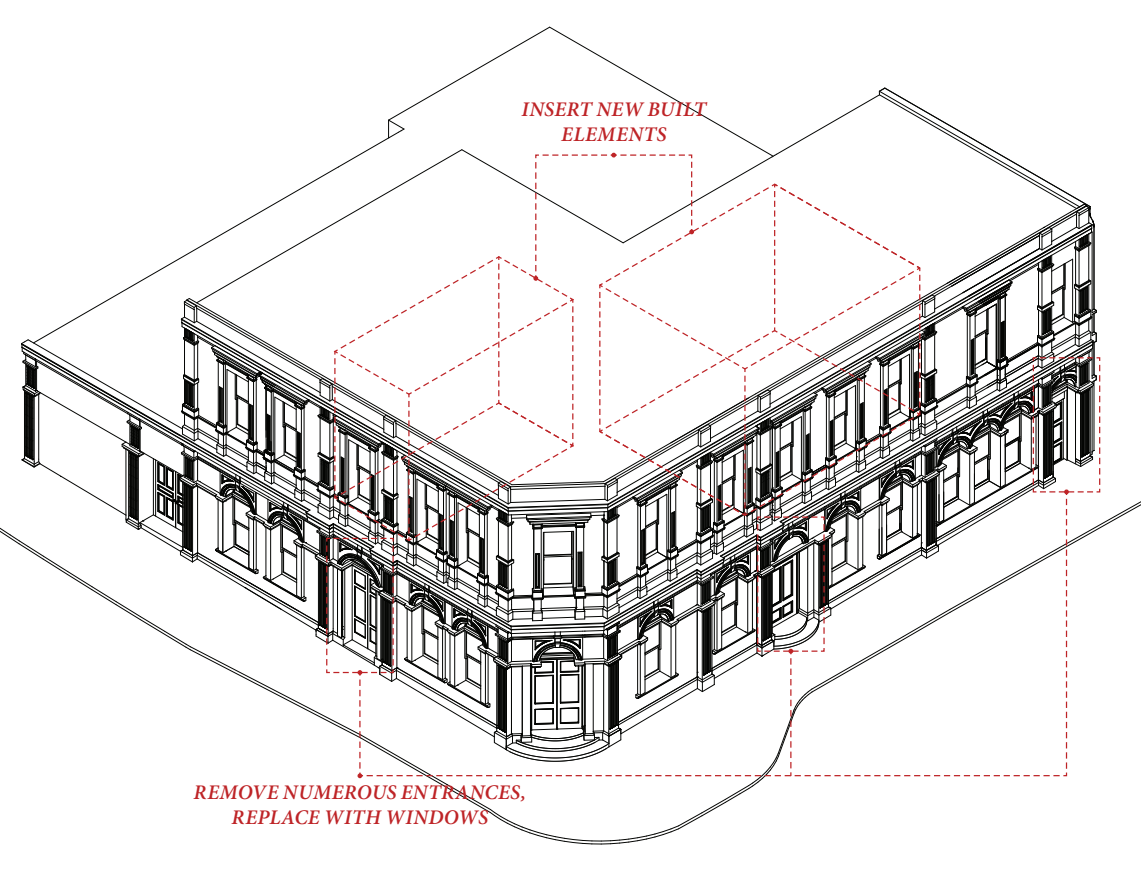

Figure 6.2: Existing Building with Proposed Alterations. 


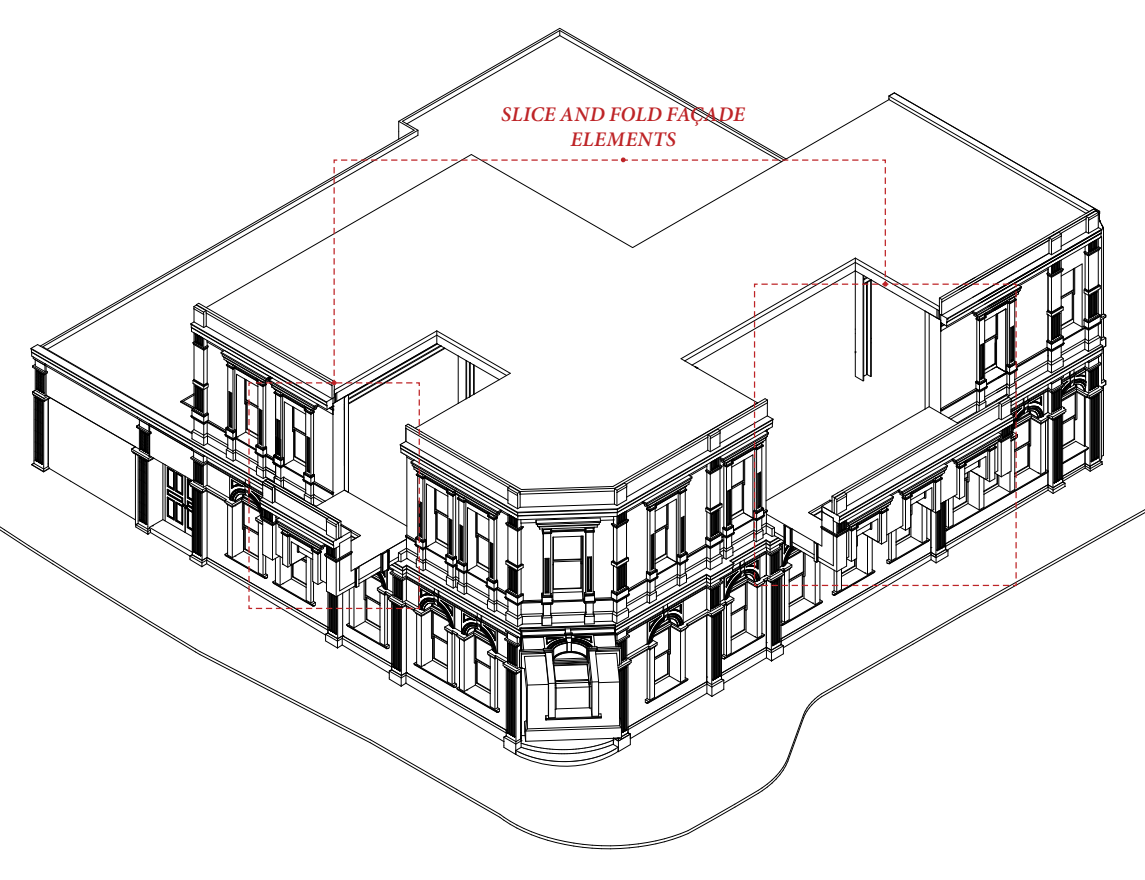

Figure 6.3: Existing Building with Alterations.

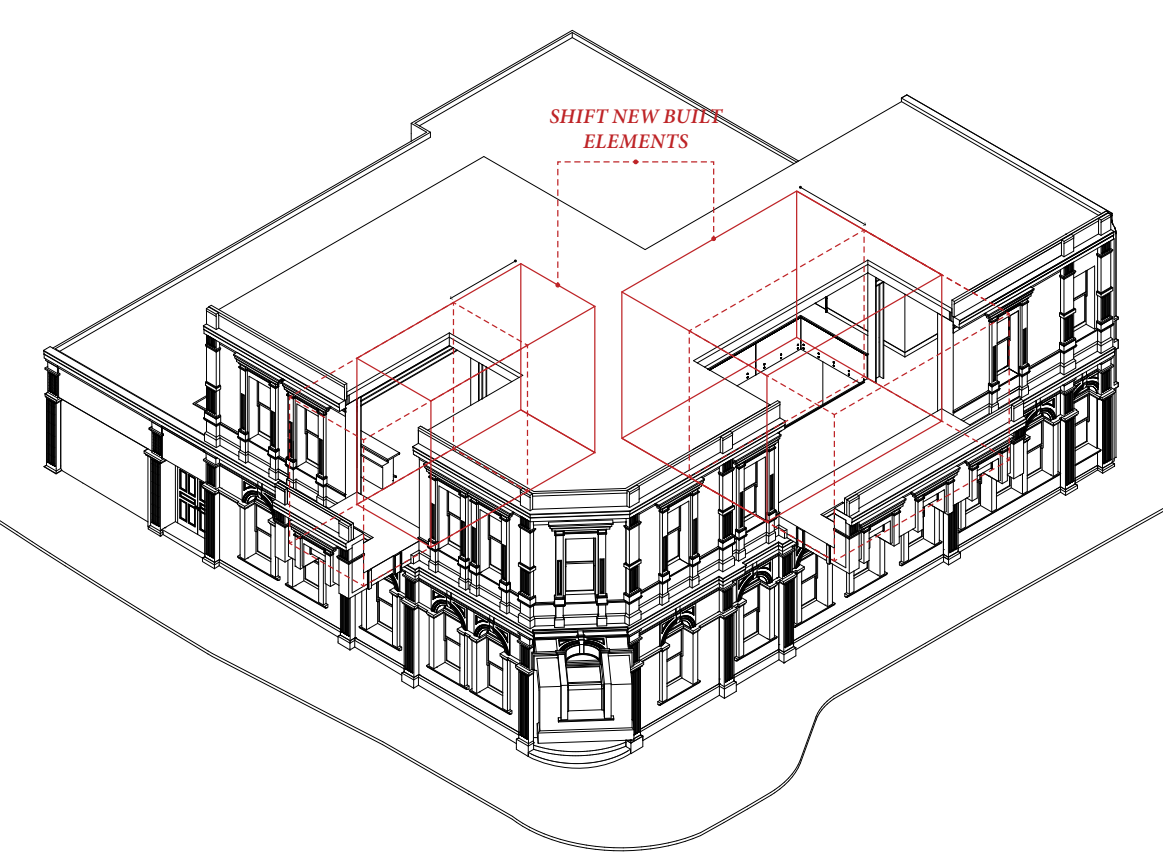

Figure 6.4: Shifting New Built Elements to Develop a New Interior Layout. 
What eventuated is a design response that has sought to implement and directly contrast newly built elements from historic ones. The inserted function rooms not only help to provide a new use for the currently redundant building, but they also serve "to enhance and intensify the building itself" (Brooker \& Stone, 2004, p. 103).

Through the relationship and dialogue that has developed between the two architectural styles, the two styles, although speaking in different languages, seek to "complement and enhance the other [and through such], generates a building of a new and greater worth" (Brooker \& Stone, 2004, p. 103).

The design response is challenging the norm when considering the rehabilitative outcome of a historic building, especially given the fact that conservation initiatives and organisations such as ICOMOS call for the least degree of intervention to retain the authenticity and integrity of a place, (ICOMOS NZ Charter, 2010),

however, given the building's uncertain situation, its condition and seismic vulnerability, the absence of interior documentation, and, the successful global examples of inserting newly built elements within a historic context such as David Closes' 'Convent de Sant Francesc', the design outcome is justified. Yes, the process employed is radical particularly to preservationists, and yes, what is proposed impacts the building's authenticity and integrity, but with that said, I argue that the building can still be read and understood as it once was. However, it now possesses a contemporary interpretation injecting new life into its old bones enabling the building to once again be appreciated by young and old rather than simply sitting there, derelict, wallowing in its former glory silently waiting for its fate to be decided. 


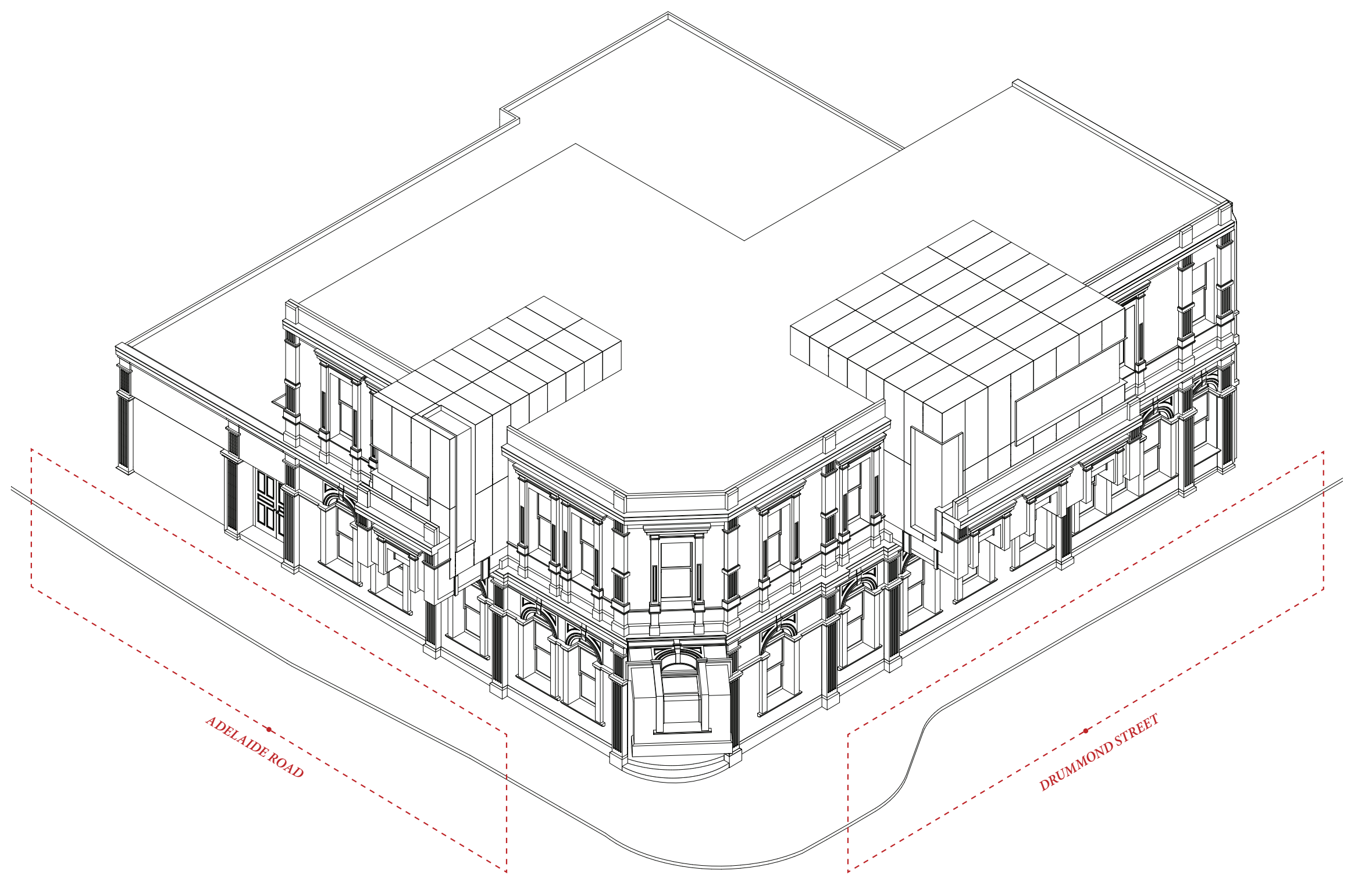

Figure 6.5: Rehabilitated Building. 


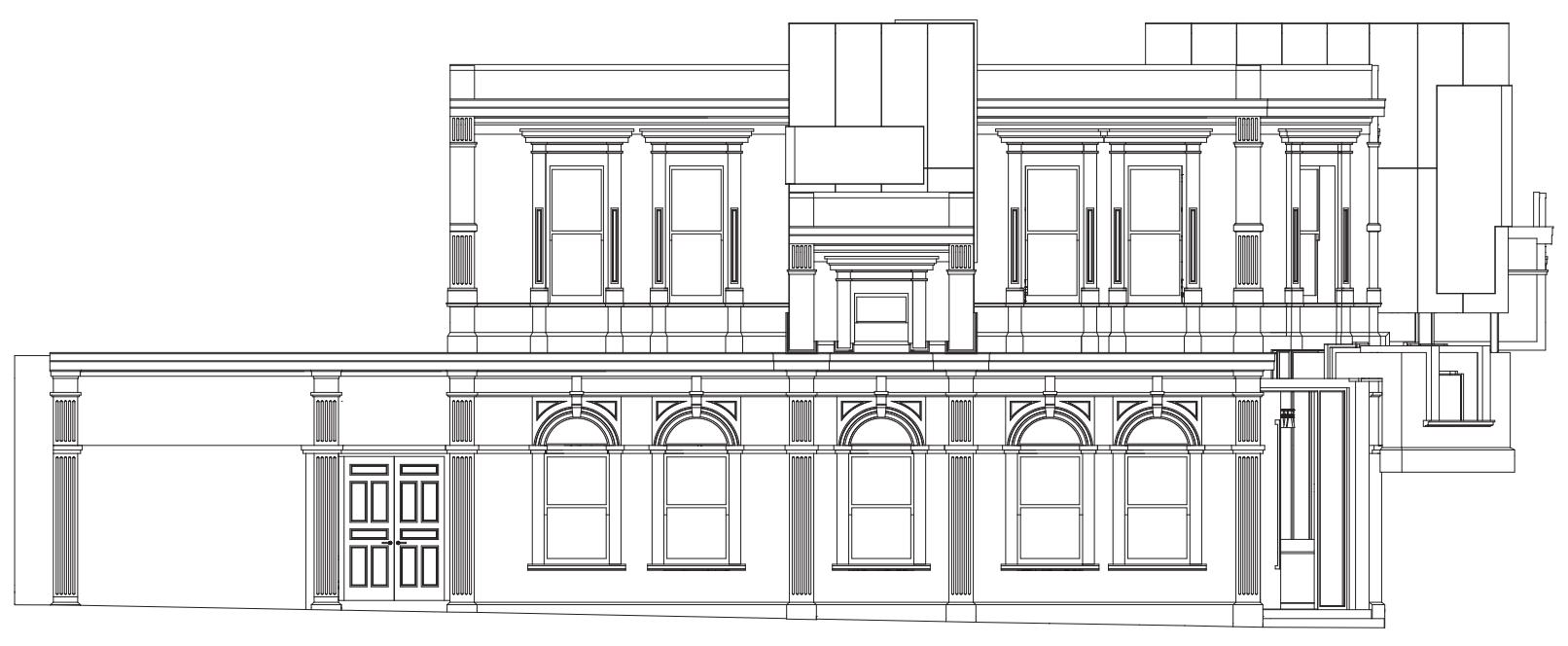

Figure 6.6: Adelaide Road Elevation.

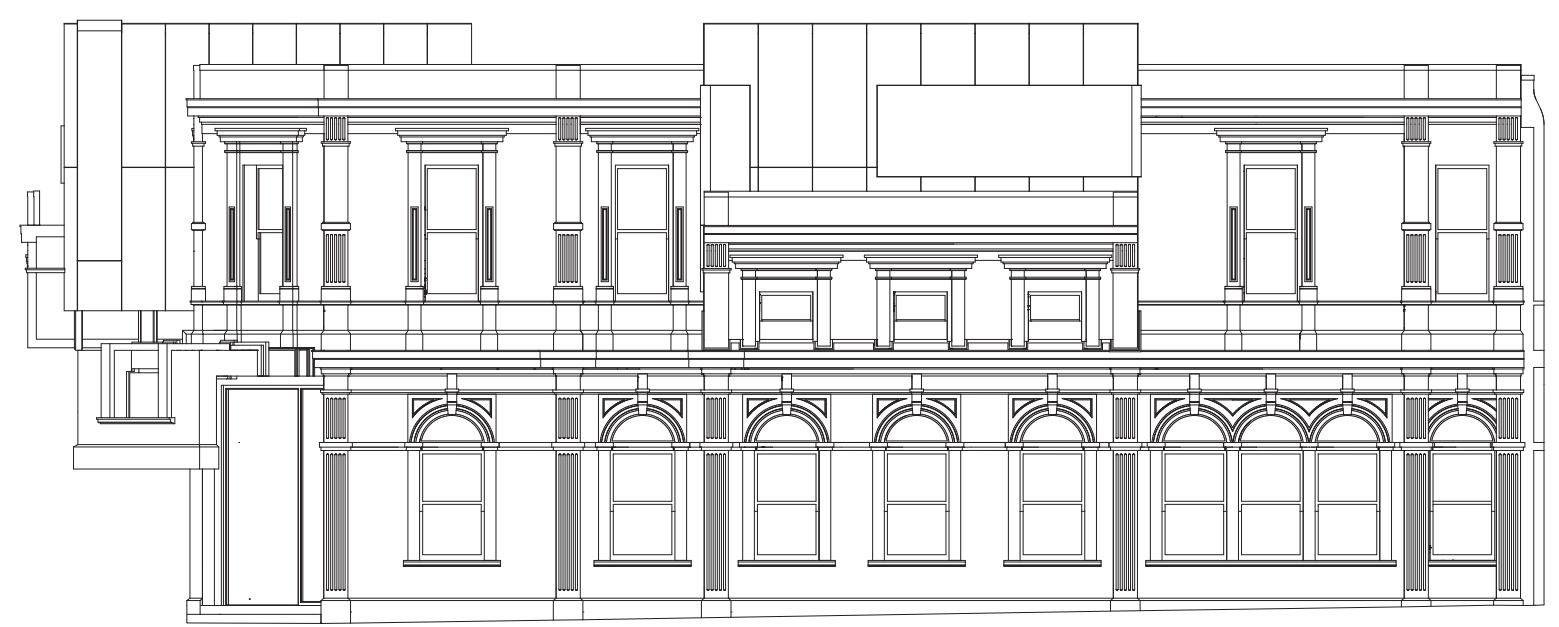

Figure 6.7: Drummond Street Elevation. 


\begin{abstract}
6.3 - PLANS
Forming out of a linear progression, the plans were developed through the act of reflecting and improving on each of my later iterations, as per the intention of my research methodology. With a lost interior history however, the challenge throughout was which avenue to explore and flesh out. Therefore, put simply, the developed design response is but one answer to the research question of potentially endless possibilities. It involves a space plan composed around accentuating the key architectural shifts within the building and thus the inserted function rooms that now protrude out over Adelaide Road and Drummond Streets respectively following their shifts. The outward shift of each, leaves behind it a trace, a void that forms a visual connection between the first and ground floors improving light dispersion and visual interest for diners whilst always conveying the notion of the architectural shifts to the building. Looking at the plans, (Figures $6.8 \& 6.9$ ), with a focus on front of house elements and diner engagement within the design, in order to make the most out of the available interior footprint and given the building's constraints, spatially, the restaurant works well. The numerous dining spaces formed in, and around the newly inserted function rooms provide a variety of dining experiences for patrons which are further differentiated through the use of materials, lighting and, furniture choices in each of the respective spaces.
\end{abstract}



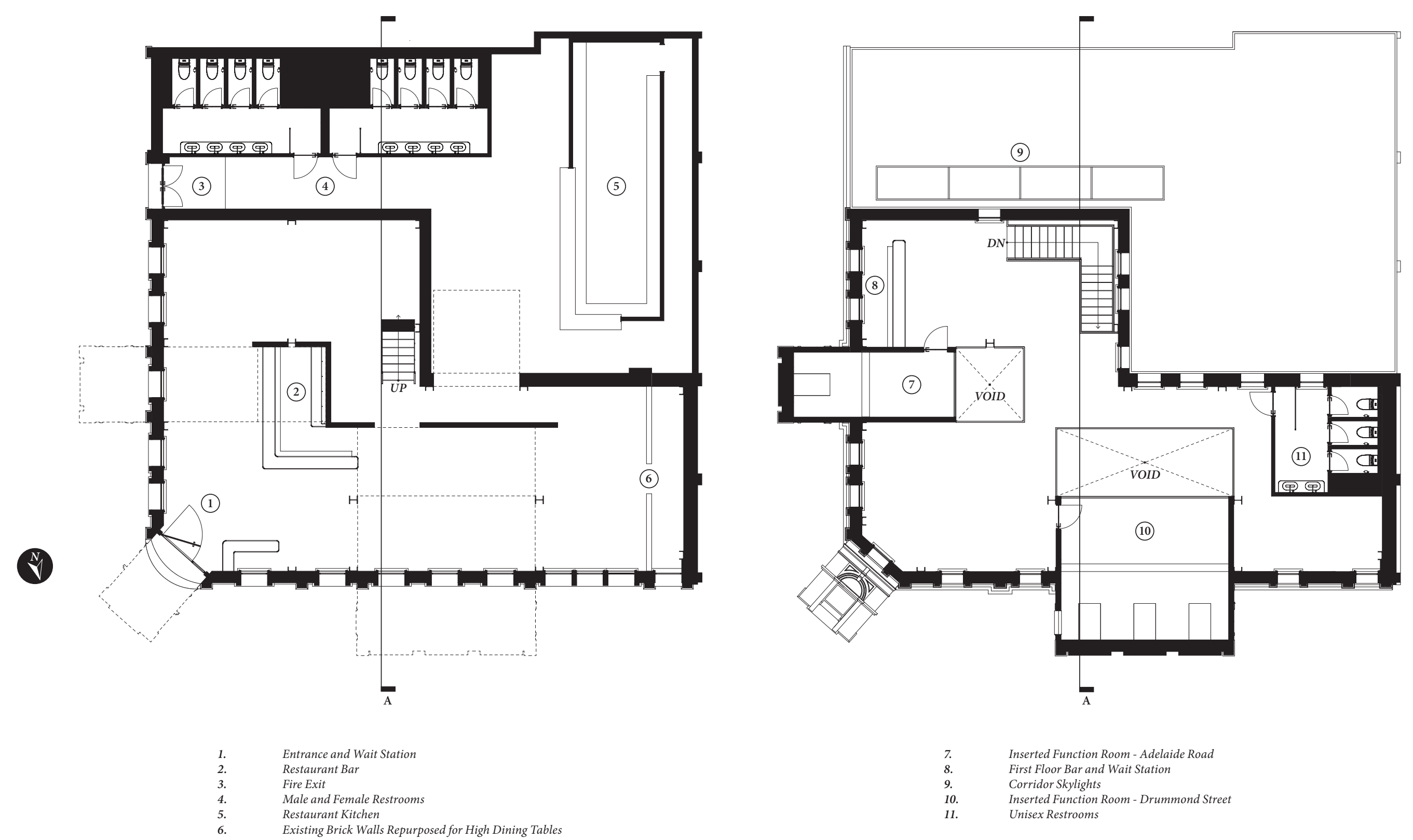


\section{4 - FROM THE STREET}

This perspective from the corner of Adelaide Road and Drummond Streets clearly illustrates the inserted function rooms in contrast to the historic façade of the existing building. Through the iterative process it became apparent that simplifying the form of the function rooms was important in order to not overshadow both the façade and the architectural alterations to the building, thus a cuboid form was chosen which were then wrapped in an exterior cladding. The placement of the function rooms' exterior windows were chosen to encompass both the sun's trajectory throughout the day to increase the amount of natural light, and to frame views surrounding the site.

Although the new insertions create interesting dialogues with the building's historic façade, and at the same time allow for new readings and interpretations of the site to occur, what has gone unanswered however is how the sections of the masonry façade are structurally viable once folded outwards. The decision for folding sections of the façade was to accentuate the shift of the function rooms and thus consolidating the architectural shifts to the building. However, this element requires further work and refinement. Considerations were made at the time to tie the sections of folded masonry into the internal seismic strengthening layer of the steel frames however, nothing was developed. Future work would investigate potentially viable systems and consequently implement them within the façade to justify and strengthen this design decision. 


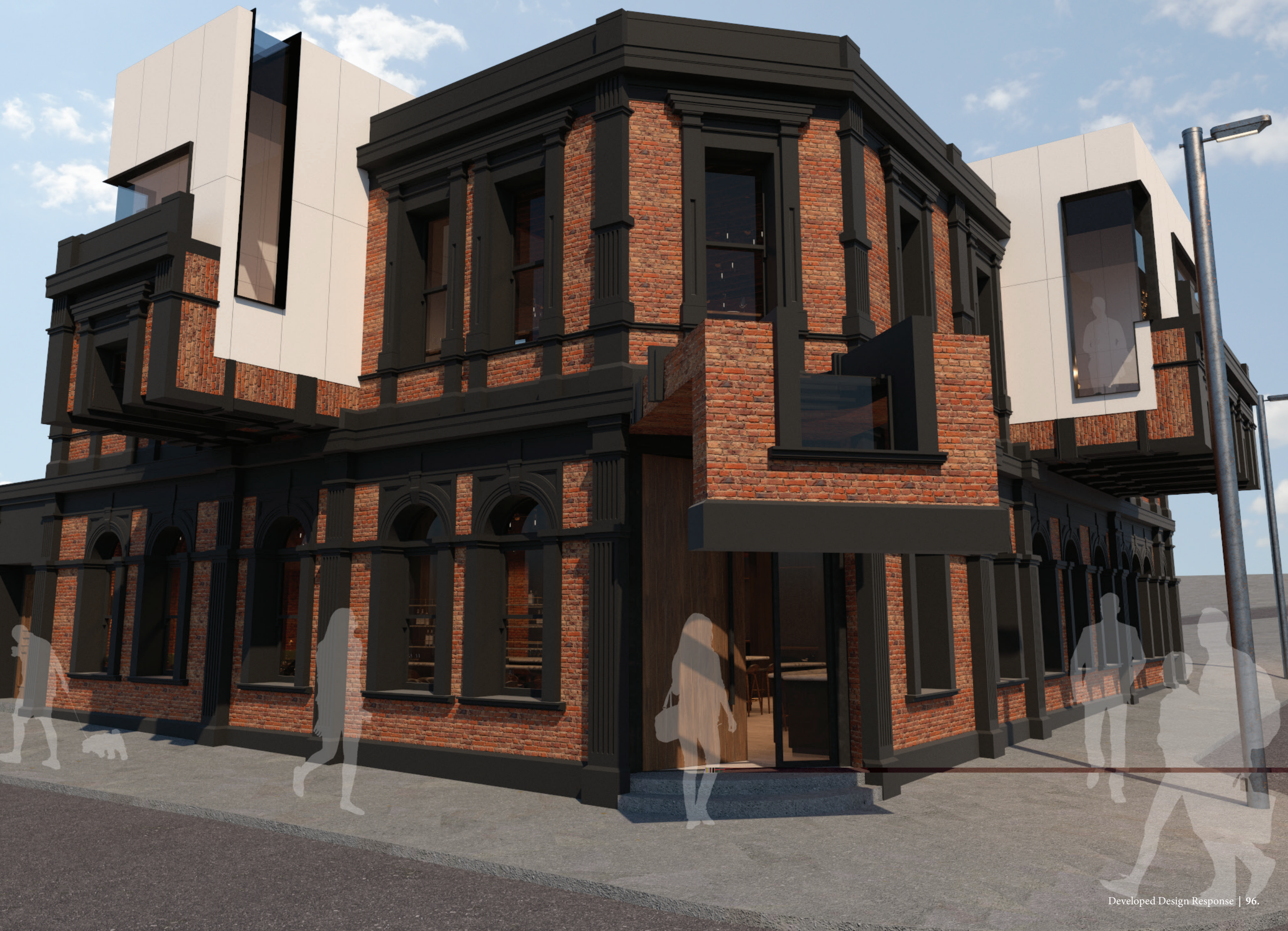





\section{5 - DRUMMOND STREET FUNCTION ROOM}

What became evident throughout the series of interior focused designs, as shown in Design Iteration 12 was that the new inserted function rooms and thus the main architectural shifts of the design were not being articulated well enough from both the existing building and other interior additions. Although the same exterior clad paneling has been implemented to alleviate this, the wall treatment of the function rooms should have been considered further. Currently the treatment seems like an afterthought rather than an intentional design decision. With more thought, a richer, more compelling interior could have developed that maintained its articulation from the rest of the building.

Privacy is also an issue with the design. Being a function room, patrons should have the option to seclude themselves from other patrons in the restaurant if they so desire. Developing a screen or similar, or, utilising technology such as switch glass would facilitate that option and hence improve the functionality of the two function rooms. 


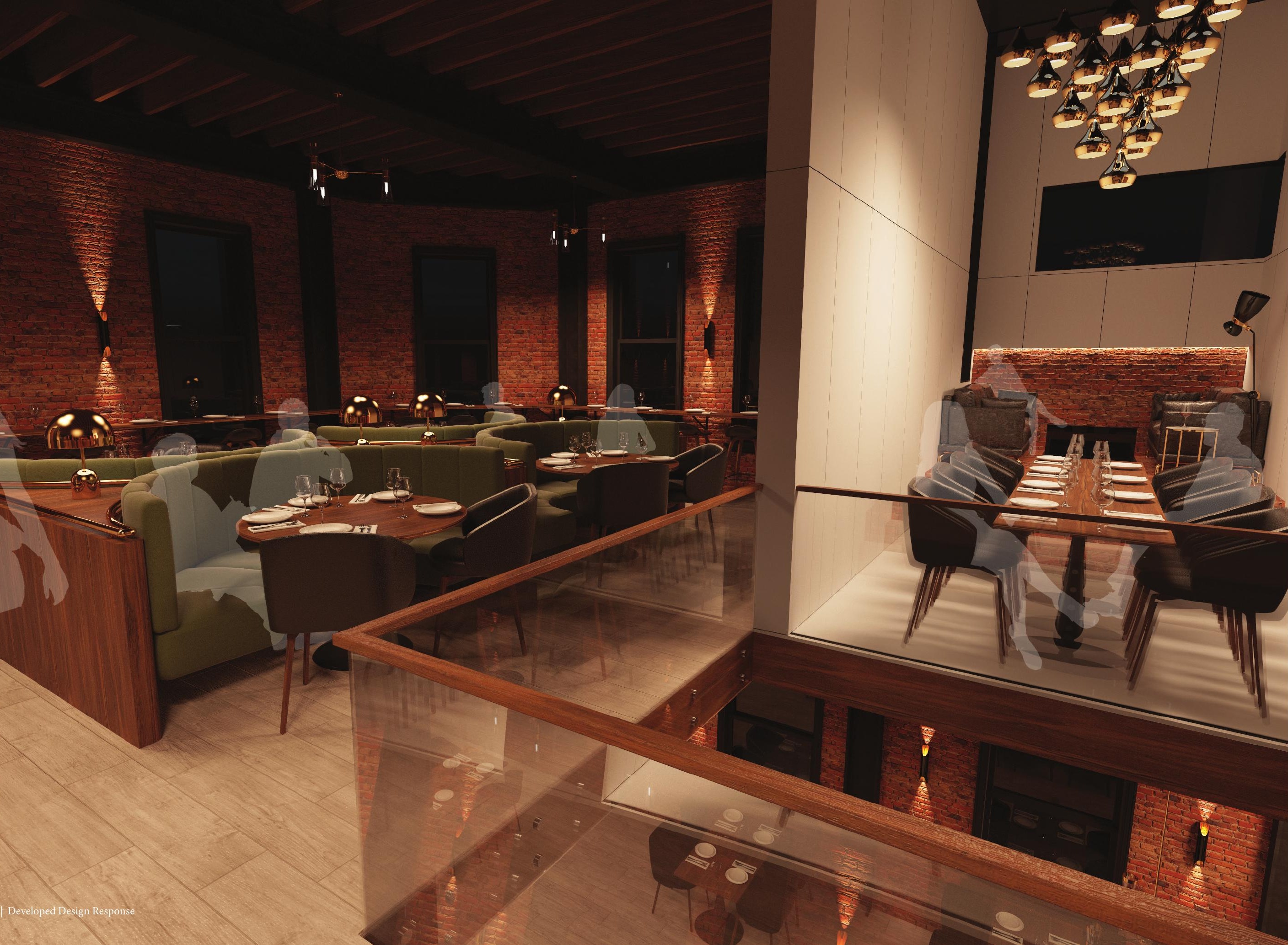




\section{6 - ADELAIDE ROAD FUNCTION ROOM}

Beyond the various forms of seating options employed throughout the restaurant that seek to improve visual interest, better utilise the available space, and increase patron capacity, the quality and choices of lighting such as that of wall sconces and strip lighting play an important role in helping establish the interior atmosphere. By not knowing what remains internally within the building, a key focus throughout the development of the design response was accentuating the known historic features of the building which are its masonry load-bearing walls and façade. Although done with clarity, instead of exposing all of the building's masonry, future work would explore how concealing and then strategically exposing certain areas could create focal points within the interior. By essentially curating the known elements, the design would therefore provide detailed glimpses into the building's history. 


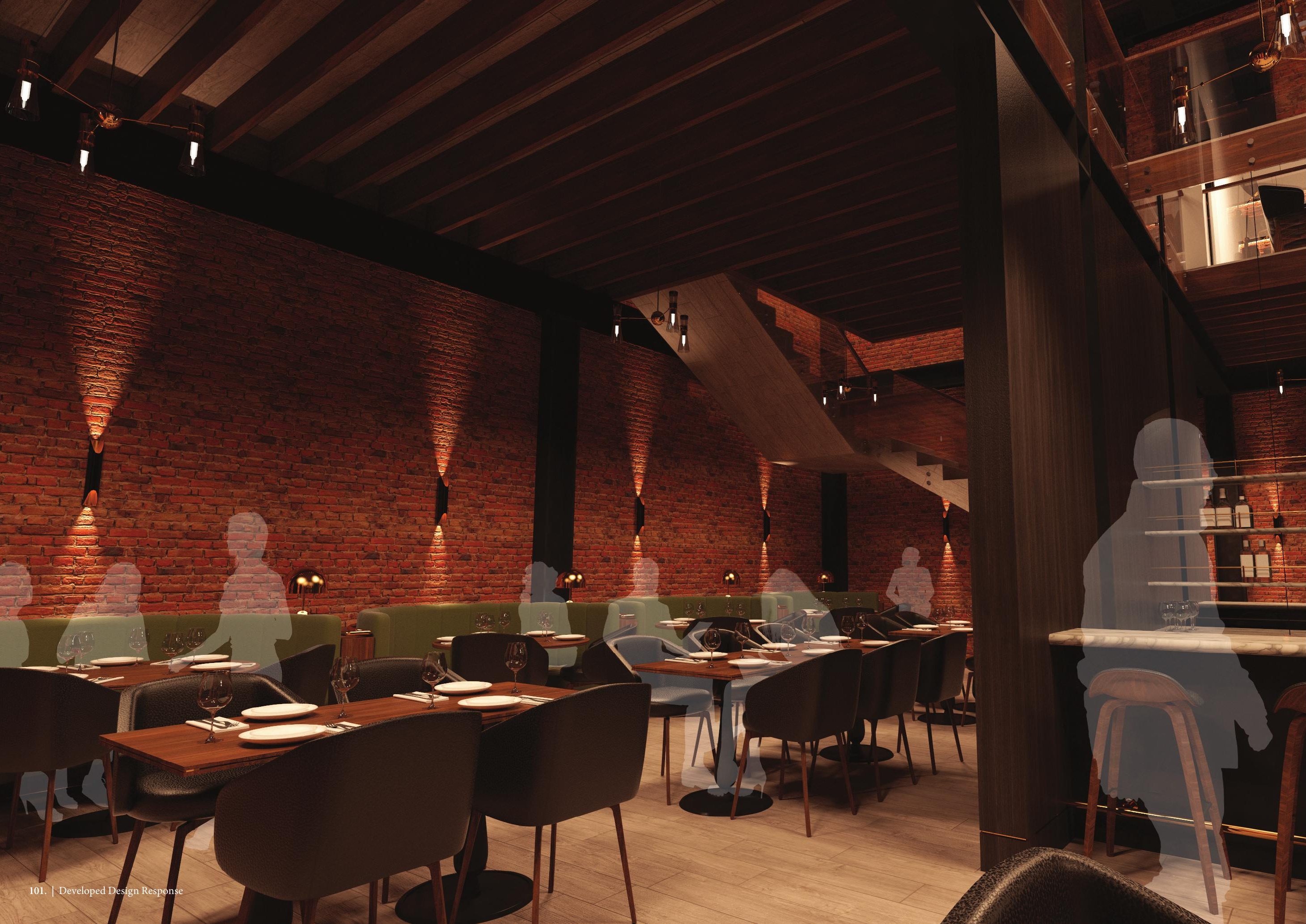




\section{7 - GROUND FLOOR RESTAURANT AND BAR}

As a means to make further reference to the architectural shifts within the building and thus the voids left behind, large mirror panels were chosen as the wall treatment behind the bar. Not only does it provide other perspectives of the shift, but it also helps increase the perceived size of the space. Although the design works as intended, the way in which it is visualised needs work. The high reflectivity of the glass balustrade is obscuring the transition between the mirror panels, and the balustrade. Therefore, there is not a clear distinction where the first floor begins. 

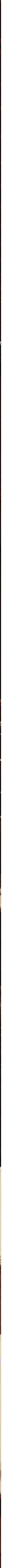


\section{8 - GROUND FLOOR DINING SPACES}

Developing an effective space plan for the restaurant was challenging. One of the main reasons for this was, as per my iterative criteria, forming effective and appropriate circulation paths that would allow for numerous patrons and staff to move throughout the restaurant without issue. Albeit that the design response acknowledges and responds to both this particular criterion, and the programmatic function of the space, the circulation paths could be improved if the space plan and dining choices were considered further. With the current space plan, the new seismic strengthening layer, the building's existing window bays, and by adhering to the amount of space necessary for forming appropriate circulation paths throughout the restaurant, the dining tables have become rather dispersed in areas. Consequently, this has developed areas which tend to feel as though there is an abundance of excess space that could be better utilised. With more time, this issue could be mitigated to form a more coherent design response which would likely improve diner experience.

The act of altering and then repurposing the two known interior masonry walls into two high tables was an advantageous decision that has added a further twenty potential patrons within the restaurant. Not only has it utilised an otherwise redundant space, but it forms a connection between the diners and the building. However, as it stands currently, the adaptive decision is lost and not understood without commentary. Therefore, with future work and refinement in mind, it would continue to explore techniques of making this adaptation stand out from the rest of the building as it has the ability to develop into a strong design statement and historic feature of the restaurant. 


\subsection{THESIS REFLECTION}


With the survival of many of Wellington's historic buildings under threat due to obsoletion, seismic damage or, becoming seismically prone, this thesis has sought to preserve one building, the former Tramway Hotel which has fallen into a state of subsequent disuse and dilapidation. By taking an interior approach, the purpose of this research was to explore how the building's forgotten interiors could be rehabilitated when no interior documentation of the building remains. Taking into account the building's condition, its earthquake vulnerability, the fact that its interior is inaccessible, and, that there is an absence of interior documentation preventing an accurate interior restoration of the building to occur, throughout the course of this thesis I have argued as to why rehabilitation is both a suitable, and beneficial treatment method for preserving and retaining this heritage listed building within Wellington's urban fabric. Furthermore, given that the site has a rich and colourful history which has seen it resonate with successive generations of Wellington residents, this thesis argues that the building deserves to live on and be shared with the next generation of Wellington residents rather than continue to face the risk of the impending bulldozer.

Based on the thesis' action research methodology, this document has explored the process in which the research took in developing the final design response. Despite the fact that there are several elements of the final design that have been identified as needing refinement or further thought and direction, in response, I have attempted to provide alternatives to these shortfalls. Even with these shortfalls however, overall, the design response has adhered to the research question by developing a response that rejuvenates the building's forgotten interiors whilst making the building fit for modern purposes once again.

Thinking beyond this point, advancing the work in the future would see more theoretical and precedent analysis conducted to inform and develop currently unconsidered design concepts or directions. The research would also examine a number of other historical sites in similar conditions to the former Tramway Hotel and subsequently explore how the techniques investigated in this thesis, as well as new techniques, could be translated within the constraints posed by such sites. Lastly, the research would evolve with a more analogue component to it.

That would involve getting out of the computer more to experience and document each site and its surroundings through a more personal, intuitive lens. Be it as it may, I have learnt so much about my personal design practice from this experience that I can now apply to future projects. From the way I work, to the way I redirect stress into becoming a motivator, and everything in between, these are the aspects that are most important to me as I continue to develop myself as a designer. 


\subsection{REFERENCES}


Aguilar, A. (2016). 41 Preservation Briefs: The Seismic Rehabilitation of Historic Buildings. Retrieved from: https://www.nps.gov/tps/how-to-preserve/preservedocs/preservation-briefs/41Preserve-Brief SeismicRetrofit.pdf

ArchDaily. (2012). Convent de Sant Francesc / David Closes. Retrieved from

https://www.archdaily.com/251389/convent-de-sant-francesc

Baum, M. (2012) City as Loft. In M. Baum \& K. Christiaanse (Eds.), City as Loft: Adaptive Reuse as a Resource for Sustainable Development (pp. 8-13). Zurich, Switzerland: gta Verlag.

Brand, S. (1994). How Buildings Learn: What happens After They're Built. New York, NY: Penguin Books.

Brooker, G. (2006). Infected Interiors: Remodelling Contaminated Buildings. Interior Design / Interior Architecture Educators Association Journal, 1(1), 1-13. Retrieved from:

http://idea-edu.com/wp-content/uploads/2013/01/2006_IDEA_Journal.pdf

Brooker, G., \& Stone, S. (2004). Rereadings: Interior Architecture and the Design Principles of

Remodelling Existing Buildings. London: England: RIBA Enterprises Ltd.

Bullen, P. A. (2007). Adaptive Reuse and Sustainability of Commercial Buildings. Facilities, 25(1/2),

20-31. Retrieved from: https://www.researchgate.net/profile/Peter_Bullen3/publication/235264539

Adaptive_reuse_and_sustainability_of_commercial_buildings/links/56b54ea808ae5ad360578ef8.pd

Bullen, P. A., \& Love, P. E. D. (2010). The Rhetoric of Adaptive Reuse or Reality of Demolition: Views from the Field. Cities, 27(4), 215-224. Retrieved from: https://www.researchgate.net/profile/Peter

Love2/publication/240428213_The_rhetoric_of_adaptive_reuse_or_reality_of_demolition_Views_ from_the_field/links/0f317534636b90ee60000000.pdf

Bullen, P. A., \& Love, P. E. D. (2011a). Adaptive Reuse of Heritage Buildings. Structural Survey, 29(5), 411-421. Retrieved from: https://www.researchgate.net/profile/Peter_Love2/publication/235274709 Adaptive_reuse_of_heritage_buildings/links/0c9605302cfd3e2e28000000/Adaptive-reuse-of-heritagebuildings.pdf

Bullen, P. A., \& Love, P. E. D. (2011b). Factors Influencing the Adaptive Re-Use of Buildings. Journal of Engineering, Design and Technology, 9(1), 32-46. Retrieved from: https://www.researchgate.net/ profile/Peter_Love2/publication/235307181_Factors_influencing the_adaptive_re-use_of buildings/ links/00b7d527f0d18567fd000000.pdf
Clark, D. (2008). Adapting an Older Building for a New Use. Retrieved from: https://www.buildings. com/article-details/articleid/5837/title/adapting-an-older-building-for-a-new-use

Coles, J. \& House, N. (2007). The Fundamentals of Interior Architecture. Lausanne, Switzerland: AVA Publishing SA.

Closes, D. (2012). Convent de Sant Francesc. Retrieved from:

https://davidcloses.wordpress.com/2012/05/18/convent-de-sant-francesc-2/

Crouch, C., Pearce, J. (2012). Doing Research in Design. New York, NY: Berg Publisher

Dedek, P. B. (2014). Historic Preservation for Designers. New York, NY. Fairchild Books.

Department of the Environment and Heritage. (2004). Adaptive Reuse: Preserving our Past, Buildin our Future. Retrieved from: http://www.environment.gov.au/system/files/resources/3845f27a-ad2c4d40-8827-18c643c7adcd/files/adaptive-reuse.pdf

Faimon, P. \& Weigand, J. (2004). The Nature of Design: How the Principles of Design Shape our Worldfrom Graphics and Architecture to Interiors and Products. Cincinnati, OH: HOW Design Books.

Frumento, S., Giovinazzi, S., Lagomarsino, S., \& Podestà, S. (2006). Seismic Retrofitting of Unreinforced Masonry Buildings in Italy. Retrieved from: https://www.nzsee.org.nz/db/2006/Paper48.pdf

Gander, K. (2016). How Architecture uses Space, Light and Material to Affect your Mood. Retrieved from: http://www.independent.co.uk/life-style/design/how-architecture-uses-space-light-andmaterial-to-affect-your-mood-american-institute-architects-a6985986.html\#gallery

Groat, L. \& Wang, D. (2002). Architectural Research Methods. New York, NY: John Wiley \& Sons, Inc.

Guh, J. T. \& Altoontash, A. (2006). Seismic Retrofit of Historic Building Structures. Retrieved from: http://quakewrap.com/frp\%20papers/SeismicRetrofitofHistoricBuildingStructures.pdf

Hamer, S. (2016). Architectural Concepts: Circulation. Retrieved from:

http://portico.space/journal//architectural-concepts-circulation

Heritage Council of New South Wales. (2008). New Uses for Heritage Places: Guidelines for the Adaptation of Historic Buildings and Sites. Retrieved from: http://www.environment.nsw.gov.au/ resources/heritagebranch/heritage/NewUsesforHeritagePlaces.pdf 
Herzog \& de Meuron. (2008). 201 CaixaForum Madrid. Retrieved from: https://www.herzogdemeuron. com/index/projects/complete-works/201-225/201-caixaforum-madrid.html

Johnson, A. (1996). Rehabilitation and Re-Use of Existing Buildings. In E. D. Mills (Eds.), Building Maintenance and Preservation: A Guide for Design and Management (2nd ed., pp. 209-230). Oxford, England: Architectural Press

Klanten, R. \& Feireiss, L. (2009). Build-On: Converted Architecture and Transformed Buildings. Berlin Germany: Gestalten.

Kurtich, J., \& Eakin, G. (1993). Interior Architecture. New York, NY: Van Nostrand Reinhold.

Langston, C. (2008). The Sustainability Implications of Building Adaptive Reuse. Retrieved from: http://epublications.bond.edu.au/cgi/viewcontent.cgi?article=1003\&context=sustainable_development

Misirlisoy, D. \& Gunce, K. (2016). Adaptive Reuse Strategies for Heritage Buildings: A Holistic Approach. Sustainable Cities, 26(1). 91-98. Retrieved from: https://www.researchgate.net/ publication/303775293_Adaptive_reuse_strategies_for_heritage_buildings_A_holistic_approach

Nanjunda Rao, K. S., Raghunath, S., \& Jagadish, K. S. (2004). Containment Reinforcement For Earthquake Resistant Masonry Buildings. Retrieved from:

http://www.iitk.ac.in/nicee/wcee/article/13_1968.pdf

National Park Service, U.S. Department of the Interior. (2017). The Secretary Of The Interior's Standards For The Treatment Of Historic Properties with Guidelines For Preserving, Rehabilitating, Restoring and Reconstructing Historic Buildings. Retrieved from:

https://www.nps.gov/tps/standards/treatment-guidelines-2017.pdf

Ng, A. (2015). Clever Facadism, Interiority Complex and Urban Magnetism: A Second Look at Herzog and De Meuron's CaixaForum Madrid. Retrieved from: http://www.architectureanddesign.com.au/ features/comment/clever-facadism-interiority-complex-and-urban-magn

Plevoets, B. \& Van Cleempoel, K. (2011). Adaptive Reuse as a Strategy Towards Conservation of Cultural Heritage: A Literature Review. Structural Studies, Repairs and Maintenance of Heritage Architecture XII, 188(1). 155-164. Retrieved from:

https://www.witpress.com/elibrary/wit-transactions-on-the-built-environment/118/22728
Rab, S. (1998). Carlo Scarpa's Re-design of Castelvecchio in Verona, Italy. In C. Barton (Ed.), 86th ACSA Annual Meeting Proceedings, Constructing Identity (pp. 443-451). Washington, D.C: Association of Collegiate Schools of Architecture

Riel, M. (2010-2017). Understanding Action Research. Center for Collaborative Action Research, Pepperdine University (Last Revision Jan, 2017). Retrieved from: http://cadres.pepperdine.edu/ccar/define.html

Rowe, P. G. (1987). Design Thinking. Cambridge, MA: The MIT Press

Ruskin, J. (1849). The Seven Lamps of Architecture. London, England: Smith, Elder \& Co.

Scott, F. (2008). On Altering Architecture. New York, NY: Routledge.

Stott, R. (2017). Spotlight: Carlo Scarpa. Retrieved from:

https://www.archdaily.com/638534/spotlight-carlo-scarpa

Swann, C. (2002, Winter). Action Research and the Practice of Design. In Design Issues, 18(2), 49-61.

Retrieved from: http://www.spatialdesign.info/blog/wp-content/uploads/2007/12/Swann _

DesIss_2002.pdf

The Evening Post. (1899, January 31). Wellington Fish Supply. To the Editor. Retrieved from: https://paperspast.natlib.govt.nz/newspapers/EP18990131.2.64

The New Zealand National Committee of the International Council on Monuments and Sites. (2010). ICOMOS New Zealand Charter: For the Conservation of Places of Cultural Heritage Value. Retrieved from: http://icomos.org.nz/wp-content/uploads/2016/08/NZ_Charter.pdf

Tumialan, J. G., Myers, J. J., \& Nanni, A. (1999). Field Evaluation of Masonry Walls Strengthened with FRP Composites at the Malcolm Bliss Hospital. Retrieved from:

https://pdfs.semanticscholar.org/b8dc/395db12a5f77342193c2587a6d8cf9073d6e.pdf

Tumialan, J. G., \& Nanni, A. (2001). In-Plane and Out-of-Plane Behavior of Masonry Walls Strengthened with FRP Systems. Retrieved from: http://quakewrap.com/frp\%20papers/ InPlaneandOutofPlaneBehaviorofMasonryWallsStrengthenedwithFRPSystems.pd

Velthuis, K., \& Spennemann, D. H. R. (2007). The Future of Defunct Religious Buildings: Dutch Approaches to their Adaptive Re-use. Cultural Trends, 16(1), 43-66. 
Wellington City Council. (2014). Centres Design Guide: Appendix 5 - Adelaide Road/Mt Cook.

Retrieved from: http://wellington.govt.nz/ /media/your-council/plans-policies-and-bylaws/districtplan/volume02/files/v2centresapp5.pdf?la=en

Wellington City Council. (2015). Our 10-Year Plan. Wellington City Council's Long-term Plan 2015-25. Volume One. Retrieved from:

http://www.our10yearplan.co.nz/assets/Uploads/files/2015-25-longtermplanvolume1-final.pdf

Wellington City Council. (2016, March 18). Council Helps Preserve the Past and Secure the Future. Retrieved from: https://wellington.govt.nz/your-council/news/2016/03/council-helps-preserve-thepast-and-secure-the-future

Wellington City Council. (n.d.-a). Adelaide Road Redevelopment. Retrieved from:

http://www.our10yearplan.co.nz/projects/inner-city-regeneration/adelaide-road-redevelopment/

Wellington City Council. (n.d.-b). Earthquake-prone Building Notices Explained. Retrieved from: https://wellington.govt.nz/services/rates-and-property/earthquake-prone-buildings/earthquakeprone-building-notices-explained

Wellington City Council. (n.d.-c). Wellington City Council Guide: Earthquake Prone Buildings. Retrieved from: http://wellington.govt.nz/ /media/services/rates-and-property/earthquake-pronebuildings/files/eq-prone-buildings-guide.pdf

Wellington City Council Heritage. (06 May 2012). Tramway Hotel (Former) Heritage Inventory Report. Retrieved from: http://www.wellingtoncityheritage.org.nz/buildings/301-450/397-tramway-hotel?q=

Whitburn, G. (2011, September 29). Historic hotel's future uncertain. The Wellingtonian. Retrieved from: http://www.stuff.co.nz/dominion-post/news/local-papers/the-wellingtonian/5699676/Historichotels-future-uncertain

\section{SEISMIC MITIGATION DIAGRAMS}

1: $\quad$ Aguilar, A. (n.d.) 41 Preservation Briefs: The Seismic Rehabilitation of Historic Buildings. Retrieved from: https://www.nps.gov/tps/how-to-preserve/briefs/41-seismic-retrofit.htm

2: $\quad$ Guh, J. T. \& Altoontash, A. (2006). Seismic Retrofit of Historic Building Structures. Retrieved from: http://quakewrap.com/frp\%20papers/SeismicRetrofitofHistoricBuilding Structures.pdf

3: $\quad$ Frumento, S., Giovinazzi, S., Lagomarsino, S., \& Podestà, S. (2006). Seismic Retrofitting of Unreinforced Masonry Buildings in Italy. Retrieved from:

https://www.nzsee.org.nz/db/2006/Paper48.pdf

4: $\quad$ Wellington City Council. (n.d.). Wellington City Council Guide: Earthquake Prone Buildings. Retrieved from: http://wellington.govt.nz/ /media/services/rates-and-property/ earthquake-prone-buildings/files/eq-prone-buildings-guide.pdf

5: $\quad$ Nanjunda Rao, K. S., Raghunath, S., \& Jagadish, K. S. (2004). Containment Reinforcement For Earthquake Resistant Masonry Buildings. Retrieved from:

http://www.iitk.ac.in/nicee/wcee/article/13_1968.pdf

6: $\quad$ Boiser, A. (2017). Unreinforced Masonry (URM) Structures - Strengthening.

Retrieved from: https://www.linkedin.com/pulse/unreinforced-masonry-urm-structuresstrengthening-andre-boiser

7: $\quad$ Tumialan, J. G., \& Nanni, A. (2001). In-Plane and Out-of-Plane Behavior of Masonry Walls Strengthened with FRP Systems. Retrieved from: http:/quakewrap.com/frp\%20papers/ InPlaneandOutofPlaneBehaviorofMasonryWallsStrengthenedwithFRPSystems.pdf

8: $\quad$ Ehsani, M. (2007). Repairing and Strengthening Masonry Walls with FRPs. Retrieved from: http://www.masonryconstruction.com/products/materials/repairing-and-strengtheningmasonry-walls-with-frps_o

9: $\quad$ Reid Construction Systems. (2012). Flexus Bendable Concrete - Shotbond System. Retrieved from: http://www.reids.co.nz/wp-content/uploads/2012/05/23152-REID1FLEXUS-REDESIGN-SSSV3a-REDO-web.pdf 
Figure 0.1: '2017 The former Tramway Hotel in disarray'. Author's own image.

\subsection{INTRODUCTION}

Figure 1.1: 'Defining the Research Question'.

Author's own image.

Figure 1.2: 'Action Research Cycle' Author's own image.

\subsection{CONTEXT ANALYSIS}

Figure 2.1: 'Snapshots of Wellington's heritage listed areas and buildings' Author's adaptation of Wellington's satellite imagery. Retrieved from: https://data.linz.govt.nz/layer/1871-wellington-01m-urban-aerial-photos-2012-2013/

Figure 2.2: 'Snapshots of Wellington's heritage listed areas and buildings'. Author's adaptation of Wellington's satellite imagery. Retrieved from: https://data.linz.govt.nz/layer/1871-wellington-01m-urban-aerial-photos-2012-2013/

Figure 2.3: 'Original 1899 drawings for the masonry built Tramway Hotel'. Author's adaptation of the architect's original drawings. Retrieved from: http://www.wellingtoncityheritage.org.nz/buildings/301-450/397-tramway-hotel?q=

Figure 2.4: '2017 The former Tramway Hotel in disarray'. Author's own image.

Figure 2.5: '2017 The former Tramway Hotel in disarray'. Author's own image.

Figure 2.6: '2017 The former Tramway Hotel in disarray'. Author's own image.

Figure 2.7: 'Aerial maps outlining the local amenities surrounding the site'. Author's adaptation of Wellington's satellite imagery. Retrieved from: https://data.linz.govt.nz/layer/1871-wellington-01m-urban-aerial-photos-2012-2013/
Figure 2.8: 'Aerial maps outlining the local amenities surrounding the site'.

Author's adaptation of Wellington's satellite imagery. Retrieved from https://data.linz.govt.nz/layer/1871-wellington-01m-urban-aerial-photos-2012-2013/

\subsection{LITERATURE REVIEW}

Figure 3.1: 'Reconstruction of Plevoets \& Van Cleempoel's (2011) graph'.

Plevoets, B. \& Van Cleempoel, K. (2011). Analogy between described strategies towards adaptive reuse. [Digital Graph]. Retrieved from:

https://www.witpress.com/elibrary/wit-transactions-on-the-built-environment/118/22728

Figure 3.2: 'A diagrammatic series of possible seismic mitigation strategies'. Author's own image.

Figure 3.3: 'A diagrammatic series of possible seismic mitigation strategies continued'. Author's own image.

\subsection{PRECEDENT ANALYSIS}

Figure 4.1: 'Exterior view of the Castelvecchio with the Cangrande I statue on full display'. Guthrie, P. (2010). IMG_0464. [Photograph]. Retrieved from: https://www.flickr.com/photos/pg/4925389433/in/album-72157624803076462/

Figure 4.2: 'Layers of accumulative history converging'. Omniboni, L. (2014). IMG_4589_edited. [Photograph]. Retrieved from https://archiobjects.org/wp-content/uploads/2014/04/IMG_4589_edited.jpg

Figure 4.3: 'Perimeter floor voids frame the interior gallery spaces'. Omniboni, L. (2014). IMG 4560 edited. [Photograph]. Retrieved from: https://archiobjects.org/wp-content/uploads/2014/04/IMG_4560_edited.jpg

Figure 4.4: 'New staircase sympathetically adjoins the historic masonry wall within the Castelvecchio'. Guthrie, P. (2010). IMG_0503. [Photograph]. Retrieved from: https://www.flickr.com/photos/pg/4925389433/in/album-72157624803076462/

Figure 4.5: 'A series of explorations of how detailing could be utilised to fuse new and existing elements of a staircase'.

Author's own image. 
Figure 4.6: 'A series of explorations of how detailing could be utilised to fuse new and existing elements to form a handrail and balustrade'.

Author's own image.

Figure 4.7: 'A series of explorations of how detailing could be utilised to fuse new and existing elements wall elements'.

Author's own image.

Figure 4.8: 'Exterior perspective of the CaixaForum Madrid with its juxtaposition of form, materials and language'.

Pagni, M. (2014). 20. [Photograph]. Retrieved from:

https://commons.wikimedia.org/wiki/File:Caixaforum_Madrid_(2).jpg

Figure 4.9: 'Contemporary interior design incorporating faceted, metallic finishes that have no reference to the former building'.

SeaDave. (2009). Amazing stairwell at the Caixa Forum Madrid. [Photograph]. Retrieved from: https://www.flickr.com/photos/seadave/3389469069/

\subsection{THE PROCESS}

Figure 5.1: 'Self-reflective scales to critique each design iteration against'

Author's own image.

Figure 5.2: 'Design Iteration 1 Collage'. Author's own images.

Figure 5.3: 'Design Iteration 2 Collage' Author's own images.

Figure 5.4: 'Design Iteration 3 Collage'. Author's own images.

Figure 5.5: 'Design Iteration 3.1 Collage' Author's own images.

Figure 5.6: 'Design Iteration 4 Collage' Author's own images.
Figure 5.7: 'Design Iteration 5 Collage' Author's own images.

Figure 5.8: 'Design Iteration 6 Collage' Author's own images.

Figure 5.9: 'Design Iteration 7 Collage'. Author's own images.

Figure 5.10: 'Design Iteration 8 Collage'. Author's own images.

Figure 5.11: 'Design Iteration 9 Collage'. Author's own images.

Figure 5.12: 'Design Iteration 10 Collage'. Author's own images.

Figure 5.13: 'Design Iteration 11 Collage' Author's own images.

Figure 5.14: 'Design Iteration 12 Collage'. Author's own images.

Figure 5.15: 'All design iterative reflections mapped against one another'. Author's own image.

\subsection{DEVELOPED DESIGN RESPONSE}

Figure 6.1: 'Existing Building'. Author's own image.

Figure 6.2: 'Existing Building with Proposed Alterations' Author's own image.

Figure 6.3: 'Existing Building with Alterations'. Author's own image. 
Figure 6.4: 'Shifting New Built Elements to Develop a New Interior Layout'. Author's own image.

Figure 6.5: 'Rehabilitated Building'. Author's own image.

Figure 6.6: 'Adelaide Road Elevation'.

Author's own image.

Figure 6.7: 'Drummond Street Elevation'. Author's own image.

Figure 6.8: 'Ground Floor Plan. Scale 1:200’. Author’s own image.

Figure 6.9: 'First Floor Plan. Scale 1:200'. Author's own image.

Figure 6.10: 'From the Street'. Author's own image.

Figure 6.11: 'Drummond Street Function Room'. Author's own image.

Figure 6.12: 'Adelaide Road Function Room'. Author's own image.

Figure 6.13: 'Ground Floor Restaurant and Bar'. Author's own image.

Figure 6.14: 'Ground Floor Dining Spaces'. Author's own image. 
APPENDIX A:

Investigating a rendering style in

which the history of the building

could be overlaid over computer

renderings.

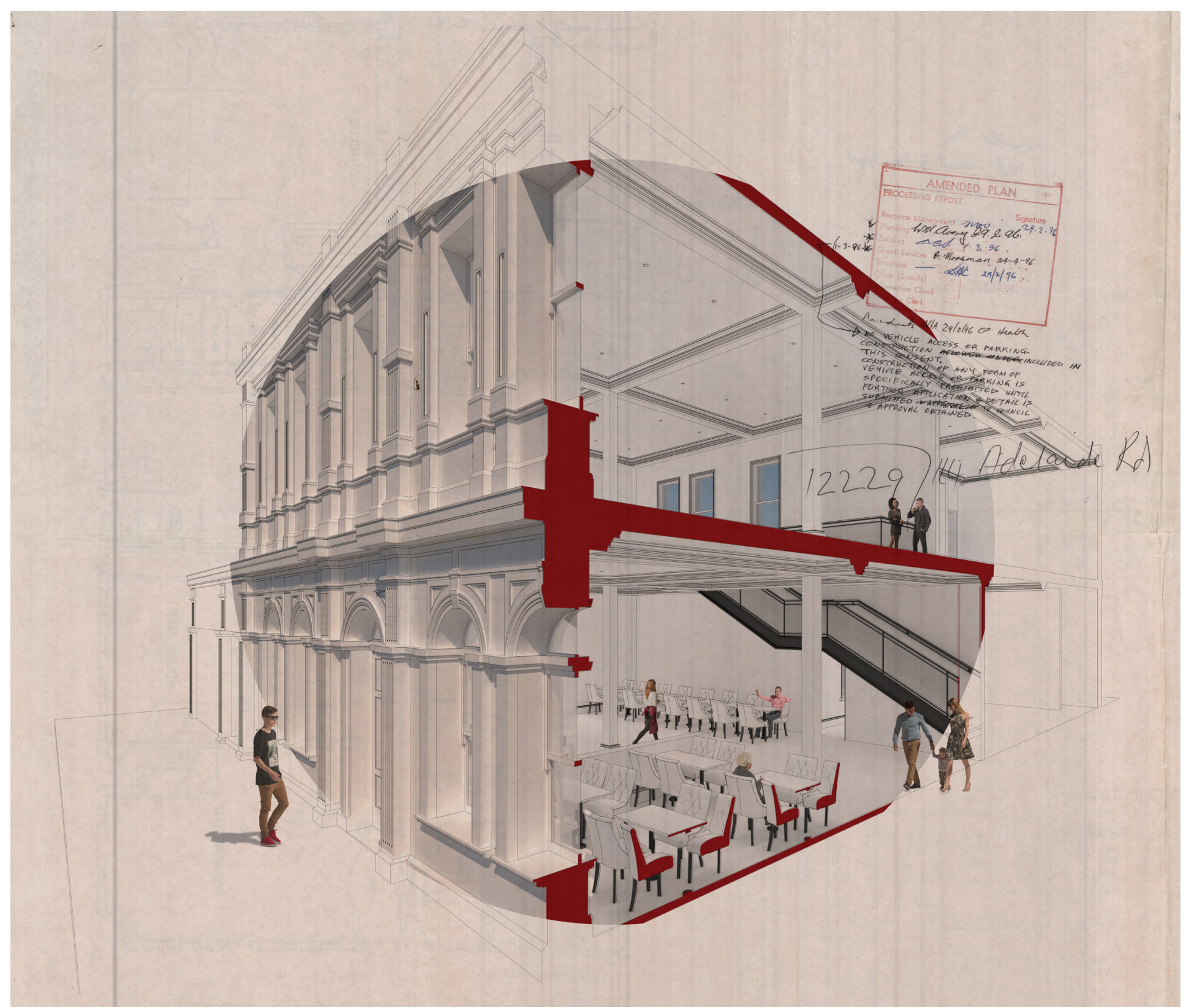

